\title{
Energy metabolism, fat mass regulation and predisposition to obesity
}

Citation for published version (APA):

Joosen, A. M. C. P. (2005). Energy metabolism, fat mass regulation and predisposition to obesity. [Doctoral Thesis, Maastricht University]. Datawyse / Universitaire Pers Maastricht. https://doi.org/10.26481/dis.20051214aj

Document status and date:

Published: 01/01/2005

DOI:

10.26481/dis.20051214aj

Document Version:

Publisher's PDF, also known as Version of record

\section{Please check the document version of this publication:}

- A submitted manuscript is the version of the article upon submission and before peer-review. There can be important differences between the submitted version and the official published version of record.

People interested in the research are advised to contact the author for the final version of the publication, or visit the DOI to the publisher's website.

- The final author version and the galley proof are versions of the publication after peer review.

- The final published version features the final layout of the paper including the volume, issue and page numbers.

Link to publication

\footnotetext{
General rights rights.

- You may freely distribute the URL identifying the publication in the public portal. please follow below link for the End User Agreement:

www.umlib.nl/taverne-license

Take down policy

If you believe that this document breaches copyright please contact us at:

repository@maastrichtuniversity.nl

providing details and we will investigate your claim.
}

Copyright and moral rights for the publications made accessible in the public portal are retained by the authors and/or other copyright owners and it is a condition of accessing publications that users recognise and abide by the legal requirements associated with these

- Users may download and print one copy of any publication from the public portal for the purpose of private study or research.

- You may not further distribute the material or use it for any profit-making activity or commercial gain

If the publication is distributed under the terms of Article $25 \mathrm{fa}$ of the Dutch Copyright Act, indicated by the "Taverne" license above, 
Energy metabolism, fat mass regulation and predisposition to obesity 


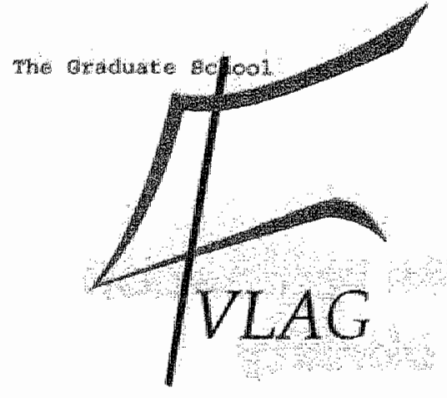

The studies presented in thils thesis were performed at the Nutrition and Toxicology Research institute Maastricht (NUTRIM), which participates in the graduate school VLAG (Food Technology, Agrobiotechnology, Nutrition and Health Sciences), accredited by the Royal Netherlands Academy of Arts and Sciences.

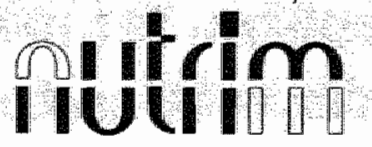

Financial support from the Nederlandse Associatie voor de Studie van Obesitas (NASO) and the Dutch Diabetes Research Foundation for printing of this thesis is gratefully acknowledged.

Cover design: Annemiek Joosen, Datawyse

Cover: derived from Leonardo da Vinci's Vitruvian Man; white adipose tissue (A.L. Kierszenbaum, Histology and Cell Biology, 2002)

Layout: Annemiek Joosen

Printed by: Datawyse, Universitaire Pers Maastricht

(C) A.M.C.P. Joosen, Maastricht 2005

ISBN 9052785007 


\title{
Energy metabolism, fat mass regulation and predisposition to obesity
}

\author{
PROEFSCHRIFT \\ ter verkrijging van de graad van doctor \\ aan de Universiteit Maastricht, \\ op gezag van de Rector Magnificus, \\ Pirof. mr. G.P.M.F. Mols, \\ volgens het besluit van het College van Decanen, \\ in het openbaar te verdedigen \\ op woensdag 14 december 2005 om 12:00 uur \\ door
}

Anna Maria Cornelia Petronella Joosen

geboren te Breda op 3 juli 1978

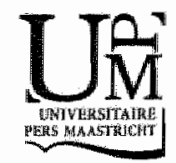




\section{Promotor}

Prof. dr. K.R. Westerterp

\section{Co-promotor}

Dr. A.H. Bakker

\section{Beoordelingscommissie}

Prof. dr. E.C.M. Mariman (voorzitter)

Prof. dr. M.H. Hofker

Prof. dr. M. Müller (Wageningen Universiteit)

Prof. ar. ur. A.M.W.J. Schols

Prof. dr. Y. Schutz (University of Lausanne, Switzerland) 


\section{CONTENTS}

Chapter 1

Introduction

Chapier 2

Energy expenditure during overfeeding

\section{Chapter 3}

Metabolic efficiency and energy expenditure during short-term overfeeding

\section{Chapter 4}

PPAR $\gamma$ activity in subcutaneous abdominal fat tissue and fat mass gain during short-term overfeeding

\section{Chapter 5}

The effect of the PPARY ligand rosiglitazone on energy balance regulation

\section{Chapter 6}

The short-term effect of the PPAR $y$ ligand rosiglitazone on fat mass

regulation during a positive energy balance in healthy, non-obese males

\section{Chapter 7}

Genetic analysis of physical activity in twins

\section{Chapter 8}

Discusion

Summary

Samenvatting

Dankwoord

Publications 
1

Introduction 


\section{GENERAL INTRODUCTION}

In healthy adults, body weight normally fluctuates around a relatively constant value. A stable body weight is a reflection of a balance between energy intake (E) and energy expenditure (EE). A long-term positive energy balance results in weight gain, which is mainly gain in fat mass. An excessive accumulation of body fat is the characteristic feature of obesity. Body weight is generally classified by the body mass index $\left(\mathrm{BMI}=\right.$ body weight $(\mathrm{kg}) /$ height $\left.(\mathrm{m})^{2}\right)$ as underweight, normal weight, overweight or obese (Table 1). Overweight and obesity, defined as BMI $\geq$ $25 \mathrm{~kg} / \mathrm{m}^{2}$, are associated with many diseases, such as type 2 diabetes and cardiovascular disease, and health risks increase with increasing BMl (1).

Table 1 The WHO classification of body mass index (BMI) for adults (2)

\begin{tabular}{|c|c|c|}
\hline$B M \|\left(\mathrm{kg} / \mathrm{m}^{2}\right)$ & Classification & Associated health risks \\
\hline$<18.5$ & Underweight & Low (but risks of other clinical problems increased) \\
\hline $18.5 \times 24.9$ & Normal range & Average \\
\hline$\geq 25.0$ & Overweight & \\
\hline $25.0-29.9$ & Pre-obese & Increased \\
\hline $30.0-34.9$ & Obese class | & Moderately increased \\
\hline $35.0-39.9$ & Obese class ll & Severely increased \\
\hline$\geq 40.0$ & Obese class |||I & Very severely increased \\
\hline
\end{tabular}

In many countries, the prevalence of obesity has increased over the past decades (3) showing an increased disability to maintain an energy balance. The increasing prevalence coincides with changing dietary habits and sedentary lifestyles, which might indicate a causal link $(4,5)$. However, there are still many questions regarding the determinants of weight gain, not only in obese persons but in a normal weight population as well.

A major contribution of environmental factors to the etiology of obesity is apparent, but different lines of research point at an important interaction between environmental and genetic factors. The Pima Indians living in the USA have an extremely high prevalence of obesity. In contrast, Pima Indians living in Mexico in their habitual environment with high levels of physical activity and traditional diets, have a significantly lower mean BMI despite a similar genetic background (6). Overfeeding of monozygotic twins clearly indicated that a large part of the variation in weight gain is attributable to genetic factors (7) "It seems that some persons can increase their energy expenditure above the obligatory costs for 
cellular and organ functions when they are overfed, resulting in a reduced fat storage. As the main energy storing tissue, the adipose tissue and thus adipocyte functioning is likely to be an important factor in the ability to gain weight. Differences in energy metabolism and fat mass regulation are likely to be involved in a predisposition to obesity.

\section{ENERGY METABOLISM}

\section{Metabolic efficiency}

The body needs energy to perform cellular and organ functions. This energy is provided by the oxidation of protein, carbohydrate, fat or alcohol, which are present in food. The production of energy from the main macronutrients is shown in Figure 1. The macronutrients are digested and absorbed into the blood. In the target organs they are converted to energy in the form of adenosine triphosphate (ATP), a process in which oxygen is consumed and carbon dioxide is produced. The production of ATP is not entirely efficient, therefore a major part of the energy will be dissipated as heat. Subsequently, all energy stored in ATP will become heat. In rest, all energy used is converted into heat. When ATP is used for external labour, energy is converted both into labour and heat ( 8 ).

For the oxidlation of the main macronutrients, a large part of the ATP is synthesized by mitochondrial oxidative phosphorylation. This process involves the transport of $\mathrm{H}^{+}$out of the mitochondrial matrix and the re-entry of $\mathrm{H}^{+}$across the mitochondrial inner membrane. The re-entry of $\mathrm{H}^{+}$can follow different pathways, yielding variable amounts of ATP $(8,9)$. For heat production to increase in response to environmental factors like diet, which is defined as adaptive thermogenesis $(9,10)$, the coupling between mitochondrial oxidation and ATP synthesis must be reduced. Alternatively, the use of ATP can be increased without functional results, which can be referred to as wasting of ATP in futile cycles (9). Although the relevance of adaptive thermogenesis in the etiology of obesity is controversial, as the magnitude is believed to be no more than a few percent $(10-$ 12), a reduced flexibility of energy expenditure to increase in response to the environment may predispose to obesity. Especially as small differences in energy balance on a daily basis can lead to significant weight gain over years.

\section{Components of total energy expenditure}

Total energy expenditure (TEE) consists of four components (Figure 2): sleeping metabolic rate (SMR), the energy cost of arousal, diet-induced thermogenesis (DIT) and activity-induced energy expenditure (AEE). The SMR and energy cost of arousal together form the basal metabolic rate (BMR). 


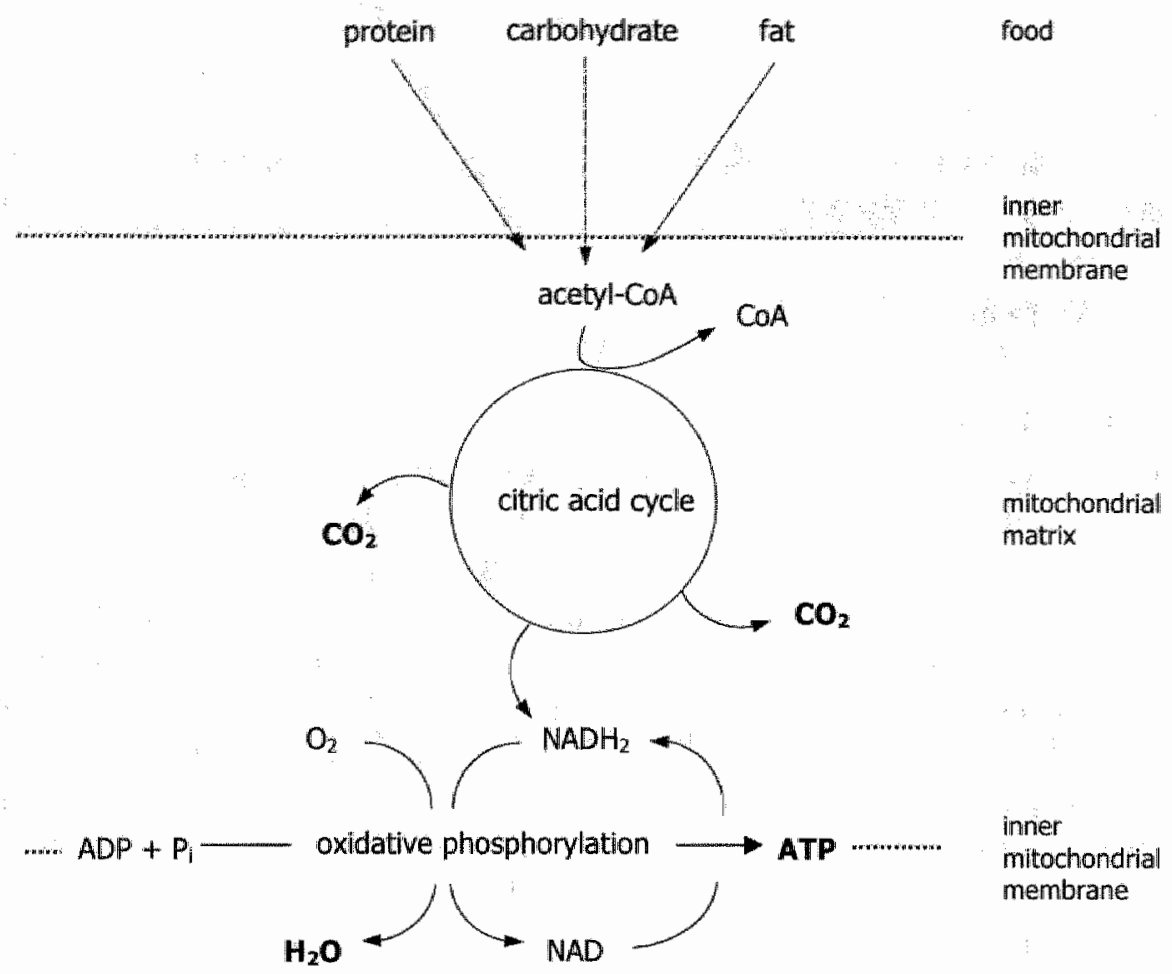

Figure 1 The production of energy from the main macronutrients.

The SMR is the energy expended during sleep and represents the minimal energy requirements. On average, SMR is $5 \%$ below $B M R$, which includes the energy used when aroused (13). SMR and BMR are both measures of the energy expenditure during rest and are therefore closely related to the amount of metabolically active cell mass, in particular the fat-free mass (FFM) (14).

DIT is the EE due to the digestion and absorption of food. The postprandial increase in EE lasts for several hours and depends on the amount and macronutrient composition of the diet (14). DIT is increased on a diet high in protein and carbohydrate compared to a diet high in fat (15). DiT is assumed to be $10 \%$ of TEE in subjects consuming average mixed diets and being in energy balance (14).

AEE is the EE that results from physical activity and is determined by the amount and intensity of the activities as well as body size and composition $(14,16)$. The contribution of AEE to TEE can range from $25 \%$ in sedentary persons to $75 \%$ during heavy sustained exercise (17). 


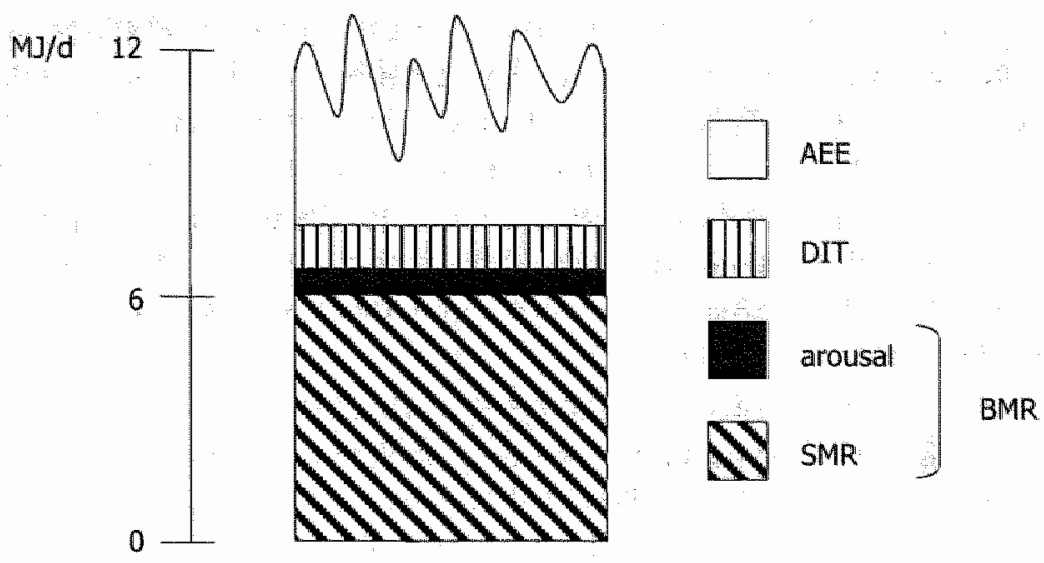

Figure 2 The components of total energy expenditure: sleeping metabolic rate (SMR), energy cost of arousal, basal metabolic rate (BMR), diet-induced thermogenesis (D|T) and activity-induced energy expenditure (AEE). Values are for an average adultt male $(70 \mathrm{~kg}, 10 \%$ body fatt) in energy balance (42).

\section{Measurement of energy intake, energy expenditure and substrate oxidation}

Frequently used methods to measure energy intake include the 24-h dietary recall, dietary record, double portion technique and food frequency questionnaire. However, these methods are subject to under-reporting and undereating, and can thus not accurately measure energy intake (18). An accurate method, which can be well applied in most intervention studies, is to provide the subjects with all foods and drinks.

Energy expenditure can be measured by indirect calorimetry, which allows the division of TEE in components ( $S M R, B M R$, DIT and AEE). EE is calculated (accurately to $2 \%$ ) from $\mathrm{O}_{2}$-consumption and $\mathrm{CO}_{2}$-production by measuring the airllow through a ventilated hood or respiration chamber and the $\mathrm{O}_{2}-$ and $\mathrm{CO}_{2}=$ concentrations in the ingoing and outgoing air (19-21). This technique can only be applied over shorter periods of time, from hours (ventilated hood) to days (respiration chamber), as subjects are generally not allowed to move while lying under the ventilated hood) or are limited in their activities due to the confined area of the respiration chamber. For measuring free-living TEE, the doubly labeled water (DLW) method is the golden standard, with an accuracy of $1-2 \%$ (22). Subjects are given a mixture of the stable isotopes ${ }^{2} \mathrm{H}$ and ${ }^{13} \mathrm{O}$, which are gradually eliminated from the body, ${ }^{2} \mathrm{H}$ in ${ }^{2} \mathrm{H}_{2} \mathrm{O}$ and ${ }^{18} \mathrm{O}$ in $\mathrm{H}_{2}{ }^{18} \mathrm{O}$ and $\mathrm{C}^{16} \mathrm{O}_{2}$. The difference between both elimination rates, measured in urine, blood or saliva, is a measure of $\mathrm{CO}_{2}$-production. TEE can be calculated using a measured or estimated respiratory quotient ( $\mathrm{RQ}=\mathrm{CO}_{2}$-production $/ \mathrm{O}_{2}$-consumption). Un moderately active subjects, TEE can be measured for periods up to 15 days (23). Free-living 
physical activity can be quantified by the physical activity level (PAL), which is TEE divided by SMR or BMR, assuming that variation in TEE is due to differences in body size and composition and physical activity (14). In addition, accelerometers allow direct measurement of body movements and quantify physical activity in terms of total amount, intensity, duration and frequency (24). In combination with body composition, SMR or BMR, they are good predictors of TEE in daily life, thus providing a valid supplement to and alternative for the expensive DLW method $(25,26)$.

TEE essentially consists of the oxidation of carbohydrate, fat and protein. The oxidation of the separate substrates can be calculated from $\mathrm{O}_{2}$-consumption and $\mathrm{CO}_{2}$-production, measured by indirect calorimetry, and urinary nitrogen excretion by assuming that the RQ for carbohydrate, fat and protein, respectively, is 1.0 , 0.71 and 0.83 and the liters $\mathrm{O}_{2}$ consumed per gram of oxidized substrate are $0.746,2.019$ and $1.002(27,28)$.

\section{ADIPOSE TISSUE METABOLISM}

The adipose tissue is can vary widely in mass, from non-measurable amounts, for instance in patients with anorexia nervosa, to seemingly unlimited amounts in morbid obese subjects. Fat mass generation involves an increase in both adipocyte number and volume (29). The peroxisome proliferator-activated receptor $y$ (PPAR $\gamma$ ) is a key mediator of both processes $(30,31)$.

\section{Adipocyte number}

The differentiation from preadipocytes into adipocytes (adipogenesis) results in an increase in adipocyte number (32). Preadipocytes are fibroblast-like cells present in the stromo-vascular fraction of the adipose tissue that have the potential to become adipocytes in the presence of appropriate stimuli (33). During adipogenesis the cells convert from a fibroblastic to a spherical shape and these morphological changes are accompanied with the induction of adipocyte-specific gene expression and the accumulation of triacylglycerol (34).

Adipocyte differentiation depends on the expression of a cascade of specific transcription factors (Figure 3 ). In response to hormonal and nutritional stimulation, the CCAAT/enhancer binding proteins $\beta$ and $\delta(\mathrm{C} / \mathrm{EBP} \beta$ and $\delta)$ induce the expression of PPARy. PPARy then induces the expression of C/EBP $\alpha$, thereby maintaining each other's expression, and thus the differentiated state, through a positive feedback loop. To become active, PPARy has to form a heterodimer with another nuclear hormone receptor, the retinoid $X$ receptor ( $R X R)$, which binds to the PPAR response element in the promoter region of the target gene. An important determinant of the activity of this complex is the binding of a ligand to 
the heterodimer, which strongly influences mRNA synthesis. The adipocyte determination and differentiation factor 1 or sterol regulatory element binding protein 1 (ADD1/SREBP1) is involved in the production of a currently unknown endogenous PPAR ligand, which modulates PPAR $\gamma$ activity (34).

Adipocyte differentiation might predispose to obesity as the ability to differentiate preadipocytes as well as the number of preadipocytes varies considerably between persons $(35,36)$.

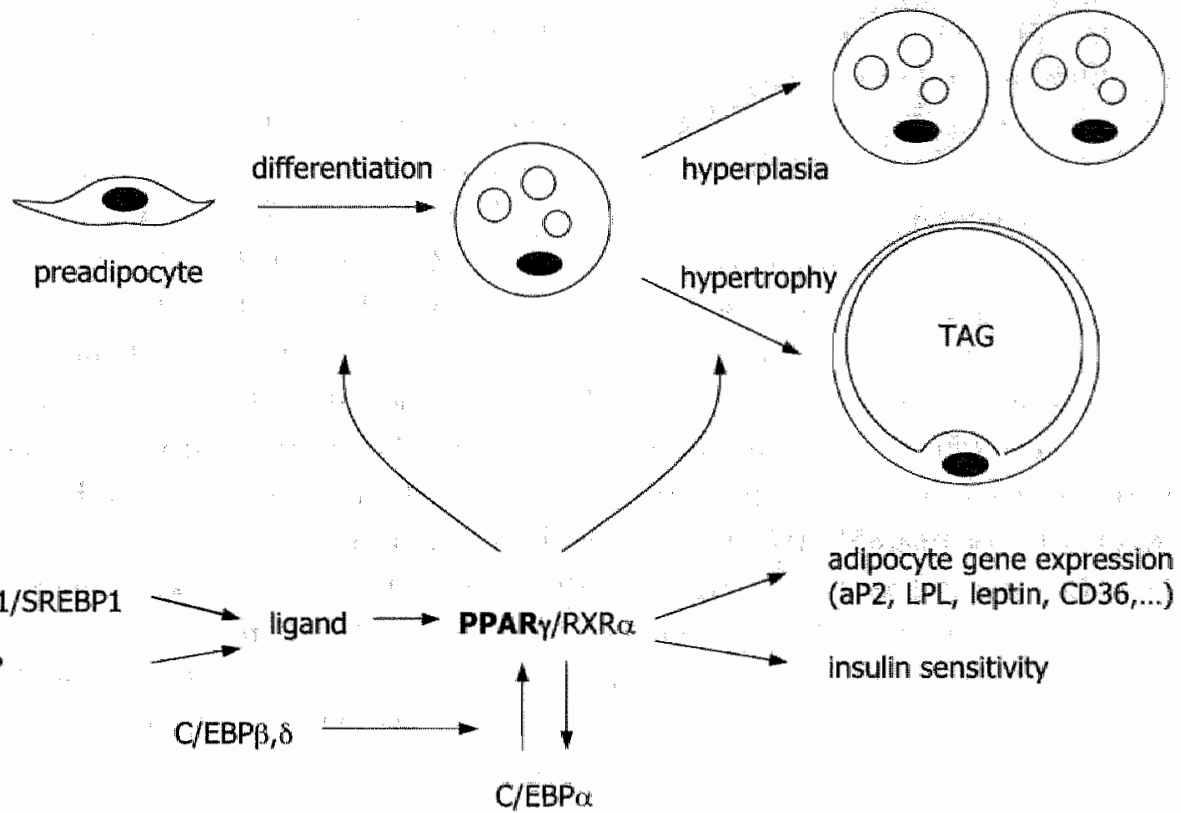

Figure 3 Genes involved in the regulation of adipose tissue mass.

\section{Adipocyte size}

The adipocyte size is the net result of lipogenesis and lipolysis and reflects the amount of triacylglycerol stored in the adipocyte (32). Lipogenesis involves the deposition of fat. Triacylglycerols (TAG), in the form of chylomicrons (from digestion and absorption of dietary fat) or lipoproteins (synthesized in the liver) are hydrolyzed by the adipocyte-derived enzyme lipoprotein lipase into glycerol and free fatty acids (FFA). FFA are taken up by the adipocytes, where they are reesterified into TAG. Lipolysis results in the release of TAG from adipose tissue after hydrolization into glycerol and FFA by hormone-sensitive lipase (37). 
Adipocyte size is an important factor in cell functioning, as metabolic disturbances associated with obesity (including insulin resistance and an increased production of FFA, leptin and TNFa) are typically associated with adipocyte hypertrophy (38).

\section{GENETIC CONTRIBUTION}

There is a clear familial effect on the development of obesity, hence it is important to determine how much of the predisposition to obesity is due to genetic factors. The genetic and environmental contribution to a phenotypic variance can be quantified in studies of twins. Monozygotic (MZ) twins share $100 \%$ of their genes, dizygotic twins on average $50 \%$. Differences within $M Z$ twin pairs are due to environmental factors while differences within $D Z$ twin pairs are additionally affected by genetic factors (39-41). The similarity in a phenotype in pairs can be expressed as an intra-pair correlation ( $\mathrm{MZZ}$ for $\mathrm{MZ}$ twins, $\mathrm{rDZ}$ for $\mathrm{DZ}$ twins). The intra-pair correlation corresponds perfectly with the degree of genetic relatedness if the phenotype is entirely due to genes that act additively and there is no dominant genetic effect or interaction between genes, thus $\mathrm{rMZ}=1.0, \mathrm{rDZ}=0.5$ and no correlation in genetically unrelated pairs. Environmental factors that are unique to each member of the pair contribute to the phenotype when the $r M Z$ is below 1.0, for example 0.8 , together with correlations in other pairs that follow the ratios according to genetic relatedness, i.e. $\mathrm{rDZ}=0.4$. The phenotype is additionally influenced by environmental factors that are shared by both members of the pair when the intra-pair correlation is higher than expected from the degree of genetic relatedness, for example $\mathrm{rDZ}=0.6(40,41)$. The heritability is the proportion of the total variation that can be attributed to genetic factors (40). As this value depends on the population studied, the twins should be representative of the population from which they are drawn (39). In addition, $M Z$ twin pairs have to share common environmental factors to a similar extent as DZ twin pairs (39).

\section{OUTLINE OF THE THESIS}

The increasing prevalence of obesity is thought to be mainly the result of a poor control of both $\mathrm{E}$ and $\mathrm{EE}$, which accelerates weight gain. However, within the same obesigenic environment there are persons that maintain a stable body weight seemingly without any effort. They seem to regulate their energy balance unconsciously, suggesting that the susceptibility to become obese is at least in part genetically determined. The ability of the body to convert excess energy into heat may be involved in a genetic predisposition to obesity. Whether humans can adapt their $\mathrm{EE}$ to an increase in $\mathrm{El}$, and thereby reduce the efficiency of weight 
gain, was investigated in chapters 2 and 3 . Weight gain mainly comprises of an increase in fat mass. Adipose tissue mass is determined by the differentiation of preadipocytes into mature adipocytes (adipocyte number) and the accumulation of triacylglycerol in adipocytes (adipocyte size). These processes are induced and maintained by a network of transcription factors that is influenced by nutritional and hormonal activators and suppressors. In this network, PPAR p plays a key role, therefore the effect of overfeeding on PPARY activity and fat mass generation was investigated (chapter 4). In addition to its function as fat storage depot, the adipose tissue actively secretes adipokines involved in energy metabolism, indicating a role for PPAR $y$ in the regulation of the energy balance. In chapters 5 and 6 the influence of PPARy activity on substrate usage, EE, El and fat mass generation was investigated. The most variable component of $\mathrm{EE}$ and thereby the component most likely to influence differences in susceptibility to obesity, is the activity-induced energy expenditure. In a twin study, the relative contribution of genetic and environmental factors to the variation in physical activity and AEE was determined (chapter 7). The regulation of energy metabolism and fat mass in relation to a predisposition to obesity is discussed in chapter 8 . 


\section{REFERENCES}

1. Sullivan PW, Morrato EH, Ghushchyan V, Wyatt HR, Hill IO. Obesity, inactivity, and the prevalence of diabetes and diabeter-related cardiovascular comorbidities in the u, , 2000-2002. Diabetes Care 2005;28:1599-603.

2. WHO. Obesty: preventimg and managing the global epidemic, Geneva: WHO, 1998.

3. Seidell IC. Epidemiology of obesity. Semin Vase Med 2005;5:3-14.

4. Jebb SA, Moore MS. Contribution of a sedentary lifestyle and inactivity to the etiology of overweight and obesity: current evidence and research issues. Med Sci Sports Exerc $1999,31: 5534.41$.

5. Silventoinen $K$, Sans $S$, Tolonen $H$, et al. Trends in obesity and energy supply in the WHO MONICA Project. Int J Obes Relat Metab Disord 2004;28:710-8.

6. Rawussin E, Valencia ME, Esparza J, Bennett PH, Schulz LO. Effects of a traditional lifestyle on obesity in Pima Indians. Diabetes Care 1994,17:1067-74.

7. Bouchard $C$, Tremblay $A$, Despres $J$, et al. The response to long-term overfeeding in identical twins. N Eng / Med 1990;322:1477-82.

8. Crabtree B, Garlick PJ. Fuels of tissues. In: Garrow IS, James WPT, eds. Human nutrition and dietetics. 9th ed. New York: Churchill Livingstone, 1993:119-36.

9. Lowell BB, Spiegelman BM. Towards a molecular understanding of adaptive thermogenesis. Nature 2000;404:652-60.

10. Dulloo $\mathrm{AG}$, Jacquet 1. Adaptive thermogenesis is important in the aetiology of obesity: the case for. 9th ed: John Libbey Eurotext Ltd: 2003.

11. James WP, McNeill G, Ralph A. Metabolism and nutritional adaptation to altered intakes of energy substrates. Am \Clin Nutr 1990;51:264\%9.

12. Flatt JP. Adaptive changes in thermogenesis are not important in the aetiology of obesity (Abstract). Int J Obes Relat Metab Disord 2002;26:56.

13. Goldberg GR, Prentice AM, Davies HL, Murgatroyd PR. Overnight and basal metabolic rates in men and women. Eur J Clin Nutr 1988;42:137-44.

14. Westerterp KR. Energy metabolism and body composition: general principles. Eur Respir Mon $2003 ; 24: 1-10$.

15. Westerterp KR, Wilson $S A$, Rolland V. Diet induced thermogenesis measured over $24 \mathrm{~h}$ in a respiration chamber: ffect of diet composition. Unt \ Obes 1999;23:287-92.

16. Prentice AM, Black AE, Coward WA, et al. High levels of energy expenditure in obese women. Br Med I (Clin Res Ed) 1986;292:983-7.

17. Westerterp KR. Alterations in energy balance with exercise. Am J Clin Nutr 1998;68:970S-4S.

18. Goris $A H C$, Meijer EP, Westerterp KR. Repeated measurement of habitual food intake increases under-reporting and induces selective under-reporting. Brit J Nutr 2001;85:629-34.

19. Adriaens MP. Schoffelen PF, Westerterp KR. Intra-individual variation of basal metabolic rate and the influence of daily habitual physical activity before testing. Br I Nutr 2003;90:419-23.

20. Schoffelen PF, Westerterp KR, Saris WH, Ten Hoor F. A duall-respiration chamber system with automated calibration. I Appl Physiol 1997;83:2064-72.

21. Westerterp KR, Goran MI. Age and energy balance: In: Westerterp-Plantenga MS, Steffens AB, Tremblay $A$, eds. Regullation of food intake and energy expenditure. Milan: Edra, 1999:325-48. 
22. Schoeller DA, Hnilicka JM. Reliability of the doubly labeled water method for the measurement of total daily energy expenditure in free-living subjects. I Nutr 1996,126:3485 5445.

23. Westerterp KR, Wouters $L$, Marken Lichtenbelt WDy. The Maastricht protocol for the measurement of body composition and energy expenditure with labeled water. Obes Res $1995 ; 3: 49-57$.

24. Westerterp KR. Physical activity assessment with accelerometers. Int / Obes Relat Metab Disord 1999:23 Suppl 3:S45-9.

25. Bouten CVC, Verboeket-Van De Venne WPHG, Westerterp KR, Verduin $M_{n}$ Janssen ID. Daily physical activity assessment: comparison between movement registration and doubly labeled water. I Appl Physiol 1996;81:1019-26.

26. Plasqui $G$, loosen AMCP, Kester $A$, Goris AHC, Westerterp KR. Measuring free-living energy expenditure and physical activity with triaxial accelerometry. Obes Res 2005;13:1363-9.

27. Brouwer $\mathrm{E}$. On simple formulae for calculating the heat expenditure and the quantities of carbohydrate and fat oxidized in metabolism of men and animals, from gaseous exchange (Oxygen intake and carbonic acid output) and urine-N. Acta Physiol Pharmacol Neerl $1957 ; 6: 795-802$.

28. Livesey G, Elia M. Estimation of energy expenditure, net carbohydrate utilization, and net fat oxidation and synthesis by indirect calorimetry: evaluation of errors with special reference to the detailed composition of fuels. Am I Clin Nutr 1988;47:608-28.

29. Salans LB, Cushman SW, Weismann RE. Adipose cell size and number in nonobese and obese patients. I Clin Invest 1973;52:929-41

30. Kubota $N$, Terauchi $\gamma$, Miki $H$, et al. PPAR $\gamma$ mediates high-fat diet-induced adipocyte hypertrophy and insulin resistance. Mol Cell 1999;4:597-609.

31. Rosen ED, Sarraf $P_{x}$ Troy $A_{k}$ et al. PPARY is required for the differentiation of adipose tissue in vivo and in vitro. Mol Cell 1999;4:611-7.

32. Prins JB, O'Rahilly S. Regulation of adipose cell number in man. Clinical Science 1997;92:3-11.

33. Halworsen YDC, Bond $A$, Sen $A$, et al. Thiazolidinediones and glucocorticoids synergistically induce differentiation of human adipose tissue stromal cells: biochemical, cellular, and molecular analysis. Metabolism 2001;50:407-13.

34. Rosen ED, Walkey CJ Puigserver P, Spiegelman BM. Transcriptional regulation of adipogenesis. Genes Dev 2000;14:1293-307.

35. Sen A, Lea-Currie YR, Sujkowska D, et al. Adipogenic potential of human adipose derived stromal cells from multiple donors is heterogeneous. 1 Cell Biochem 2001;81:312 29.

36. Bakker AH, Van Dielen FM, Greve IW, Adam IA, Buurman WA. Preadipocyte number in omental and subcutaneous adipose tissue of obese individualis. Obes Res $2004,12: 488998$.

37. Gurr M. Fats. In: Garrow 15, James WPT, eds. Human nutrition and dietetics. 9th ed. New York: Churchill Livingstone, 1993:77-102.

38. Farnier $C$, Krief $S$, Blache $M$, et al. Adipocyte functions are modulated by cell size change: potential involvement of an integrin/ERK signalling pathway. lnt I Obes Relat Metab Disord 2003;27:1178-86.

39. Maes $H H$, Neale MC, Eaves L.). Genetic and environmental factors in relative body weight and human adiposity. Behav Genet 1997:27:325-51

40. Beunen $G$, Thomis $M$. Genetic determinants of sports participation and daily physical activity. Int J Obes Rellat Metab Disord 1999;23 Suppl 3:555-63.

41. Posthuma D, Beem AL, de Geus El, et al. Theory and practice in quartitative genetics. Twin Res 2003;6:361-76. 
16 |Chapter 1

42. Raveissin E, Bogardus C. Relationship of genetics, age, and physical titness to daily energy expenditure and fuel utilization. Arn / Clin Mutr 1989;49:968-75. 


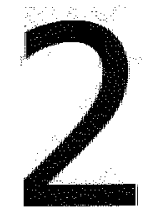

\section{Energy expenditure during overfeeding}

Annemiek M.C.P. Joosen and Klaas R. Westerterp

Submitted for publication 


\begin{abstract}
The large inter-individual variation in weight gain during standardized overfeeding together with a weight gain that is often less than theoretically calculated from the energy excess suggest inter-individual variation in the ability to increase energy expenditure above obligatory costs. The question is whether there is experimental evidence for such a process, defined as adaptive thermogenesis. From the numerous human overfeeding experiments those studies were selected that applied protocols and measurement techniques suitable for investigating adaptive thermogenesis. From 16 studies thus selected, five claimed to have found evidence for adaptive thermogenesis, 11 did not find such evidence. Weight gains smaller than expected or increased thermogenesis above obligatory costs were considered evidence for, while weight gain proportional to the amount of overfeeding and increased thermogenesis associated with theoretical costs of an increased body size and a larger food intake suggest there was no adaptive thermogenesis. These results show that in humans, there is still little evidence for adaptive thermogenesis. However, it does not rulle out the existence of adaptive thermogenesis, but emphasizes that if present, adaptive changes in energy expenditure are rather small. In addition, it is not clear in which component or components of total energy expenditure adaptive changes can occur and whether components can overlap due to measurement limitations.
\end{abstract}




\section{INTRODUCTION}

Overfeeding experiments show that weight gain is often less than expected from the energy excess. In part this is the result of the obligatory increase in energy expenditure (EE) due to the increased body weight and fat-free mass (1) and the increase in diet-induced thermogenesis due to the larger amount of food ingested (2). Additionally, however, there is a wide inter-individual variation in weight gain on the same amount of overfeeding, which suggests that some persons can adjust their EE to the increased energy intake (EI) to resist weight gain by expending energy in excess of the obligatory costs. This facultative or adaptive thermogenesis is the regulated production of heat in futile substrate cycles that consume ATP (3). Differences in the capacity for adaptive changes in thermogenesis may be involved in the susceptibility to obesity.

The relevance of adaptive thermogenesis in the etiology of obesity is controversial, as adaptive changes in EE are believed to be no more than a few percent (4-6). But as obesity is the result of an El that exceeds EE for longer periods, even a slightly positive energy balance on a daily basis can lead to a significant weight gain over years. The question is whether there is experimental evidence for adaptive thermogenesis as a mechanism to resist weight gain during a period of excess energy intake. For this purpose we selected 16 human overfeeding experiments based on their protocols. Selection criteria included the amount and duration of overfeeding, measurement techniques suitable for investigating adaptive thermogenesis, and studies with healthy adult subjects, with a weight maintenance baseline period directly before overfeeding and information on energy expenditure and weight gain.

\section{HUMAN OVERFEEDING EXPERIMENTS}

Obesity needs a positive energy balance to develop, a situation that is mimicked in overfeeding experiments. The selection of human overfeeding studies is summarized in Table 1. To investigate the importance of adaptive thermogenesis, the component or components of energy expenditure involved need to be defined and reflected in the study design.

The most reliable studies with regard to overfeeding are studies conducted with subjects living in the research institute during the entire study period. Then, however, a disadvantage is the induction of different lifestyles even when physical activity is not limited. In other experiments, subjects were studied as outpatients, which consume one or more meals per day at the research institute, but otherwise stayed in their own environments. 


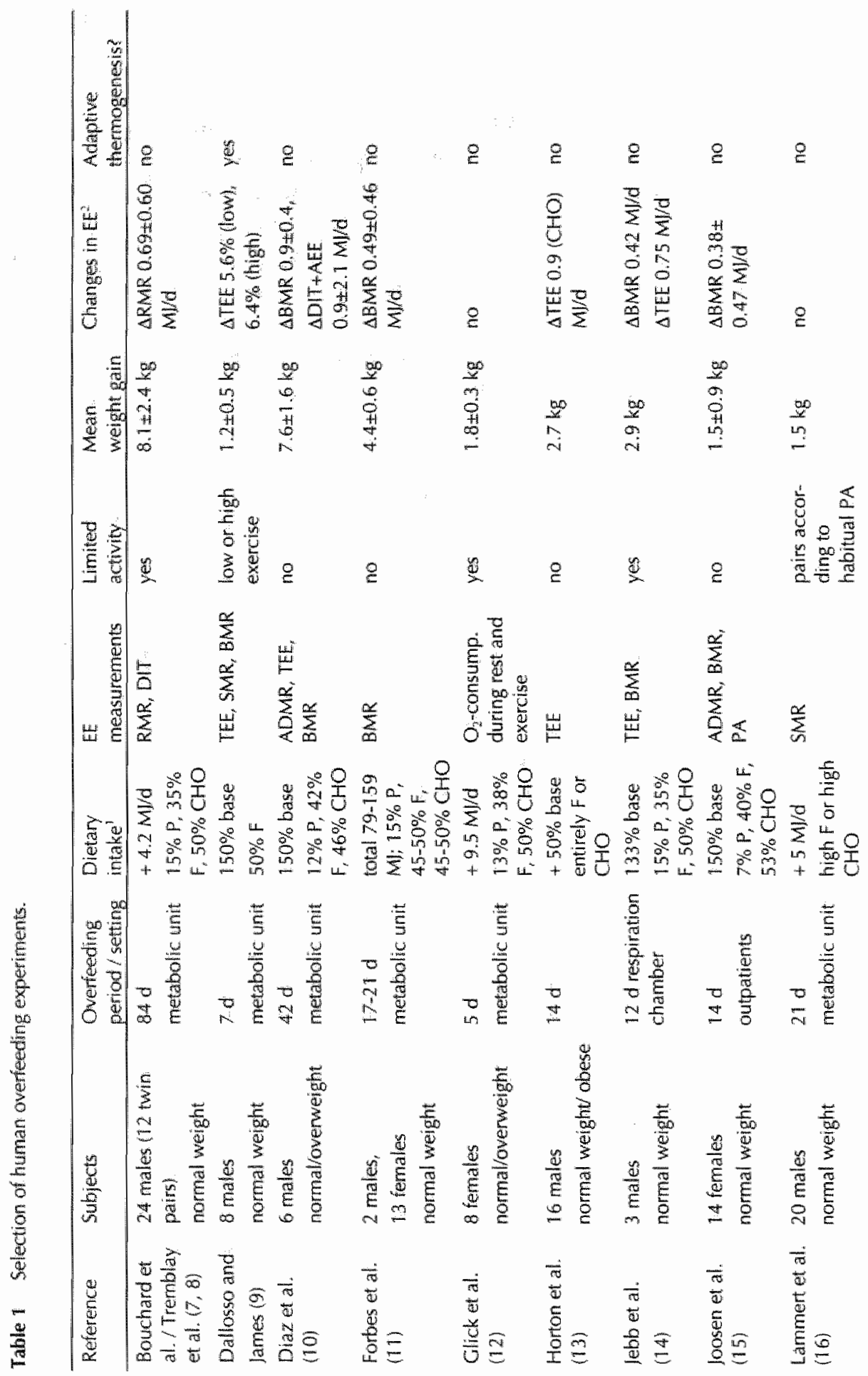


3

in

iो ${ }^{m}+{ }^{4}$

$m$ in

녕

战岩学。

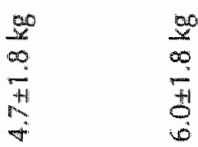

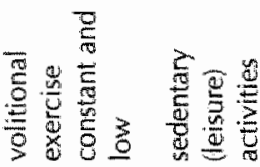

$\sum_{\infty}^{\infty} e^{x}$

율

离

氡

要䒰

8

음

它管

出衣定岕

홀웅원 事㚔全 a + 究以

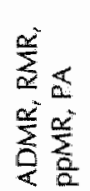

웅오

i

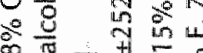

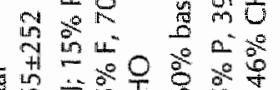

을 守守要

\section{웅}

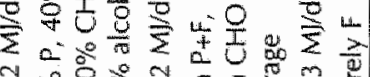

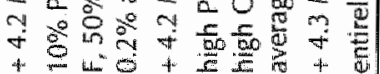

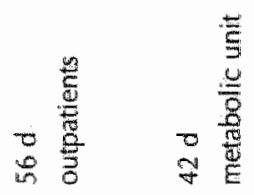

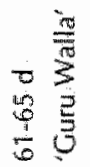

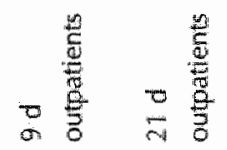

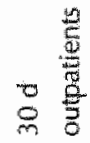

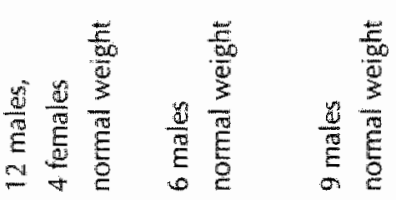

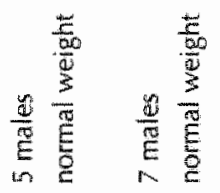

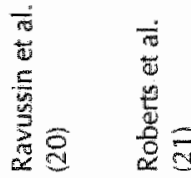

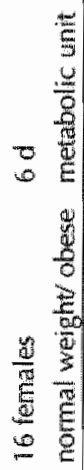

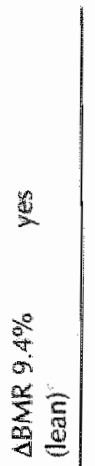

然

2.

홀

a.

政

i1 $\frac{x}{2}$

है

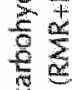

11 远

坾

$\frac{4}{4} \frac{\pi}{4}$

嵒

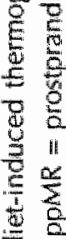

11

늠

눈

ए

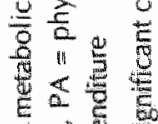

ज酸

的文

11 $\frac{\alpha}{2} 6$.

哭要要

两 $\frac{2}{2}$

过过

足㟧

密喓

है.

斑

종

品 $=$

谨

焉总

II $\frac{4}{4}$

ए il 
In both conditions, the golden standard for measuring EE over longer periods is the doubly labeled water (DLW) method. In combination with sleeping or basal metabolic rate (SMR or BMR), activity-induced energy expenditure (AEE) can be determined without restricting the subjects. In addition, physical activity (PA) can be objectively measured with accelerometers, which measure body movements in terms of frequency, duration and intensity (24). Respiration chambers allow measurements of total energy expenditure (TEE) and its components ( $S M R, B M R$, diet-induced thermogenesis $(D \mid T)$ and $A E E)$. Though PA is limited due to the confined area, there is still considerable variation between subjects while intraindividual variation is low (2).

The duration of overfeeding mainly determines the reliability of changes in body weight as a reflection of energy storage. The overfeeding period should be long enough to expect an increase in body weight in excess of changes due to bowel contents and oedema (i.e. excessive storage of body fluids above the increase in body water that is part of an increase in lean body mass).

\section{ENERGY EXPENDITURE DURING OVERFEEDING}

\section{Macronutrient intake and oxidation}

When digested foods enter the bloodstream the macronutrients are not just randomly oxidized. There is an oxidative hierarchy, which means that the macronutrient that is most easily stored (fat) is the last to be oxidized. Macronutrients that can not be stored at all (alcohol), under certain circumstances (protein) or in $\|$ imited amounts (carbohydrate) are oxidized first (25). Alcohol ingestion directly increases alcohol oxidation, which is maintained until all alcohol is cleared, and suppresses fat oxidation. Protein and carbohydrate oxidation are well linked to protein and carbohydrate intake respectively. In contrast, fat intake does not stimulate fat oxidation. Moreover, fat oxidation is inhibited by high intakes of the other macronutrients in the presence of a positive energy balance (25-27). The thermic effect of the separate macronutrients is 20 to $30 \%$ for protein, 5 to $15 \%$ for carbohydrate, and 0 to $3 \%$ for fat (27). The figure for the thermic effect of alcohol is not clear, values observed in different studies range between 6 and $30 \%(28)$.

Though the intake of any macronutrient in excess of energy needs will lead to fat storage, particularly the poor control of fat oxidation could affect EE and thus fat storage during overfeeding. A reduced capacity for fat oxidation could therefore predispose to obesity. Diaz et al. (10) overfed subjects $50 \%$ above baseline energy requirements for $42 \mathrm{~d}$, which suppressed fat oxidation by $37 \%$ in lean subjects, but by $64 \%$ in overweight subjects. These results were confirmed by Horton et al. (13) who overfed $50 \%$ above baseline El with isoenergetic amounts of fat and 
carbohydrate for $14 \mathrm{~d}$. During both overfeeding periods; obese subjects had a higher average $\mathrm{RQ}$ and oxidized proportionally more carbohydrate than lean subjects. Though carbohydrate overfeeding induced a significant increase in TEE whereas fat overfeeding did not in both lean and obese subjects (13), these studies did not find evidence for adaptive thermogenesis, which suggests that the capacity for fat oxidation does not relate to the capacity for adaptive thermogenesis.

DIT is increased on a high-protein, high-carbohydrate diet compared to a high-fat diet (26). In contrast, low-protein diets result in an increased DIT as well: This apparent contradiction is attributed to a mechanism for enriching nutrientdeficient diets while dissipating the excess energy on low-protein diets; whereas high-protein diets result in increased thermogenesis due to the thigh cost of metabolizing protein $(29,30)$. As this indicates the presence of adaptive thermogenesis with low-protein feeding, Stock (29) and Dulloo and Jacquet (30) suggested low-protein overfeeding as a tool to discriminate between metabolically efficient and metabolically inefficient persons by maximizing DIT. Dulloo and Jacquet (30) reviewed the results of the normal- (15 energy\%) and low- (3 energy\%) protein overfeeding studies of Miller $(31,32)$ and showed that DIT is enhanced with low-protein overfeeding. They concluded that the capacity for adaptive thermogenesis is individually determined, as the energy costs of weight gain on normal- and low-protein overfeeding were positively related. However, overfeeding healthy females $50 \%$ above baseline energy requirements for $14 \mathrm{~d}$ with a low-protein ( 7 energy\%) diet did not indicate adaptive changes in energy expenditure (15).

\section{Components of energy expenditure}

The component of daily EE most affected by changes in body weight is the BMR (1): any adaptive changes in TEE are therefore likely to appear in this component. Several studies reported an increased $B M R$ after overfeeding $(8,10,11,14,15$, 17, 19-21,23). This increase is due to the energy cost of fat and fat-free mass gains as well as the costs of maintaining a larger body weight (1).

Another component, DIT, will increase due to the increased amount of food that has to be digested and absorbed. Yet, several studies did not find a significant increase in DIT, independent of dietary composition and duration of the experiment $(7,8,21,23)$. Others could explain significant increases in DIT solely

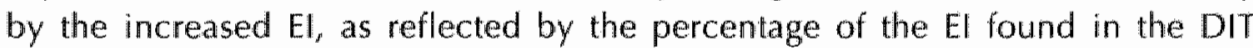
component being similar before and after overfeeding (20) or the response to a fixed meal being unaltered (17). Pasquet et all. (19) reported a similar increase in DIT with long-term high-carbohydrate overfeeding compared to overfeeding with a typical western, mixed diet $(7,8,21,23)$, but concluded that this increase 
included an adaptive component as the increase was even larger after adjusting for a reduction in physical activity.

The last component, $A E E$, is the most variable component of TEE between persons (33), and thus is most likely the main contributor to variation in weight gain during overfeeding. Indeed, several overfeeding experiments show that those subjects with the largest increase or decrease in AEE have respectively the lowest and highest weight gains $(10,17)$. But large changes in AEE above increased costs of performing physical activity due to an increased body weight might reflect behavioral changes rather than adaptive thermogenesis.

It should be noted that the division of TEE into its components might induce overor underestimations of the separate components. Particularly AEE is hard to determine, as measurement errors in TEE, BMR and DIT are accumulated in AEE (2). SMR might be confounded by DIT; the influence of a large evening meal has been shown to continue well during the night (34), which might confound measurement of BMR in the morning as well $(10,15)$. In addition, there is an interaction between DIT and physical activity both at high and low levels of activity $(35,36)$, which will not only affect DIT but also influences determination of the energy costs of physical activity (10).

\section{ENERGY STORAGE}

Energy can not get lost, thus energy that is not expended will be stored. As the digestibility of foods is not affected by intake level or subject $(10,37)$, energy storage during overfeeding can be callculated as the difference between energy intake and energy expenditure.

The macronutrient composition of the diet can influence energy storage. With carbohydrate overfeeding 75 to $85 \%$ of the excess energy was stored and the remaining expended, while with fat overfeeding 90 to $95 \%$ of the excess energy was stored, but there was no difference in fat storage after $14 \mathrm{~d}$ between the two diets fed isoenergetically to the same subjects (13). Lammert et al. (16) also found similar fat storage on high-carbohydrate and high-fat overfeeding. Overfeeding mixed diets resulted in a large variation in energy storage. The percentage of the excess $\mathbb{E}$ that was stored ranged between 60 to $90 \%(7,8,18,20,21)$. This variation is at least partly due to limitations in the measurement of small $(<1 \mathrm{~kg})$ changes in body composition.

The composition of the overfeeding-induced body weight gain is fairly constant over different studies. Between 60 to $67 \%$ of the weight gain comprised an increase in fat mass, the remaining part was an increase in fat-free mass of 33 to $40 \%(7,8,10,16)$. The high storage capacity of the adipose tissue, together with 
the low costs of fat gain $(6.3 \mathrm{M} / / \mathrm{kg})$ compared to high costs of depositing protein $(29.4 \mathrm{MJ} / \mathrm{kg})$ favour the deposition of fat compared to fat-free mass.

In addition, there are other ways to store excess energy as fat. The storage of body fat from dietary fat is the most energy efficient $(\sim 0.02 \mathrm{M}$ ) per $\mathrm{Ml}$ ingested fat), but also dietary protein and carbohydrate can be stored as fat $(\sim 0.25 \mathrm{MJ}$ per $\mathrm{M})$ ingested protein or carbohydrate) (25). Though several overfeeding studies showed the presence of de novo lipogenesis during carbohydrate overfeeding (16, 38-40), the storage of carbohydrate as fat through de novo lipogenesis is considered a quantitatively negligible process in humans during overfeeding with a mixed diet containing at least the equivalent of the excess energy as fat.

\section{EVIDENCE OR NO EVIDENCE FOR ADAPTIVE THERMOGENESIS DURING OVERFEEDING}

Overfeeding studies that have not found evidence for adaptive thermogenesis mainly base their conclusions on the observation that there is no elevation in metabolic rate above obligatory costs, i.e. EE associated with an increased body size and tissue gain $(7,8,10,13,18)$, an increased DIT due to the increased amount of food eaten $(10,20)$, increased costs for the same body movements due to an increased body weight $(10,20)$ and a body weight gain proportional to the total amount of excess energy consumed $(11,14,21)$. All studies show a large inter-individual variation in weight gain, but comparing metabolically efficient and inefficient subjects showed no differences in EE changes (15). Although these overfeeding experiments failed to show adaptive changes in $\mathrm{EE}$, this does not mean there is no adaptive thermogenesis. In most studies there is still a considerable proportion of excess El that was not accounted for $(7,8,18)$, which is probably due to errors in the methods and assumptions used. In addition, the study period might have been too short, while adaptive thermogenesis is involved in long-term energy balance regulation (12).

Other studies conclude that adaptive thermogenesis must be present during overfeeding, because weight gain is smaller than expected (22) and the theoretical cost of storing dietary fat is exceeded (9). They show that thermogenesis did increase above obligatory costs $(17,19,22)$, either in DIT (19) or in the EE associated with PA like fidgeting, sitting and standing, which is called nonexercise activity thermogenesis (NEAT) (17).

If adaptive thermogenesis is present and contributes to the etiology of obesity then it is likely that obesity-prone persons have a reduced capacity for adaptive thermogenesis compared to obesity-resistant persons. As the predisposition to obesity in humans is hard to define, if to define at all, one usually compares lean and overweight or obese subjects. Results suggest that the thermogenic response 
to fat is flexible in lean subjects but that subjects with familial obesity have a reduced response (23). Though fat oxidation differs between lean and obese subjects on overfeeding $(10,13)$, the thermogenic response of lean and obese subjects was not different $(10,12,13,22)$. But, as overfeeding experiments are designed to result in weight gain, the number of overweight and obese subjects willing to participate is for obvious reasons often limited.

\section{CONCLUSION}

In humans, there is still little evidence for adaptive thermogenesis. Though most studies did find increases in EE during overfeeding, these were mainly explained by the energy costs of weight gain and the maintenance of a larger body weight. Changes in EE above these obligatory costs are considered adaptive thermogenesis, but the magnitude is generally no more than a few percent and includes measurement errors, errors in assumptions made and small (day-to-day) differences in physical activity. This makes the existence of adaptive thermogenesis hard to prove. However, there are large differences in thermogenesis and weight gain between subjects, independent of body weight. In search for evidence for adaptive thermogenesis, it would therefore be interesting to define obesity-prone and obesity-resistant persons based on their response to overfeeding. 


\section{REFERENCES}

1. Leibel $\mathrm{RL}_{\mathrm{w}}$ Rosenbaum $M$, Hirsch ]. Changes in energy expenditure resulting from altered body weight. N Engl I Med 1995;332:621-8.

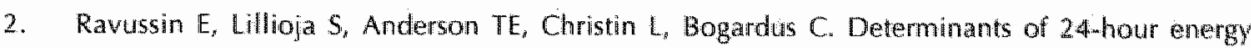
expenditure in man. Methods and results using a respiratory chamber. I Clin Invest $1986 ; 78: 1568-78$

3. Lowell BB, Spiegelman BM. Towards a molecular understanding of adaptive themogenesis. Nature 2000:404:652-60.

4. James WP, MCNeill $G$, Ralph A. Metabolism and nutritional adaptation to altered intakes of energy substrates. Am J Clin Nutr 1990; $51: 264-9$.

5. Dulloo AG. Thermogenesis is important in the aetiology of obesity: "the case for" (Abstract). Int) Obes Rellat Metab Disord 2002;26:S6.

6. Flatit JP. Adlaptive changes in thermogenesis are not important in the aetiology of obesity (Abstract). Int) Obes Relat Metab Disord 2002;26:56.

7. Bouchard $C$, Tremblay $A$, Despres JP, et al. The response to long-term overfeeding in identical twins. N Eng I Med 1990;322:1477-82.

8. Tremblay $\mathcal{A}_{x}$ Despres JP, Theriault $G$, Foumier $G_{n}$ Bouchard $C$. Overfeeding and energy expenditure in humans. Am I Clin Nutr 1992;56:857-62.

9. Dallosso HM, James WPT. Whole-body calorimetry studies in adult men (1. The effect of fat over-îeeding on 24 h energy expenditure). Brit J Nutr 1984;52:49-64.

10. Diaz EO, Prentice AM, Goldberg GR, Murgatroyd PR, Coward WA. Metabolic response to experimental overfeeding in lean and overweight healthy volunteers. Am I Clin Nutr $1992 ; 56: 641-55$.

11. Forbes $\mathrm{GB}$, Brown $\mathrm{MR}$, Welle $\mathrm{SL}$, Lipinski $\mathrm{BA}$. Deliberate overfeeding in women and men: energy cost and composition of the weight gain. Brit I Nutr 1986;56:1 -9.

12. Glick $Z$, Shvartz E, Magazanik A, Modam M. Absence of increased thermogenesis during shortterm overfeeding in normal and overweight women. Am I Clin Nutr 1977;30:1026-35.

13. Horton Tl, Drougas $H$, Brachey $A$, Reed GW, Peters $J C_{p}$ Hill 10 . Fat and carbohydrate overfeeding in humans: different effects on energy storage. Am J Clin Nutr 1995;62:19-29.

14. Jebb $5 A$, Prentice AM, Goldberg GR, Murgatroyd PR, Black AE, Coward WA. Changes in macronutrient balance during over- and underfeeding assessed by $12-d$ continuous whole-body calorimetry. Am / Clin Nutr 1996;64:259-66.

15. Joosen AMCP, Bakker AHF, Westerterp KR. Metabolic efficiency and energy expenditure during short-term overfeeding. Physiol Behav 2005;85:593-7.

16. Lammert $\mathrm{O}$, Grunnet $N_{r}$ Faber $P$, et al. Effects of isoenergetic overfeeding of either carbohydrate or fat in young men. Brit I Nutr 2000;84:233-45.

17. Levine $\mid A_{\text {, }}$ Eberhardt NL, Jensen MD. Role of nonexercise activity thermogenes is in resistence to fat gain in humans. Science 1999:283:212-4.

18. Norgan $\mathrm{NG}_{\text {, }}$ Durnin JV. The effect of 6 weeks of overfeeding on the body weight, body composition, and energy metabolism of young men. Am J Clin Nutr 1980; $33 ; 978-88$.

19. Pasquet $P, B$ rigant $L$, Froment $A$, et al. Massive overfeeding and energy balance in men: the Guru Walla model. Am J Clin Nutr 1992;56:483-90.

20. Ravussin E, Schutz $Y$, Acheson KJ, Dusmet M, Bourquin L, Jequier E. Short-term, mixed-diet overfeeding in man: no evidence for "luxuskonsumption". Am I Physiol 1985;249:E470-7. 
21. Roberts SB, Young VR, Fuss $P$, et al. Energy expenditure and subsequent nutrient intakes in overfed young men. Am I Plysiol 1990;259:R461-9.

22. Webb P. Annis JF. Adaptation to overeating in lean and ovenveight men and women. Hum Nutr Clin Nutr 1983:37:117.31.

23. Zed C. James WP. Dietary thermogenesis in obesity: fat feeding at different energy intakes. Int J Obes 1986:10:375-90.

24. Westenterp KR, Plasqui $G$. Physical activity and human energy expenditure. Curr Opin Clin Nutr Metab Care 2004;7:607-13.

25. Stubbs I, Raben A, Westerterp-Plantengal MS. Macronutrient metabolism and appetite. In: Westerterp.Plantenga MS, Steffens AB, Trembialy A, eds. Regulation of food intake and energy expenditure. Milan: Edra, 1999:59-84.

26. Westerterp $K R$, Wilson $S A$, Rollland $V$. Diet induced thermogenesis measured over $24 h$ in a respiration chamber: effect of diet composition. Int J Obes 1999;23:287-92.

27. Raben A, Agerholm-Larsen L, Flint A, Holst IJ Astrup A, Meals with similar energy densities but rich in protein, fat, carbohydrate, or alcohol have different effects on energy expenditure and substrate metabolism but not on appetite and energy intake. Am I Clin Nutr 2003;77:91-100.

20. Suter PM, lequier E, Schutz $Y$. Effect of ethanal on energy expenditure. Am J Physiol 1994:266:R1204-12

29. Stock MJ. Gluttony and thermogenesis revisited. Int I Obes 1999;23:1105-17.

30. Dulloo $A G$, Jacquet J. Low-protein overfeeding: a tool to unmask susceptibility to obesity in humans. Int J Obes 1999;23:1118-21.

31. Miller DS, Mumford P. Gluttony. 1. An experimental study af overeating low- or high-protein diets. Am / Clin Nutr 1967;20:1212 22 .

32. Miller DS, Mumford P, Stock MI. Gluttony. 2. Thermogenesis in overeating man. Am ] Clin Nutr $1967: 20: 1223-9$.

33. Bilack AE, Coward WA, Cole TI, Prentice AM. Human energy expenditure in affluent societies: am analysis of 574 doubly-labelled water measurements. Eur J Clin Nutr 1996:50:72-92.

34. Goldberg GR, Prentice AM, Davies HL, Murgatroyd PR. Overnight and basal metabolic rates in men and women. Eur I Clin Nutr 1988;42:137-44.

35. Tremblay $A$, Nadeau $A$, Fournier $G$, Bouchard $C$. Effect of a three-day internuption of exercisetraining on resting metabolic rate and glucose induced thermogenesis in training individualls. Int IObes 1988;12:163-8.

36. Tataranni PA, Lanson DE, Snitker S, Ravussin E. Thermic effect of food in humans: methods and results from use of a respiratory chamber. Am I Clin Nutr 1995;61:1013-9.

37. Van Es AJ, Vogt IE, Niessen $C_{\text {, }}$ et al. Human energy metabolism below, near and above energy equilibritum. Br I Nutr 19834:52:429-42.

38. Acheson KJ, Schutz $Y$, Bessard T, Anantharaman K, Flaft IP, Jequier E. Glycogen storage capacity and de novo lipogenesis during massive carbohydrate overfeeding in man. Am 1 Clin Nutr $1988: 48: 240-7$.

39. Aarsland $A$, Chinkes D, Wolfe RR. Hepatic and wholebody fat synthesis in humans during carbohydrate overfeeding. Am I Clin Nutr 1997:65:1774-82.

40. Minehira K, Vega N, Vidal H, Acheson K, Tappy L. Effect of carbohydrate overfeeding on whole body macronutrient metabolism and expression of lipogenic enzymes in adipose tissue of lean and overweight humans. Int J Obes Relat Metab Disord 2004;28:1291-8. 


\section{Metabolic efficiency and energy expenditure during short-term overfeeding}

Annemiek M.C.P. Joosen, Arjen H.F. Bakker and Klaas R. Westerterp

Physiology \& Behavior 2005;85:593-597 


\section{ABSTRACT}

Objective To investigate whether efficiency of weight gain during a short period of overfeeding is related to adaptive differences in basal metabolic rate and physical activity.

Subjects Fourteen healthy females (age $25 \pm 4 \mathrm{y}$, BMl $22.1 \pm 2.3 \mathrm{~kg} / \mathrm{m}^{2}$ ).

Design and measurements Subjects were overfed with a diet supplying $50 \%$ more energy than baseline energy requirements for $14 \mathrm{~d}$. Overfeeding diets provided $7 \%$ of energy from protein, $40 \%$ from fat and $53 \%$ from carbohydrates. Body composition was determined using hydrodensitometry and isotope dilution, total energy expenditure (TEE) with doubly labeled water and basal metabolic rate (BMR) with indirect calorimetry. Physical activity (PA) was recorded with a triaxial accelerometer.

Results Body weight increased by $1.45 \pm 0.86 \mathrm{~kg}$ (mean \pm SD) $(P<0.0001)$, fat mass increased by $1.05 \pm 0.75 \mathrm{~kg}$. Energy storage was $57.0 \pm 17.9 \mathrm{MJ}$, which is the difference between energy intake (207.2 MJ) and energy expenditure (150.2 MI) during overfeeding. There was no difference between metabolically efficient and metabolically inefficient subjects in changes in BMR and PA.

Conclusion These results indicate that the metabolic efficiency of weight gain was not related to adaptive changes in energy expenditure. 


\section{INTRODUCTION}

An energy intake that exceeds energy expenditure for longer periods will lead to weight gain. However, when healthy adults are overfed, most persons gain less weight than expected from the excess energy intake and show a wide interindividual range in weight gain on the same overfeeding regime (1-6). One possible explanation is that some persons can increase their energy expenditure when overeating to resist weight gain. Whether there are adaptive physiological changes in energy expenditure is studied intensively. While some investigators found evidence for adaptive thermogenesis (7) others did not $(1,8,9)$ but accuracy and sophistication of methods used to measure energy expenditure and physical activity could be improved. Three overfeeding studies, approximately comparable in amount and duration of overfeeding, measured free-living energy expenditure with doubly labeled water but reached different conclusions. Levine et al. (5) found that individual changes in non-exercise activity thermogenesis (NEAT), defined as the thermogenesis associated with fidgeting, maintenance of posture and other activities of daily life, could explain differences in fat gain in subjects overfed with $4.2 \mathrm{Ml} / \mathrm{d}$ for $56 \mathrm{~d}$. Diaz et al. (3) found no evidence for any adaptive energy-dissipating mechanism when overfeeding subjects with $50 \%$ more energy than baseline requirements (mean $6.2 \mathrm{MJ} / \mathrm{d}$ ) for $4.2 \mathrm{~d}$. Also Roberts et al. (4) did not find a significant increase in energy expenditure in young and older men overfed with $4.2 \mathrm{Ml} / \mathrm{d}$ for $21 \mathrm{~d}$.

Diet composition is known to influence energy expenditure, as different substrates will increase diet-induced thermogenesis (DIT) to various degrees. DIT is greater on a high-protein and-carbohydrate diet than on a high-fat diet (10). In several studies the metabolic response to overfeeding diets of different composition (lowprotein, high-carbohydrate, high-fat) has been investigated $(6,7,11,12)$. These experiments show considerable inter-individual differences in energy cost of weight gain within and between experiments. Stock (13) and Dulloo and Jacquet (14) showed that differences were most noticeable when diets were unbalanced with respect to protein and therefore suggested that overfeeding low-protein diets could serve as a tool to exaggerate individual differences in energetic efficiency by maximizing DIT. We overfed 14 healthy females with a low-protein diet to investigate whether efficiency of weight gain is related to adaptive differences in BMR and physical activity. 


\section{SUBIECTS AND METHODS}

\section{Subjects}

Fourteen healthy female subjects, aged $19-36$ years, participated in the study. Characteristics of the subjects are shown in Table 1 . Before participating in the study subjects were medically screened by a detalled health questionnaire. Subjects had had at stable body weight (body weight changes $\leq 2 \mathrm{~kg}$ ) for at least a year at the start of the study. Three were light smokers; they maintained their habitual smoking pattern during the study. All subjects recelved verball and written information and signed a written consent form. The study was approved by the Ethics Committee of Maastricht University.

Table 1 Initial characteristics of the 14 famale subjects.

\begin{tabular}{lll}
\hline & mean & SD \\
\hline Age $(\mathrm{y})$ & 25 & 4 \\
Height $(\mathrm{m})$ & 1.72 & 0.06 \\
Body weight $(\mathrm{kg})$ & 64.8 & 7.0 \\
Body mass index $\left(\mathrm{kg}^{\mathrm{m}} \mathrm{m}^{3}\right)$ & 22.1 & 2.3 \\
Body fat $(\%)$ & 27.5 & 4.4 \\
\hline
\end{tabular}

\section{Experimental design}

Baseline energy requirements were defined over a 7 d period (days 1-8). During the 14-d overfeeding period (days 8-22) subjects were overfed with a diet supplying $50 \%$ more energy than the baseline energy requirements. All foods and drinks were provided dally in weighed food packages while subjects consumed the main course (dinner) at the university. Alcohol consumption was not allowed during the study. Body weight was measured on days 1,8 and 22. Body composition and basal metabolic rate were measured at baseline and after overfeeding (days 8 and 22). Total energy expenditure was measured with doubly labeled water during the 2 weeks preceding overfeeding $(n=7$, because of limited availability of doubly labelled water) and during the 2 weeks of overfeeding $(n=14)$. For the entire study period subjects wore an accelerometer to measure physical activity. Subjects maintained their normal lifestyles (i.e. work, education, sports participation) throughout the study. 


\section{Dietary intake}

During the baseline period subjects chose their diets from a variety of food items provided daily in weighed food packages, bringing back the left-overs the next day, for calculation of habitual energy intake. When subjects had not been in energy balance (i.e. body weight changed from day $\mathbb{t}$ to day 8 ), baseline energy requirements were calculated from basal metabolic rate measured with indirect calorimetry and physical activity level measured with accelerometry. Subjects were overfed with a diet containing 50\% more energy than the baseline energy requirements. The excess energy intake during the overfeeding period was introduced gradually to allow the bowels to adjust to the increased amount of food. Overfeeding diets were calculated to be relatively low in protein, providing $7 \%$ of energy from protein as derived from the analysis of overfeeding experiments by Stock (13), $40 \%$ from fat and $53 \%$ from carbohydrates. Food composition of the diets was largely the same for each subject, but some adjustments were made according to the subject's preferences to make the overfeeding diets more palatable. All foods and drinks were weighed to the nearest gram. Macronutrient composition of baseline and overfeeding diets was assessed with a computerized version of the Dutch food composition table (Komeet, version 2.0d, 1996, B·ware Nutrition Soltware).

\section{Procedures}

Anthropometry and body composition Measurements were carried out in the morning after voiding and before breakfast. Body weight and height were measured to the nearest $0.01 \mathrm{~kg}$ and $0.1 \mathrm{~cm}$ respectively. Body mass index (BMI, $\mathrm{kg} / \mathrm{m}^{2}$ ) was calculated as body weight $(\mathrm{kg})$ divided by height $(\mathrm{m})$ squared. Body composition was estimated using hydrodensitometry and isotope dilution. Body density was determined by underwater weighing with simultaneous measurement of residual lung volume with the helium dilution technique. Total body water (TBW) was determined with deuterium dilution following the Maastricht protocol (15). Body composition was calculated from body density and TBW using the three-compartment model of Siri (16).

Total energy expenditure (TEE) was measured with the doubly labeled water (DLW) technique following the Maastricht protocol (15). Brilefly, isotopes were administered as a mixture of $5 \mathrm{At} \%{ }^{2} \mathrm{H}_{2} \mathrm{O}$ and $10 \mathrm{At} \% \mathrm{H}_{2}{ }^{18} \mathrm{O}$ resulting in an initial excess body water enrichment of $150 \mathrm{ppm}$ for deuterium and $300 \mathrm{ppm}$ for oxygen-18, leaving a sufficient excess enrichment at the end of the observation period. The volume was $80-160 \mathrm{ml}$. Subjects collected a background urine sample immediately before isotope consumption to correct for isotopic backgrounds, subsequent urine samples were collected from the second and the 
last voiding on the first, mid and last day of the $14 \mathrm{~d}$ observation period. Isotope enrichments of the urine samples were analyzed with isotope ratio mass spectrometry (Optima, VG, UK). Theoretical considerations and calculations of energy expenditure by the DLW method as described in detail elsewhere by Westerterp et al. (15) were checked for validity during overfeeding.

Basal metabolic rate (BMR) was measured by indirect calorimetry using an opencircuit, ventilated-hood system (17) in the morning after an overnight fast with subjects lying in a supine position for $30 \mathrm{~min}$. BMR was calculated from $\mathrm{O}_{2}$ consumption and $\mathrm{CO}_{2}$ production using the formula of Weir (18).

Physical activity was registered with a tri-axial accelerometer for movement registration (Tracmor, Philips Research, Eindhoven, The Netherlands), which measures frequencies covering the frequency content of activities of daily living (19). The tril-axial accelerometer has been validated against DLW (20) and has been used before in our department $(21,22)$. Subjects wore the accelerometer on a belt at the lower back during waking hours.

\section{Statistical analysis}

All results are presented as mean $\pm S D$. Student's paired t-test (two-sided) was used to compare parameters before and after overfeeding. A simple regression analysis between weight gain and energy storage (which is the difference between energy intake and energy expenditure during overfeeding) was used to distinguish between metabolically efficient (positive residuals) and metabolically inefficient (negative residuals) subjects. Metabolically efficient and inefficient subjects were compared regarding changes in BMR and physical activity using a one-way ANOVA. $P<0.05$ was considered as statistically significant. SPSS 11 for Macintosh (2002, SPSS Inc.) was used for the analysis.

\section{RESULTS}

\section{Dietary intake}

Table 2 summarizes the changes in energy balance parameters induced by overleeding. Self-selected baseline diets provided mean percentages energy of 14 $\pm 2 \%$ from protein, $30 \pm 3 \%$ from fat and $57 \pm 4 \%$ from carbohydrates. The macronutrient composition of the overfeeding diets was as intended: $7 \%$ of energy from protein, $40 \%$ from fat and $53 \%$ from carbohydrates, which was low in protein on a relative basis $(\%)$ and on an absolute basis $(61 \pm 6.1 \mathrm{~g} / \mathrm{d})$. The 
mean energy intake during baseline was $9.2 \pm 1.2 \mathrm{M} / \mathrm{d}$. During overfeeding mean energy intake was $14: 8 \pm 1.6 \mathrm{Mj} / \mathrm{d}$ or a total of $207.2 \pm 21.6 \mathrm{MJ}$ (Table 2).

\section{Body weight and body composition}

Body weight increased by $1.45 \pm 0.86 \mathrm{~kg}(\mathrm{P}<0.0001)$ with a range from 0.19 to $3.00 \mathrm{~kg}$. Fat mass increased by $1.05 \pm 0.75 \mathrm{~kg}$ ( $\mathrm{P}<0.001)$ ranging from 0.12 to $2.65 \mathrm{~kg}$ (Table 2). There was no significant effect of menstrual cycle (defined as the change from pre- to post-ovulation $(n=6)$ or from post- to pre-ovulation $(n=8)$ during the overfeeding period) on weight gain, neither alone nor after correction for energy storage (data not shown).

Table 2 Energy balance parameters at baseline and after 14 days overfeeding:

\begin{tabular}{|c|c|c|c|c|}
\hline & \multicolumn{2}{|c|}{ Baseline } & Overfeeding & \multirow{2}{*}{$\frac{P}{<0.0001}$} \\
\hline Body weight (kg) & 64.8 & \pm 7.0 & $66.3 \pm 6.7$ & \\
\hline Fat mass (kg) & 18.0 & \pm 4.5 & $19.0 \pm 4.3$ & $<0,001$ \\
\hline Energy intake (M//d) & 9.2 & \pm 1.2 & $14.8 \pm 1.6$ & $<0.0001$ \\
\hline $\operatorname{TEE}(M) / d) \quad(n=7)$ & 10.2 & \pm 0.7 & $10.6 \pm 1.0$ & 0.10 \\
\hline$(n=1.4)$ & & - & $10.7 \pm 1.1$ & - \\
\hline BMR $(M) / d)$ & 5.7 & \pm 0.4 & $6.1 \pm 0.6$ & $<0.01$ \\
\hline Physical activity (Mcounts/d) & 6666 & \pm 1286 & $7177 \pm 1645$ & 0.21 \\
\hline Energy storage (=EL-TEE) (MI) & & . & $57.0 \pm 17.9$ & - \\
\hline
\end{tabular}

$B M R=$ basal metabolic rate, $E l=$ energy intake, $T E E=$ total energy expenditure

"Values are mean $\pm \mathrm{SD}$

\section{Metabolic efficiency and energy expenditure}

There were no indications for malabsorption, therefore energy storage was calculated as the difference between energy intake $(207.2 \mathrm{MJ})$ and energy expenditure (150.2 Mj) during overfeeding. Mean energy storage was $57.0 \pm 17.9$ M) (Table 2).

Figure 1 shows the individual changes in body weight plotted against energy storage. Subjects with a positive residual from the regression line were considered metabolically efficient (relatively high weight gain for the amount of energy stored), subjects with a negative residual from the regression line were considered metabolically inefficient (relatively low weight gain for the amount of energy stored). For the whole group mean BMR increased significantly with $0.38 \pm 0.47$ $M / / d(P<0.01)$, with a large inter-individual variation. When comparing metabolically efficient and inefficient subjects we did not observe significant 
difference in $B M R$ change $(P=0.09)$. The progress of energy expenditure during overfeeding was examined by comparing mean TEE during the first and the second week of overfeeding. TEE increased by $0.38 \pm 0.68 \mathrm{M} / \mathrm{d}$ from the first to the second week, but this increase was not statistically significant. Although not statistically significant, there was a tendency towards a relation between this increase in TEE and the increase in BMR, which was measured before and after overfeeding.

Physical activity as measured with accelerometry did not change significantly ( $511 \pm 1450$ Mcounts/d). There was no difference in change in physical activity between metabolically efficient and inefficient subjects ( $P=0.43$ ). When we compared the subjects outside the $95 \%$ confidence interval of the mean, there was still no difference in BMR change $(P=0.12)$ or physical activity change $(P=$ $0.50)$.

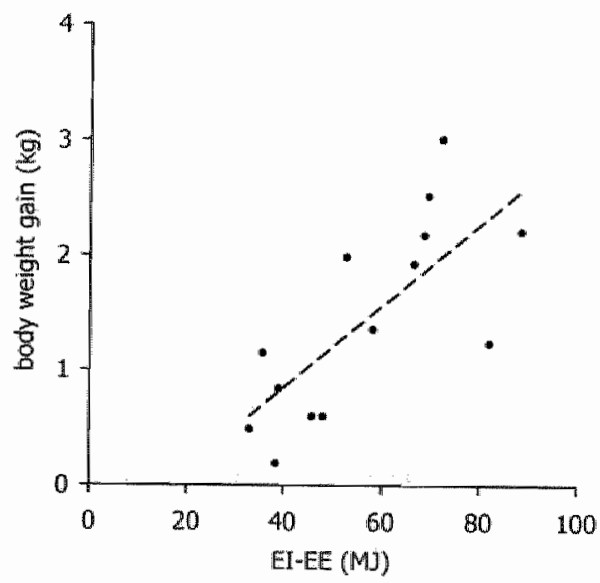

Figure 1 Individual changes in body weight plotted against energy storage (EI-EE (MII). EE = energy expenditure, $\mathrm{El}=$ energy intake

\section{DISCUSSION}

The relevance of adaptive changes in thermogenesis in the etiology of obesity is controversial as such changes are believed to be no more than a few percent 23 , 24). With prolonged overfeeding changes in energy expenditure are of the order of $5-15 \%$, which depends on the type and amount of overfeeding (DIT) $(25,26)$. The unexplained large inter-individual variation in efficiency of weight gain with 
overfeeding (1-6) shows that the matter of adaptive thermogenesis is still an issue. The aim of the present study was to investigate whether efficiency of weight gain is related to adaptive differences in BMR and physical activity by overfeeding healthy females for $14 \mathrm{~d}$ with a diet supplying $50 \%$ more energy than baseline requirements. If eniergy expenditure does not follow excess energy intake to the same extent, absolute energy storage will be greater in a subject with a baseline energy intake of for instance $12 \mathrm{MJ} / \mathrm{d}(252-168=84 \mathrm{MJ})$ compared to a subject with a baseline energy intake of $8 \mathrm{MJ} / \mathrm{d}(168-112=56 \mathrm{M})$. This absolute difference in excess energy intake will also influence absolute weight gain. The absolute differences allowed us to distinguish between subjects with a relatively high weight gain for the amount of energy stored (metabolically efficient) and a relatively low weight gain for the amount of energy stored (metabolically inefficient).

If any adaptive thermogenesis is present, this will show up in the BMR. Mean BMR did increase, however, when we compared those subjects that gained body weight efficiently with those that did not, we did not see any difference in BMR change. The changes in BMR were equivalent to the expected rise in DIT due to the increased amount of food eaten. The 9-10 h interval between the last food consumption in the evening and measurement of BMR in the morning did not eliminate influences of DIT on metabolic rate. Goldberg et al. (27) showed that after overfeeding the DIT from a large evening meal caused a higher sleeping metabolic rate compared to normal conditions. BMR measured directly at waking was still increased, despite a 13 -h interval between the last meal and the measurement. This suggests that the increase in DIT due to the increased amount of food eaten persists for $24 \mathrm{~h}$ a day and is therefore observed in our BMR changes.

The most variable component of energy expenditure is AEE, which can be divided in exercise activity thermogenesis. (EAT) and non-exercise activity thermogenesis (NEAT). EAT is the thermogenesis accompanied with sports participation, NEAT is defined as the thermogenesis that accompanies fidgeling, maintenance of posture, and other physical activities of daily life. The concept of NEAT seems important in energy balance regulation as in the study of Levine et al. (5) who overfed 16 nonobese subjects with $4.2 \mathrm{MJ} / \mathrm{d}$ for $56 \mathrm{~d}$, changes in NEAT directly predicted resistance to fat gain with overfeeding. In this study physical activity was registered with a tri-axial accelerometer, which is sensitive to small human body accelerations and very low frequencies of accelerations and can therefore detect fidgeting (28). Subjects maintained their normal lifestyles throughout the study period (i.e. work, education, sports participation). Mean accelerometer output did not change significantly, therefore both exercise and non-exercise activity remained constant. 
When comparing TEE during the first and the second week of overfeeding there seemed to be a gradual increase in TEE, but this was not statistically significant. This increase in TEE tended towarcls a relation with the increase in BMR and although this relation was not statistically significant, we believe that the rise in TEE on overfeeding is largely due to an increase in BMR, and thus DIT.

However, we were not able to answer the question why some subjects can store a certain amount of energy with hardly any weight gain. We have no indications for non-compliance to the diet or measurement errors for the whole group and these subjects in particular. We can only speculate on how the excess energy was stored, by either hypertrophy or hyperplasia of the fat cells.

In short, we did not find differences in BMR and physical activity between metabolically efficient and metabolically inefficient subjects during overfeeding, indicating that the metabolic efficiency of weight gain is not related to adaptive changes in energy expenditure. 


\section{REFERENCES}

1. Norgan NG, Durnin IV. The effect of 6 weeks of owerfeeding on the body weight, body composition, and energy metabolism of young men. Am J Clin Nutr 1980;33:978-88.

2. Bouchard $C$, Tremblay $A$, Despres IP, et al. The response to long-term overfeeding in identical twins. N Eng J Med 1990,322:1477-82.

3. Diaz EO, Prentice AM, Goldberg GR, Murgatroyd PR, Coward WA. Metabolic response to experinental overfeeding in lean and overweight healthy volunteers. Am 1 Clin Nutr $1992 ; 56: 641-55$

4. Roberts SB, Fuss P, Dallal GE, et al. Effects of age on energy expenditureand substrate oxidation during experimental overfeeding in healthy men. J Gerontal A Biol Sci Med Sci 1996;51:B148. 57.

5. Levine $\mathbb{A}$, Eberhardt NL, Jensen MD. Role of nonexercise activity thermogenesis in resistence to fat gain in humans. Science 1999;283:212-4.

6. Lammert $\mathrm{O}$, Girunnet $N$, Faber $P_{x}$ et al. Effects of isoenergetic overfeeding of either carbohydrate or fat in young men. Brit I Nutr 2000;84:233-45.

7. Webb $P_{*}$ Annis IF. Adaptation to overeating in lean and owerweight men and women. Hum Nutr Clin Nutr 1983;37:117-31.

8. Ravussin E, Schutz $Y$, Acheson $\mathrm{KJ}$, Dusmet $\mathrm{M}$, Bourquin L, Jequier $\mathrm{E}$. Short-term, mixed-diet overfeeding in man: no evidence for "luxuskonsumption". Am J Physiol 1985;249:E470-7.

9. Forbes $G B, B r o w n M R$, Welle SL Lipinski BA. Deliberate overfeeding in women and $m e n:$ energy cost and composition of the weight gain. Brit I Nutr 1986;5:6:1-9.

10. Westerterp KR, Wilson SAJ, Rolland $\mathrm{V}$. Diet induced thermogenesis measured over 24 h in a respiration chamber: effect of diet composition. Int J Obes 1999:23:287-92.

11. Miller DS, Mumford P. Gluttony. 1. An experimental study of overeating low- or high-protein diets. Am J Clin Nutr 1967;20:1212-22.

12. Horton TJ, Drougas $H$, Brachey $A$, Reed $G W$, Peters $J C$, Hill JO. Fat and carbohydrate overfeeding in humans: different effects on energy storage. Am J Clin Nutr 1995;62:19-29.

13. Stock My. Gluttony and thermogenes is revisited. Int J Obes 1999;23:1105-17.

14. Dulloo AG, Jacquet J. Low-protein overfeeding: a tool to unmask susceptibility to obesity in humarns. Int J Obes 1999;23:1118-21.

15. Westerterp KR. Wouters $L$, Marken Lichtenbelt WDW. The Maastricht protocol for the measurement of body composition and energy expenditure with labeled water. Obes Res $1995: 3: 49-57$.

16. Siri WE. Body composition from fluid spaces and density: analysis of methods. 1961. Nutrition 1993:9:480-91; discussion, 92.

17. Adriatens MP. Schoffelen PF, Westerterp KR. Intra-indiwidual variation of basal metabolic rate and the influence of daily habitual physical activity before testing. Br \Nutr 2003;90:419-23.

18. Weir IdV. New methods for calculating metabolic rate with special reference to protein metabolism. I Phyiol 1949;109:1-9.

19. Sun $M$, Hill JO. A method for measuring mechanical work and work efficiency during human activities. J Biomech 1993;26:229-41.

20. Bouten CVC, Verboeket-Van De Venne WPHG, Westerterp KR, Verduin M, Janssen DD. Daily physical activity assessment: comparison between movement registration and doubly labelied water. A Appl Physiol 1996;81:1019-26. 
21. Conis $A H C$. Meijer EP, Westerterp KR. Repeated meastrement of habitual food intake increases under-reporting and induces selective under-reporting. Brit I Nutr 2001;85:629-34.

22. Goris $A M C$, Meijer EP, Kester $A$, Westerterp KR. Use of a triaxal accelerometer to validate reponted food intakes. Am I Clin Nutr 2001;73:549-53.

23. Dulloo AGi. Thermogenesis is important in the aetiology of obesity: "the case for" (Abstract). Int ) Obes Relat Metab Disord 2002, $26: 56$.

24. Flatt IP. Adaptive changes in thermogenesis are not important in the attiology of obesity (Abstract). Int) Obes Relat Metab Disord 2002;26:56.

25. James Wis, McNeill G; Ralph A Metabolism and nutritional adaptation to altered intakes of energy substrates. Ami / Clim Nutr 1990;51:264-9.

26. Norgan. Thermogenesis above maintenance in humams. Proc Nutr Soc 1990;49:217-26.

27. Coldberg CR, Prentice AM, Davies HL, Murgatroyd PR. Overnight and basal metabolic rates in men and women. Eur \& Clin Nutr 1988;42:137-44.

28. Bouten CV, Westerterp KR, Verduin $M$, Janssen JD. Assessment of energy expenditure for physical activity using a triaxial accelerometer. Med Sci Sports Exerc 1994;26:1516-23. 


\section{PPAR $\gamma$ activity in subcutaneous abdominal fat tissue and fat mass gain during short-term overfeeding}

Annemiek M.C.P. Joosen, Arjen H.F. Bakker, Antoine H.G. Zorenc, Sander Kersten, Patrick Schrauwen and Klaas R. Westerterp

International Journal of Obesity (in press) 


\section{ABSTRACT}

Objective As the peroxisome proliferator-activated receptor $\gamma$ (PPARy) plays a central role in fat mass regulation, we investigated whether initial subcutaneous PPARy activity is related to fat mass generation during overfeeding.

Subjects Fourteen healthy females (age $25 \pm 4$ y, BMI $22.1 \pm 2.3 \mathrm{~kg} / \mathrm{m}^{2}$ ).

Design and measurements Subjects were overfed with a diet supplying $50 \%$ more energy than baseline energy requirements for $14 \mathrm{~d}$. Fasting blood samples were analyzed for leptin, insulin and glucose. Fasting subcutaneous abdominal fat biopsies were obtained for analysis of PPAR 1 1, PPAR 2 , aP2 and UCP2 mRNAs.

Results Initial PPARY1 and 2, aP2 and UCP2 mRNAs were not related to fat gain $(P>0.12)$. However, PPAR 1, PPAR 2 and aP2 mRNA changes were positively related to changes in plasma leptin $(P<0.05)$ and, except aP2 $(P=0.06)$, to fat gain $(P<0.05)$. PPARy and aP2 mRNA changes were positively related $(P<0.01)$, indicating that PPAR $y$ mRNA levels reflected PPAR' $\gamma$ activity.

Conclusion These data suggest that the ability to increase PPARY activity might be involved in the susceptibility to gain weight during a positive energy balance. 


\section{INTRODUCTION}

Obesity is characterized by an excessive fat mass. But also within a normal weight population large differences in fat mass are observed. Overfeeding identical twins with a fixed amount of energy resulted in at least threefold more variance in gains in body weight and fat mass between pairs than within pairs (1), which indicates that body weight and composition are largely genetically controlled. An interaction between environmental factors (e.g. food intake) and genes involved in adipose tissue metabolism may therefore determine the susceptibility to obesity.

The peroxisome proliferator-activated receptor $\gamma$ (PPAR $\gamma$ ) has been shown to be both sufficient and obligatory for fat mass generation (2). In addition, PPARy has an important role in fat storage (leading to an increased adipocyte volume) and metabolism in differentiated adipocytes by stimulating the expression of adipocyte-specific genes (2). PPARY is a member of the nuclear hormone receptor superfamily and is expressed as two isoforms, PPARY1 and PPAR 2 , generated from the same gene by alternative promoter usage and alternative splicing. Both isoforms are expressed at high levels in adipose tissue (3-5). PPAR $\gamma$ activity requires the formation of heterodimers and the binding of ligands. These heterodimers are formed with another nuclear hormone receptor, the retinoid $X$ receptor (RXR), which binds to PPAR response elements in the promoter region of target genes and activates DNA transcription upon ligand binding (4). Several ligands and agonists of PPAR $y$ are known, including certain polyunsaturated fatty acids and eicosanoids and the antidiabetic thiazolidinedione (TZD) class of drugs (6).

As PPARy plays a central role in fat mass regulation, we investigated whether initial PPARY activity is related to fat mass gain during overfeeding. In this context, it is important to know whether increased PPARY mRNA levels reflect an increase in PPAR $\gamma$ activity. The adipocyte-specific fatty acid binding protein (aP2) is primary a PPARy response gene and is therefore commonly used as an adipocyte specific marker in vitro $(7,8)$. In addition, PPARY is involved in the regulation of the uncoupling protein 2 (UCP2) as PPARy agonists are shown to increase UCP2 expression in adipose tissue (9-11). UCP2 mRNA levels are reduced in adipose tissue from obese compared to lean persons (12), which suggests a role for UCP2 in obesity by influencing energy metabolism although a specific uncoupling function has not been confirmed in humans (10). We investigated whether UCP2 influences fat mass gain during overfeeding. 


\section{SUBJECTS AND METHODS}

\section{Subjects}

Males and females were recruited through advertisements in the university and the university hospital. However only females responded, therefore fourteen female subjects, aged 19-36 years, participated in the study. Characteristics of the subjects are shown in Table 1. Selection criteria included being healthy, between the age of 18 and 40 years, Caucasian, non- or light $(<10$ cigarettes/d) smoker, with a BMI between 18.5 and $27 \mathrm{~kg} / \mathrm{m}^{2}$ and weight stable body weight changes $s$ $2 \mathrm{~kg}$ ) for at least a year at the start of the study. Before participating in the study subjects were medically screened by a detailed health questionnaire, only subjects in good health were included. All subjects received verbal and written information and signed a written consent form. The study was approved by the Ethics Committee of Maastricht University.

Table 1 Baseline characteristics of the 14 flemale subjects.

\begin{tabular}{lll}
\hline & mean & 50 \\
\hline Age $(\mathrm{y})$ & 25 & 4 \\
Height $(\mathrm{m})$ & 1.72 & 0.06 \\
Body weight $(\mathrm{kg})$ & 64.8 & 7.0 \\
Body mass index $\left(\mathrm{kg} / \mathrm{m}^{2}\right)$ & 22.1 & 2.3 \\
Body fat $(\%)$ & 27.5 & 4.4 \\
\hline
\end{tabular}

\section{Experimental design}

The study enclosed a $7-d$ baseline period (days 1-8) and a 14-d overfeeding period (days 8-22). During the baseline period subjects chose their diets from a variety of food items provided daily in weighed food packages, bringing back the left-overs the next day, for calculation of habitual energy intake. When subjects had not been in energy balance (i.e. body weight changed from day 1 to day 8 ), baseline energy requirements were calculated from basal metabolic rate and physical activity level. During the overfeeding period diets contained $50 \%$ more energy than the baseline energy requirements $(14.8 \pm 1.6 \mathrm{MJ} / \mathrm{d}$ or a total of 207.2 $\pm 21.6 \mathrm{MJ}$ ). The excess energy intake was introduced gradually to allow the bowels to adjust to the increased amount of food. Overfeeding diets provided $7 \%$ of energy from protein, $40 \%$ from fat and $53 \%$ from carbohydrates (Dutch food composition table, Komeet, version 2.0d, 1996, B.ware Nutrition Software). All foods and drinks were provided daily in weighed food packages while subjects 
consumed dinner at the university. Alcohol consumption was not allowed during the study. Body weight was measured on days 1,8, and 22. Body composition was measured on days 8 and 22 and on the same days blood samples and fat biopsies were taken. Subjects maintained their normal lifestyles (i.e. work, education, sports participation) throughout the study.

\section{Procedures}

Anthropometry and body composition Measurements were carried out in the morning after voiding and before breakfast. Body weight and height were measured to the nearest $0.01 \mathrm{~kg}$ and $0.1 \mathrm{~cm}$ respectively. Body mass index (BMI, $\mathrm{kg} / \mathrm{m}^{2}$ ) was calculated as body weight $(\mathrm{kg})$ divided by height $(\mathrm{m})$ squared. Body composition was estimated using hydrodensitometry and isotope dilution. Body density was determined by underwater weighing with simultaneous measurement of residual lung volume with the helium dilution technique. Total body water (TBW) was determined with deuterium dilution following the Maastricht protocol (13). Body composition was calculated from body density and TBW using the three-compartment model of Siri (14).

Plasma glucose, insulin and leptin After an overnight fast blood samples were obtained and mixed with citrate to prevent clotting. Plasma was obtained by centrifugation $\left(4^{\circ} \mathrm{C}, 3000 \mathrm{rpm}, 10 \mathrm{~min}\right)$, frozen in liquid nitrogen and stored at $80^{\circ} \mathrm{C}$ until analysis of concentrations of glucose (hexokinase method, Glucose HK 125 kit, ABX diagnostics, Montpellier, France), insulin (ELISA, Mercodia, Uppsala, Sweden) and leptin (double-antibody RIA, human leptin specific RIA kit, Linco Research Inc, St Charles, USA).

Fat biopsy Abdominal subcutaneous fat biopsies were obtained by needle liposuction under local anesthesia (lidocain 2\% with adrenalin 1:80000, AstraZeneca BV, Nederland) after an overnight fast. The tissue was immediately washed in cold saline, homogenized in $1 \mathrm{ml}$ Trizol (Gibco BRL, Life Technologies) in a mini-beadbeater (Biospec Products, Bartlesville, OK), frozen in liquid nitrogen and stored at $-80^{\circ} \mathrm{C}$ until RNA extraction. Total RNA was isolated using the method of Chomczynski and Sacchi (15) and $10 \mu \mathrm{gg}$ glycogen was added to each sample. Extracted RNA was quantified and assessed for purity by UV spectrophotometry.

Quantification of PPAR 1 , PPAR $\gamma 2$ and aP2 mRNA expression by real-time RTPCR CDNA was synthesized from $500 \mathrm{ng}$ RNA in a volume of $20 \mu \mathrm{l}$ containing 2 $\mu l$ RT buffer (Sensiscript RTkit, Qiagen, Hilden, Germany), $2 \mu l$ dNTPs, $1 \mu$ l oligo 
(dT) primer, $0.25 \mu 1$ RNase inhibitor and 1 HI reverse transcriptase (Sensiscript RTkit, Qiageny. The RT reaction was performed at $37^{\circ} \mathrm{C}$ for $60 \mathrm{~min}$.

$P C R$ reactions were performed in a final volume of $25 \mu /$ containing $0.2 \times$ SYBR Green/fluorescein in DMSO (5X SYBR Green/ 0.25 HM fluorescein), $1 \times$ Taq buffer, 0.02 U/ul Taq polymerase, $0.2 \mathrm{mM}$ dNTPs, $3 \mathrm{mM} \mathrm{MgCl} 2,0.6 \mathrm{pmol} / \mu /$ of each primer and $25 \mathrm{ng} / \mu \mathrm{l}$ CDNA. The PCR program was $94^{\circ} \mathrm{C}$ for $2 \mathrm{~min}$, followed by 45 cycles of $94^{\circ} \mathrm{C}$ for $15 \mathrm{sec}$ and $60^{\circ} \mathrm{C}$ for 1 min. After every cycle the fluorescence of SYBR Green was measured, which represents the amount of double-stranded DNA amplified to that point in the PCR. Subsequently, melt curve analysis $\left(45^{\circ} \mathrm{C}\right.$ for $5 \mathrm{~min}, 100$ cycles of $65^{\circ} \mathrm{C}$ for $10 \mathrm{sec},+0.3^{\circ} \mathrm{C}$ after cycle 2) indicated specific product for each pair of primers. The primer sequences were as follows: PPAR 1 forward 5'-AAGGCCATTTTCTCAAACGA-3', reverse 5'AGGAGTGGGAGTGGTCTTCC-3"; PPAR 2 forward 5'-CCATGCTGTTATGGGTGAAA-3', reverse 5'-TCAAAGGAGTGGGAGTGGTC-3'; aP2 forward 5'GCATTCCACCACCAGTTTATC-3', reverse 5'- CAGGAAAGTCAAGAGCACCAT$3^{n} ; \beta$-actin forward 5"-AGAAAATCTGGCACCACACC-3*, reverse 5;-AGAGGCGIACAGGGATAGCA-3'. For target and housekeeping genes, standard curves were created from a specific PCR product. To account for differences in RNA loading, target $\mathrm{mRNA}$ was expressed relative to $\beta$-actin $\mathrm{MRNA}$. The $\mathrm{MRNA}$ concentration of $\beta$-actin was not different between baseline and overfeeding 1109 \pm 67 and $88 \pm 87$ respectively based on photospectrometry, $P=0.48$ ). The threshold cycle $\left(C_{T}\right)$ is the cycle number at which the fluorescence is first recorded statistically significant above background. The $C_{\mathrm{T}}$ always occurs during the exponential phase of the amplification and thus shows a negative linear relationship with the log CDNA: the more CDNA present at the beginning of the PCR, the fewer number of cycles it takes to reach the $C_{T}$. The PCR amplification efficiencies of the target and housekeeping genes were similar and therefore the amount of target mRNA relative to the amount of $\beta$-actin $m$ RNA in each sample was calculated as follows: $\Delta C_{Y}=C_{r}($ target $)-C_{Y}(\beta$-actin), relative expression level $=2^{-A C H}$

\section{Quantification of UCP2 mRNA expression by RT-competitive PCR Total RNA} (0.2 $\mathrm{Hg}$ ) was reverse transcribed as described above using Tth DNA polymerase and specific primers. Target cDNA $(0.2 \mu \mathrm{g})$ was coamplified with known amounts of the target CDNA competitor in the same tube. The PCR reaction was performed with 5'-ATCGACGCCTACAGAACCAT-3' as sense primer and 5'-ATAGGTGACGAACATCACCACG-3' as antisense primer, and specific competitor DNA obtained by the deletion of 55 bp from a 290-nt long UCP2 CDNA fragment. The PCR program was $94^{\circ} \mathrm{C}$ for $3 \mathrm{~min}, 35 \mathrm{cycles}$ of $94^{\circ} \mathrm{C}$ for $1 \mathrm{~min}, 57^{\circ} \mathrm{C}$ for $45 \mathrm{sec}$ and $72^{\circ} \mathrm{C}$ for $2 \mathrm{~min}$, followed by $74^{\circ} \mathrm{C}$ for $5 \mathrm{~min}$. PCR products were analyzed 
with the ALF sequencer. The amount of UCP2 mRNA, expressed as amol / $\mu \mathrm{g}$ total RNA, was obtained from the point where the initial amount of target CDNA corresponds to the initial amount of competitor (log density ratio competitor / target $\mathrm{CDNA}=0$ ).

\section{Statistical analysis}

Results are presented as mean \pm SD unless otherwise specified. The nonparametric paired Wilcoxon signed rank test (two-sided) was used to test the effect of overfeeding on the parameters. Significance of correlations was tested with the non-parametric Spearman rank correlation $\left(r_{s}\right) . P<0.05$ was considered statistically significant. StatView statistical software (1992-98, SAS Institute Inc., NC, USA) was used for the analysis.

\section{RESULTS}

Overfeeding resulted in a mean body weight gain of $1.45 \pm 0.86 \mathrm{~kg}(\mathrm{P}<0.0001)$, with a range from 0.19 to $3.00 \mathrm{~kg}$. Fat mass increased by $1.05 \pm 0.75 \mathrm{~kg}(\mathrm{P}<$ 0.001 ) ranging from 0.12 to $2.65 \mathrm{~kg}$.

Mean fasting plasma glucose, insulin and leptin concentrations before and after overfeeding are shown in Table 2. Changes in plasma insulin and leptin concentrations were positively correlated $\left(r_{S}=0.77, P<0.01\right)$. Changes in plasma leptin concentrations were related to fat mass gain $\left(r_{s}=0.62, P=0.02\right)$, changes in plasma insulin concentrations were not statistically significant related to fat mass gain $(P=0.08)$.

Table 2 Fasting plasma concentrations of glucose, insulin and leptin at baseline and after overfeeding.

\begin{tabular}{lllll}
\hline & $\begin{array}{l}\text { Baseline } \\
\text { mean }\end{array}$ & SD & \multicolumn{3}{c}{ Overfeeding } \\
\hline Glucose (mmol/s) & 4.4 & 0.2 & mean & SD \\
Insulin $(\mu \mathrm{U} / \mathrm{m} /)$ & 5.7 & 1.7 & 4.4 & 0.3 \\
Leptin $(\mathrm{ng} / \mathrm{mll})$ & 5.9 & 2.5 & 7.0 & 2.6 \\
\hline
\end{tabular}

$p=0.001$

Table 3 shows the median fasting mRNA levels of PPARY1 and 2, aP2 and UCP2 in subcutaneous abdominal adipose tissue before and after overfeeding. 
PPARY1 and 2 and aP2 mRNA levels at baseline were neither related to the imitial fat mass $(P>0.30)$ nor to the fat mass gain $(P>0.12)$. UCP2 mRNA levels at baselline tended to be negatively related to the initial fat mass $(P=0.06)$, but were not associated with fat mass gain ( $P=0.79)$. However, the increase in fat mass with overfeeding was related to changes in PPARy1 $\left(r_{s}=0.71, P=0.01\right.$; Figure 1a) and PPARy2 $\left(r_{s}=0.64, P=0.02\right.$; Figure $\left.1 b\right)$ mRNA with a trend towards a relation with changes in aP2 $\left(r_{s}=0.52, P=0.06\right.$; Figure $1 \mathrm{c}$ mRNA. Similar results were oblained when fat mass gain was expressed as percent change of initial fat mass (data not shown). The increase in fat mass was not related to changes in UCP2 MRNA levels ( $P=0.23$ ) and changes in PPARy2 and UCP2 mRNA levels were not statistically significant related $(\mathrm{P}=0.08)$.

Table 3 mRNA levels of PPARy1, PPARY2, aP2 and UCP2 in subcutaneous abdominal adipose tissue at baseline and after overfeeding.

\begin{tabular}{|c|c|c|c|c|}
\hline & \multicolumn{2}{|l|}{ Baseline } & \multicolumn{2}{|c|}{ Overfeeding } \\
\hline & median & range & medlian & range \\
\hline PPARY1/B-actin mRNA & 1.55 & $(0.28-15.35)$ & 1.96 & $(0.68-10.06)$ \\
\hline PPARy $2 / \beta$-actin mRNA & 0.27 & $(0.11-4.08)$ & 0.54 & $(0.22-2.04)$ \\
\hline aP2/B-actin mRNA & 22.27 & $(3,39-362.04)$ & 27.94 & $(10.34-76.11)$ \\
\hline UCP2 (amol/Hg RNA) & 0.35 & $(0.01-2.18)$ & 0.32 & $(0.05-11.54)$ \\
\hline
\end{tabular}

Interestingly, high initial PPARy 1 and 2 mRNA levels tended to relate to smaller changes in expression of these genes $\left(r_{S}=-0.54, P=0.05\right.$ for PPAR $1 ; r_{S}=-0.48$, $P=0.06$ for PPARy2). Nevertheless, PPAR 1 and $2 \mathrm{mRNA}$ levels were related to aP2 mRNA levels at baseline and after overfeeding ( $r_{5}=0.56$ to $0.85, P<0.05$ ) and changes in the expression of PPAR 1 and 2 were positively related to changes in a.P2 expression ( $r_{s}=0.88$ and 0.74 respectively, $P<0.01$; Figure 2$)$, indicating that PPARY activity is in proportion to the PPARY gene expression and to changes in gene expression.

Changes in plasma leptin concentrations were positively related to changes in mRNA levels of PPARy1, PPARy 2 and $\mathrm{aP} 2\left(r_{\mathrm{S}}=0.57\right.$ to $\left.0.71, \mathrm{P}<0.02\right)$, but these correlations disappeared after correction of changes in leptin for fat mass gain ( $P>$ $0.45)$, which indicates that the changes in gene expression were directly associated with changes in fat mass.

There was a positive relation between changes in plasma insulin concentrations and PPAR 2 mRNA levels $\left(r_{s}=0.70, P=0.01\right)$, but there was no statistically significant relation with PPARr1, aP2 and $U C P 2(P>0.06)$ mRNA levels. 
(a)

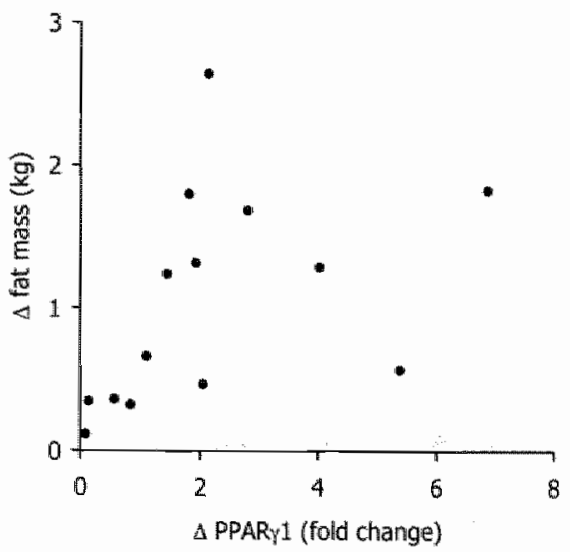

(c)

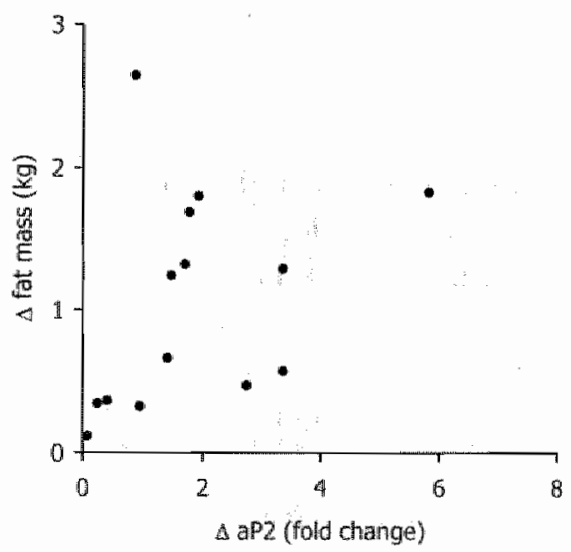

(b)

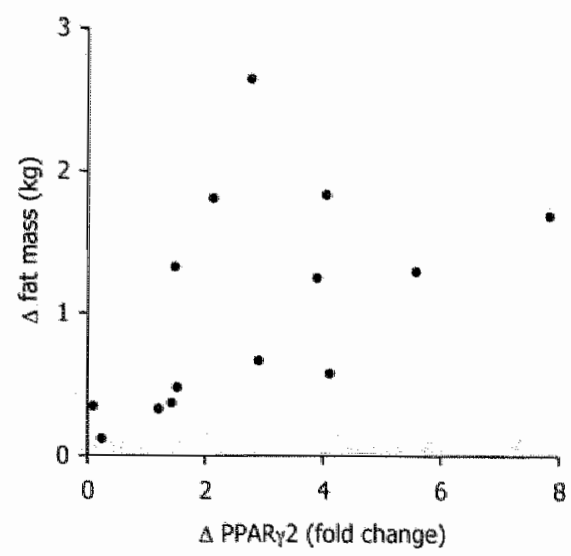

Figure 1 Relationship between changes in PPARY1 (a), PPAR2 2 (b) and aP2 (c) mRNA levels and fat mass gain.

\section{DISCUSSION}

The present study aimed to investigate whether the initial PPARy activity is related to fat mass generation during short-term overfeeding. The initial PPAR gene expression was not significantly related to fat mass gain during overfeeding, but the change in PPARy expression was positively correlated to fat mass gain. We measured the two PPARY isoforms, PPAR 1 and PPARy 2 , separately. 


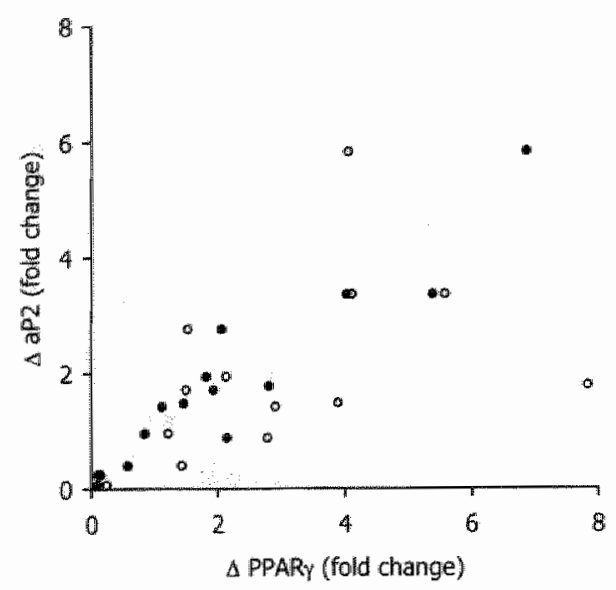

Figure 2 Relationship between changes in PPARyll (-) and PPARY2 (O) mRNA levels and changes in aP2 mRNA levels.

Both isoforms can stimulate adipogenesis but there is evidence that at low ligand concentrations, PPAR 2 has a greater ability to stimulate adipogenesis (5). In this study we did not see different activities of both isoforms: both PPAR 1 and 2 gene expressions were related to the expression of aP2 and the gene expressions were induced to the same extent. AP2 mRNA levels are primary regulated by PPARy and are shown to be a quantitative measure of $\operatorname{PPAR} \gamma$ activity $(7,8)$, therefore PPAR mRNA levels did reflect PPARy activity in vivo. This suggests that the ability to increase PPARy activity might be involved in the susceptibility to gain weight during overfeeding.

In a population of Finnish men and women, the common Pro12Ala polymorphism in the PPARY2 gene is associated with a lower BMI (16). The mutant PPARY2 protein showed an impaired ability to mediate TZD-induced adipogenesis 116 , 17), therefore the association with a lower BMI is likely to be the result of the lower transcriptionall capacity of the Ala variant of PPARy2 (16). The mRNA expression of PPAR $\gamma 2$ target genes in the adipose tissue of morbid obese subjects did not seem to be influenced by the Pro12Ala polymorphism (18), which suggests that particular environmental factors, like diet, influence the contribution of the genotype to the development of obesity.

The study included healthy non-obese and normoglycemic females. Fasting plasma glucose was the same before and after the overfeeding period, and although there were large inter-individual differences, mean fasting plasma insulin 
did not change significantly. An increased PPARY activity, leading to adipocyte differentiation, results in an increase in insulin sensitivity (19). Indeed, we found a positive relation between changes in plasma insulin and PPARY2 IRNA, and a trend towards a relation with PPARY1 mRNA. Changes in plasma insulin tended to be related to fat mass gain. This effect of short-term overfeeding was in accordance with the observed increase in PPARY mRNA levels in subcutaneous abdominal fat tissue after a $3 \mathrm{~h}$ insulin infusion (20) and the induction of PPARy MRNA in isolated human adipocytes by insulin (3).

The weight gain period in this study was 2 weeks and the extent of induction of PPAR $\gamma$ expression was positively related to fat gain over this interval. We can only speculate on the relation in the longer term. Fat mass is determined by the number of fat cells and by the continuous uptake and release of energy by the fat cell. PPARY is required for the formation of new fat cells and plays a major role in fat storage and metabolism. Therefore both slow and fast adaptation of the PPARY expression to a positive energy balance will lead to an increased fat mass but the time span may vary.

Another factor in determining fat mass gain in response to overfeeding is the thermogenic capacity of the adipose tissue. UCP2 is homologue of the brown adipose tissue UCP1, which uncouples proton entry into the mitochondrial matrix from energy production thereby dissipating energy as heat. The expression of UCP2 is reduced in adipose tissue of obese vs. lean subjects (12). In a populationbased sample from the same geographic area a common UCP2 polymorphism could account for $15 \%$ of the obesity prevalence (12) and genetic variation at the UCP2 locus is associated with energy expenditure in Pima Indians (21). Together, these observations suggest a role for UCP2 in obesity by influencing energy metabolism although a specific uncoupling function has not been confirmed in humans (10). In addition, UCP2 is at least in part regulated through PPARY as PPARy agonists increase adipose UCP2 expression (9-11). Direct evidence was provided by the observation that a $5 \mathrm{~h}$ infusion with nonesterified fatty acids upregulated UCP2 and PPARy MRNA levels in subcutaneous adipose tissue (22). However, in the present study, we found no effect of overfeeding on UCP2 MRNA and we found no statistically significant relation between changes in PPARY and UCP2 mRNA levels. Changes in plasma insulin were not related to changes in UCP2 mRNA either. This suggests that the response of UCP2 to overfeeding is not a major determinant of fat mass gain, although again, the study period might have influenced these results.

In conclusion, these data suggest that the ability to increase PPARy activity might be involved in the susceptibility to gain weight during a positive energy balance. 
54 |Chapter 4

\section{ACKNOWLEDGEMENTS}

We thank Erwin Thimister and Chris Hukshorn for obtaining blood and fat samples and Jolanda van der Meijde and Esther Moonen-Kornips for mRNA measurements. 


\section{REFERENCES}

1. Bouchard $C_{r}$ Tremblay $A$, Despres JP, et al. The response to long-term overfeeding in identical twins. N Eng I Med 1990;322:1477-82.

2. Rosen ED, Sarraf P, Troy AE, et al. PPARY is required for the differentiation of adipose tissue in vivo and in vitro. Mol Cell 1999;4:611-7.

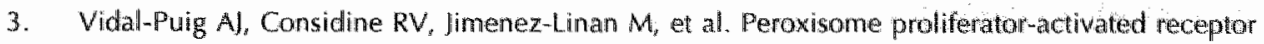
gene expression in human tissues. I Clin invest 1997;99:2416\%22.

4. Rosen ED, Walkey Cl, Puigserver P, Spiegelman BM. Transcriptional regulation of adipogenesis. Gienes Dew 2000;14:1293-307.

5. Mueller $E$, Drori $S$, Aiyer $A$, et al. Cenetic analysis of adipogenesis through peroxisome proliferator-activated receptor $y$ isoforms. I Biol Chem 2002;277:41925-30:

6. Kliewer SA, Sundseth SS, Jones SA, et al. Fatty acids and eicosanoids regulate gene expression through direct interactions with peroxisome proliferator-activated receptors $\alpha$ and $\gamma$. Proc Natl Acad Sci USA 1997;94:43 18-23.

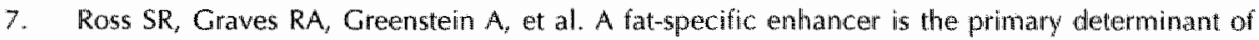
gene expression for adipocyte P2 in vivo. Proc Natl Acad Sci U S A 1990;87:9590-4.

8. Sen A, Lea-Currie YR, Sujkowska $D$, et al. Adipogenic potential of human adipose derived stromal cells from multiple donors is heterogeneous. I Cell Biochem 2001;81:312-9.

9. Kelly LI, Vicario PP, Thompson GM, et al. Peroxisome proliferator-activated receptors y and $\alpha$ mediate in vivo regulation of uncoupling protein (UCP-1, UCP-2, UCP-3) gene expression. Endocrinology 1998;139:4920-7.

10. Digby JE, Crowley VE, Sewter CP, Whitehead JP, Prins JB, O'Rahilly S. Depot-related and thiazolidinedione-responsive expression of uncoupling protein 2 (UCP2) in human adipocytes. Int J Obes Relat Metab Disord 2000;24:585-92.

11. Medvedew $A V_{r}$, Snedden $S K$, Raimbault S, Ricquier D, Collins S. Transcriptional regulation of the mouse uncoupling protein-2 gene. Double E-box motif is required for peroxisome pioliferatoractivated receptor- $\gamma$-dependent activation. I Biol Chem 2001;276:10817-23.

12. Esterbauer $H$, Schneitler $C$, Oberkofler $H$, et al. A common polymorphism in the promoter of UCP2 is associated with decreased risk of obesity in middle-aged humans. Nat Genet 2001;28:178-83.

13. Westerterp KR, Wouters L, Marken Lichtenbett WDW. The Maastricht protocol for the measurement of body composition and energy expenditure with fabeled water. Obes Res 1995:3:49-57.

14. Siri WE. Body composition from fluid spaces and density: analysis of methods. 196\%. Nutrition 1993;9:480-91; discussion, 92.

15. Chomczynski P, Sacchi N. Singlemstep method of RNA isolation by acid guanidinium thiocyamate-phenol-chloroform extraction. Anal Biochem 1987;162:156-9.

16. Deeb SS, Fajas L, Nemoto M, et al. A Pro12Ala substitution in PPARY2 associated with decreased recepior activity, lower body mass index and improved insulin sensitivity. Nat Genet $1998 ; 20: 284-7$.

17. Masugi J, Tamori Y, Mori $H$, Koike T, Kasuga M. Inhibitory effect of a proline-to-allanine substitution at codon 12 of peroxisome proliferator-activated receptor $\gamma 2$ an thiazolidinedioneinduced adipogenesis. Biochem Biophys Res Commun 2000;268:178-82. 
18. Kolehmainen $M$, Uusitupa MI, Alhava $E_{*}$ Laakso $M$, Vidal $H$. Effect of the Pro12Ala polymorphism in the peroxisome proliferator-activated receptor (PPAR) $y 2$ gene on the expression of PPARy target genes in adipose tissue of massively obese subjects. I Clin Endocrinol Metab 2003, $80 ; 1717-22$.

19. Yamauchi $T$, Kamon J, Waki $H$, al. The mechanisms by which both heterozygous peroxisome prolferatoractivated receptor $\gamma$ (PPARy) deficiency and PPARY agonist improve insulin resistance. I Biol Chem 2001;276:41245 -54.

20. Rieusset ), Andreelli $F$, Auboeuf $D$, ef al. Insulin acutely regulates the expression of the peroxisome proliferator-activated receptor-y in human adipocytes. Diabetes 1999:48:699-705.

21. Walder $K$, Norman RA, Hanson RL, et al. Association between uncoupling protein polymorphisms (UCP2-UCP3) and energy metabolism/obesity in Pima indians. Hum Moll Genet $199877: 1431 \times 5$.

22. Nisoli E, Carruba MO, Tonello C, Macor C, Federspill G, Vettor R. Induction of fatty acid translocase/CD36, peroxisome proliferator-activated receptor-y2, leptin, uncoupling proteins 2 and 3 , and tumor necrosis factor-alpha gene expression in human subcutaneous tat by lipid infusion. Diabetes $2000 ; 49: 319-24$. 


\section{The effect of the PPAR $\gamma$ ligand rosiglitazone on energy balance regulation}

Annemiek M.C.P. Joosen, Arjen H.F. Bakker, Maarten J.A. Gering and Klaas R.

Westerterp

Diabetes/Metabolism Research and Reviews (in press) 


\section{ABSTRACT}

Background and aim Fat mass generation requires an energy surplus and the activity of the peroxisome proliferator-activated receptor $\gamma$ (PPARy). We investigated if the PPARY ligand rosiglitazone influences substrate usage, energy expenditure (EE) and energy intake (EI) and thereby how PPARY activity contributes to susceptibility to obesity.

Methods 20 healthy males $(20-29 y)$ were randomly assigned to receive placebo $(n=10)$ or rosiglitazone $(8 \mathrm{mg} / \mathrm{d}) \quad(n=10)$ for 7 consecutive days, while staying in a respiration chamber. Food intake was ad libitum. Body composition was determined by underwater weighing (day 1) and deuterium dilution (day 1 and 8).

Results Mean $( \pm S E$ ) El was $15.9 \pm 0.9 \mathrm{MJ} / \mathrm{d}$ in the placebo group and $18.9 \pm 1.2$ $\mathrm{MJ} / \mathrm{d}$ in the rosiglitazone group. Mean EE was $11.3 \pm 0.3 \mathrm{MJ} / \mathrm{d}$ and $12.5 \pm 0.5 \mathrm{MJ} / \mathrm{d}$ for the placebo and rosiglitazone groups respectively. This resulted in a cumulative positive energy balance $(E B)$ of $32.3 \pm 5.1 \mathrm{MJ}$ for placebo and $44.7 \pm$ $6.9 \mathrm{MJ}$ for rosiglitazone. There were no significant differences in $\mathrm{El}, \mathrm{EE}$ and $\mathrm{EB}$ between treatments. Both groups did not adjust their fat oxidation to the increased fat intake, but fat oxidation decreased faster in the rosiglitazone group (significantly lower on days 6 and 7). During treatment with rosiglitazone, significantly more fat storage was seen in overweight subjects while this was not the case in the placebo group.

Conclusions Our results suggest a shift in substrate usage during PPARy stimulation leading to a preference for fat storage, especially in subjects with a higher BMI. 


\section{INTRODUCTION}

Obesity develops when energy intake (EI) exceeds energy expenditure (EE) for longer periods. Excess energy is stored in the main energy storing tissue the adipose tissue. The adipocyte is not only an important mediator of energy metabolism by storing excess energy as fat, but also by secreting adipokines involved in energy metabolism, like leptin, adiponectin and resistin (1). Fat mass generation requires an energy surplus and the activity of the peroxisome proliferator-activated receptor $\gamma$ (PPAR $\gamma$ ), a transcription factor that is expressed at high levels in adipose tissue, and at lower levels in skeletal muscle, liver and heart $(2,3)$. Dominant-negative PPARy mutations lead to partial lipodystrophy $(4)$, while dominant-positive PPAR $\gamma$ mutations is associated with severe obesity (5). PPAR $\gamma$ is a key factor in fat metabolism as it is required for adipogenesis, the differentiation of preadipocytes into mature adipocytes, and has an important role in fat storage (6). PPAR $\gamma$ is a member of the nuclear hormone receptor family whose transcriptional activity is regulated by the formation of heterodimers and the binding of ligands (7). Natural ligands include polyunsaturated fatty acids and eicosanoids (8). Potent synthetic ligands include the antidiabetic thiazolidinedione (TZD) class of drugs (9). TZD are widely and effectively used in the treatment of type 2 diabetes mellitus for their insulin-sensitizing effects (9). However, treatment with TZD is accompanied with weight gain in rodents (10) and obese, diabetic patients (11). Though fluid retention is a known side-effect of TZD treatment (12), the major part of the weight gain consists of fat (10) which does suggest an effect of PPARy on energy balance regulation as fat gain will only occur in the presence of an energy surplus. Indeed, PPAR $\gamma$ activation in lean rats, in diet-induced obese rats, and in insulin-resistant fatty Zucker rats resulted in weight gain due to both an increased food intake and an improved feed efficiency (13-15). On the other hand, pair-feeding of chow-fed rats and dietary obese rats to prevent hyperphagia prevented rosiglitazone-related weight gain in chow-red rats, though this was not the case with the dietary obese rats (13). Similar results were observed in humans. Obese, diabetic patients treated with TZD, who reported weight gain following TZD treatment, effectively lost weight with caloric restriction and increased physical activity (11). These observations emphasize a possible role for PPARY in the regulation of El and EE. We hypothesized that stimulation of PPAR $y$ with the PPARY ligand rosiglitazone in healthy, normal to overweight men would induce susceptibility to weight gain by affecting substrate usage, EE and $\mathrm{E}$. 


\section{SUBJECTS AND METHODS}

\section{Subjects}

Subjects were recruited through notice boards in the university and in the university hospital. Subjects tad to be male, between the age of 18 and 40 years, Caucasian, healthy and have a BMI between 20 and $32 \mathrm{~kg} / \mathrm{m}^{2}$. They had to be unrestrained eaters, as indicated by the Three-Factor Eating Questionnaire (16) with scores $\leq 9$ on Factor 1 (cognitive restrainty. Subjects completed a medical questionnaire before entering the study; only subjects in good health were included. Subjects who followed a dietary regime with the aim to lose or gain weight within a year prior to the study were excluded. The study design required that the subjects were not fully informed about the adipogenic effect of the PPARY agonist rosiglitazone as this could influence self-sellected food and energy intake and activity-induced energy expenditure. Therefore subjects were told that they would receive either a substance that influences fat metabolism or a non-active substance (placebo) in a double-blind manner (i.e. neither the subject nor the investigator knew what the subject received during the experiment). The study was approved by the Ethics Committee of Maastricht University. All subjects received verbal and written information and signed a written consent form. Twenty men between the age of 20 and 29 y participated in the study. Characteristics of the subjects are shown in Table 1.

Table 1 Baseine characteristics of the subjects.

\begin{tabular}{lllll}
\hline & \multicolumn{2}{c}{ Placebo $(\mathrm{n}=10)$} & \multicolumn{2}{c}{ Rosiglitazone $(\mathrm{n}=10)$} \\
& mean & SE & mean & SE \\
\hline Age $(\mathrm{y})$ & 22 & 1 & 24 & 1 \\
Height $(\mathrm{m})$ & 1.83 & 0.02 & 1.84 & 0.02 \\
Body weight $(\mathrm{kg})$ & 80.2 & 3.5 & 85.7 & 3.6 \\
BMl $\left(\mathrm{kg} / \mathrm{m}^{2}\right)$ & 24.0 & 1.3 & 25.1 & 0.7 \\
Body fat $(\%)$ & 19.6 & 1.9 & 20.3 & 2.4 \\
Cognitive restraint score & 5 & 1 & 4 & 1 \\
\hline
\end{tabular}

'Factor' 1 of the Three-Factor tating Questionnaire (16)

\section{Experimental design}

Subjects were studied during a stay in a respiration chamber for 7 consecutive days for EE and substrate oxidation measurements. Following a double blind, placebo-controlled design, subjects were randomly assigned to receive either 8 
$\mathrm{mg} / \mathrm{d}$ rosiglitazone (Avandia, GlaxoSmithKline BV; The Netherlands) or placebo orally. Drugs were dosed twice daily for the total stay of $7 \mathrm{~d}$ in the respiration chamber. Subjects were asked to eat ad libitum from an excess of food supplied at each mealtime and as snacks. No exercise protocol was imposed, but sleeping during daytime and strenuous physicall activity were not allowed. Subjects were woken up between 08:00 and 08:30h, they were free to choose their bedtimes in the evening. Body composition was determined by underwater weighing and deuterium dilution (day 1) or by deuterium dilution alone (day 8 ). On the same days blood samples were taken.

\section{Dietary intake}

Meals consisting of typically Dutch food items were provided three times per day, breakfast between 08:30 and 09:00h, lunch between 12:30 and 13:00 and dinner between 18:00 and 18:30h. Breakfast and lunch consisted of bread, savoury and sweet condiments, fruit, yogurt, milk, fruit juice, instant coffee (decaffeinated) and tea. For dinner, subjects could choose between readyprepared potato-, pasta- or rice-based meals with only vegetables or with vegetables plus meat or fish. They were allowed two alcoholic consumptions, white or red wine or beer, per day. A wide variety of snacks was continuously available in the chamber in packages that were refreshed every morning. Snacks consisted of savoury items (crisps, nuts), sweet items (chocolate bars, sweets), various biscuits, fruit (apple, orange, banana), instant soup, fruit juice, instant coffee (decaffeinated) and tea. Meals and snacks were supplied in excess to be eaten ad libitum; extra food items were readily available on request. All foods and drinks entering and leaving the respiration chamber were weighed to the nearest gram. Energy content and macronutrient composition of the diets were calculated using the Dutch food composition table (NEVO 1996).

\section{Procedures}

Anthropometry and body composition Measurements were carried out in the morning after voiding and before breakfast. Body weight and height were measured to the nearest $0.01 \mathrm{~kg}$ and $0.1 \mathrm{~cm}$ respectively. Body mass index (BMI, $\mathrm{kg} / \mathrm{m}^{2}$ ) was calculated as body weight $(\mathrm{kg})$ divided by height $(\mathrm{m})$ squared. Body density was determined by underwater weighing with simultaneous measurement of residual lung volume with the helium dilution technique. Total body water (TBW) was determined with deuterium dilution following the Maastricht protocol (17). Body composition was calculated from body density and TBW using the three-compartment model of Siri (18). 
Energy expenditure was measured in a respiration chamber (19) from oxygen consumption, carbon dioxide production and urinary nitrogen excretion according to the formula of Brouwer (20). The respiration chamber measures 14 $\mathrm{m}^{3}$ and is furnished with a bed, chair, table, TV, radio, telephone, computer, washbowl and toilet facilities (19).

Substrate oxidation Carbohydrate (CHO), fat (F) and protein (P) oxidation was calculated from oxygen consumption, carbon dioxide production and urinary nitrogen excretion. As subjects were allowed to have maximally two alcoholic consumptions per day, oxygen consumption and carbon dioxide production on these days were first corrected for alcohol intake, assuming that all alcohol ingested was oxidized, before calculation of $\mathrm{CHO}, \mathrm{F}$ and $\mathrm{P}$ oxidation according to the formula of Brouwer (20):

Poxidation $(\mathrm{g} / \mathrm{d})=6.25 * \mathrm{~N}$

Foxidation $(\mathrm{g} / \mathrm{d})=1.718 * \mathrm{VO}_{2}-1.718 * \mathrm{VCO}_{2}-0.315 * \mathrm{P}$

$\mathrm{CHO}$ oxidation $(\mathrm{g} / \mathrm{d})=4.17 * \mathrm{VCO}_{2}-2.965 * \mathrm{VO}_{2}-0.390 * \mathrm{P}$

with: $\quad \mathrm{N}=$ total nitrogen excreted in urine $(\mathrm{g} / \mathrm{d})$

$\mathrm{VO}_{2}=$ oxygen consumption $(\mathrm{l} / \mathrm{d})$, corrected for alcohol intake

$\mathrm{VCO}_{2}=$ carbon dioxide production $(\mathrm{l} / \mathrm{d})$, corrected for alcohol oxidation

$\mathrm{P}=$ protein oxidation $(\mathrm{g} / \mathrm{d})$

24-h urine was collected from the second voiding of the day until the first voiding of the following day. 24-h urines were collected for each of the $7 \mathrm{~d}$ in the respiration chamber separately. Urine bottles contained $10 \mathrm{ml} \mathrm{H}_{2} \mathrm{SO}_{4}$ to prevent nitrogen loss through evaporation. Volume and nitrogen concentration were measured, the latter using a nitrogen analyzer (Elemental Analyzer, CHN-ORapid, Heraeus).

Carbohydrate and fat balances were calculated as intake minus oxidation of each macronutrient. The protein balance was calculated as [ $\mathrm{N}$ intake - (urinary $\mathrm{N}+$ faecal $\mathrm{N})]^{*} 6.25$, assuming an average daily value of $3 \mathrm{~g} / \mathrm{d}$ for faecal $\mathrm{N}$ loss (21).

Blood parameters After an overnight fast blood samples were obtained and mixed with citrate to prevent clotting. Plasma was obtained by centrifugation $\left(4^{\circ} \mathrm{C}, 3000\right.$ $\mathrm{rpm}, 10 \mathrm{~min})$, frozen in liquid nitrogen and stored at $-80^{\circ} \mathrm{C}$ until analysis of concentrations of glucose (hexokinase method, Glucose HK 125 kit, ABX Diagnostics, Montpellier, France), insulin (ELISA, Mercodia, Uppsala, Sweden), leptin (double-antibody RIA, human leptin specific RIA kit, Linco Research Inc., St Charles, USA) and triacylglycerol (TAG) (Triglycerides liquicolor kit, Instruchemie, Delfzijl, The Netherlands). 


\section{Statistical analysis}

Results are presented as mean \pm standard error (SE). Differences between treatments were analyzed with one-way analysis of variance (ANOVA) or the Mann-Whitney $U$-test (blood parameters). Interaction between treatment and body weight cllass for fat balance was analyzed with an univariate ANOVA with treatment and body weight class as fixed factors. Measurements at baseline and at the end of the experiment were compared with Student's paired t-test (two-tailed) or Wilcoxon's paired signed rank test (blood parameters). $P<0.05$ was considered statistically significant. SPSS 11 for Macintosh (SPSS Inc., Chicago, IL, 2002) was used for the analysis.

\section{RESULTS}

\section{Energy intake and expenditure}

The mean daily EI was $15.9 \pm 0.9 \mathrm{MJ} / \mathrm{d}$ for placebo and $18.9 \pm 1.2 \mathrm{MJ} / \mathrm{d}$ for rosiglitazone, which was not significantly different $(P=0.06)$. Mean daily macronutrient composition was not significantly different between treatments, except for $\mathrm{CHO}$ intake, which was higher in the rosiglitazone group $(\mathrm{P}<0.05)$.

Similar results were obtained for $\mathrm{EE}$ and macronutrient oxidation. EE was not significantly different between treatments $(P=0.09)$ with mean daily values of $11.3 \pm 0.3 \mathrm{MJ} / \mathrm{d}$ for placebo and $12.5 \pm 0.5 \mathrm{MJ} / \mathrm{d}$ for rosiglitazone. Mean daily macronutrient oxidation was not significantly different between treatments, except for $\mathrm{CHO}$ oxidation, which was higher in the rosiglitazone group $(\mathrm{P}<0.05)$.

\section{Energy balance}

Energy balance (EB) was calculated as the difference between EI and EE. Figure 1 shows that cumulative EB increased from day 1 to day 7 on both treatments. By the end of day 7 , cumulative $\mathrm{EB}$ was $32.3 \pm 5.1 \mathrm{M}$ ) for placebo and $44.7 \pm 6.9 \mathrm{M}$ ) for rosiglitazone. This differed significantly from zero on both treatments $(P<$ $0.001)$, but was not significantly different between treatments $(P=0.16)$. The positive $E B$ was reflected in changes in body weight. Body weight increased by $1.39 \pm 0.37 \mathrm{~kg}(\mathrm{P}<0.01)$ in the placebo group and by $2.54 \pm 0.53 \mathrm{~kg}(\mathrm{P}=0.001)$ in the rosiglitazone group. Changes in body weight did not differ significantly between treatments $(P=0.09)$. However, body weight change on rosiglitazone was associated with an increase in TBW of $1.6 \pm 0.61(\mathrm{P}<0.05)$, whereas TBW did not significantly change in the placebo group $(-0.2 \pm 0.7 \mathbb{V} P=0.79)$. The difference in TBW change was not significantily different between treatments ( $P=$ $0.06)$. 


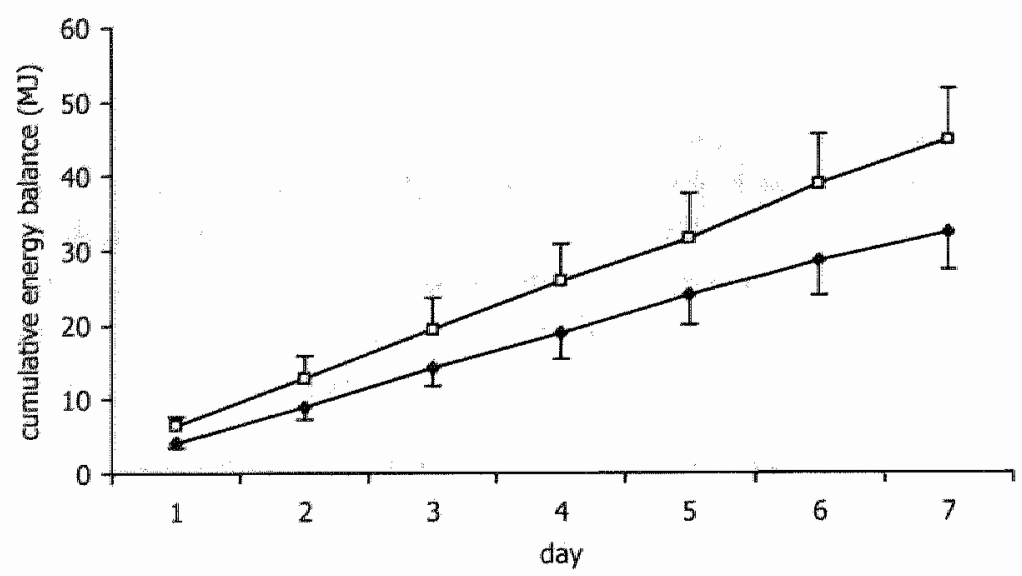

Figure 1 Mean (4SE) cumulative energy balance (MI) for the placebo ( ) and rosiglitazone (D) groups on dáys 1.7 .

The cumulative nutrient balances are shown in Figures $2 a, b$ and $c$. The cumulative protein balance became more positive from day 1 to 7 in both groups (Figure 2a). Total protein balance by the end of day 7 was significantly different from zero for rosiglitazone $(1.6 \pm 0.5 \mathrm{M}$ ); $P<0.01)$, but not for placebo $(1.0 \pm 0.6$ $\mathrm{MJ} ; \mathrm{P}=0.10$ ). Total protein balance was not significantly different between treatments $(P=0.47)$.

From day 1 to 4 the cumulative carbohydrate balance increased, but then decreased from day 5 indicating an adaptation of carbohydrate oxidation to carbohydrate intake (Figure 2b). By the end of day 7 , total carbohydrate balance was not significantly different from zero for both the placebo $(0.8 \pm 1.8 \mathrm{M})$, $\mathrm{P}=$ $0.65)$ and the rosiglitazone group $(-0.2 \pm 1.5 \mathrm{MJ}, \mathrm{P}=0.90)$. There was no significant effect of treatment on the carbohydrate balance $(P=0.67)$.

The total EB was for both treatments mainly determined by the fat balance. The cumulative fat balance gradually increased from day 1 to 7 (Figure 2c). By the end of day 7 , the cumulative fat balance was $29.5 \pm 4.9 \mathrm{M})(\mathrm{P}<0.001)$ for placebo and $42.3 \pm 6.8 \mathrm{M})(P=0.00)$ for rosiglitazone. Although this was not significantly different between the treatments $(P=0.14)$, the pattern of fat intake and fat oxidation differed. Figure 3 shows that both groups did not adjust their fat oxidation to the increased fat intake. However, fat oxidation decreased faster in the rosiglitazone group and by day 6 and 7, fat oxidation was significantly lower compared to placebo. 


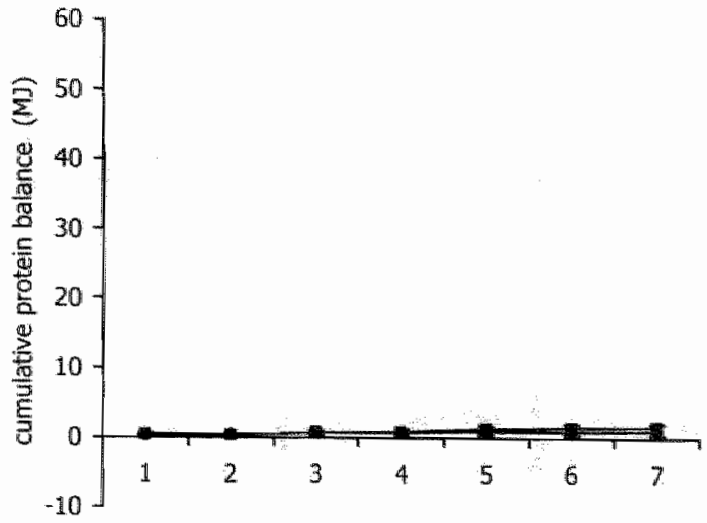

(b)

day

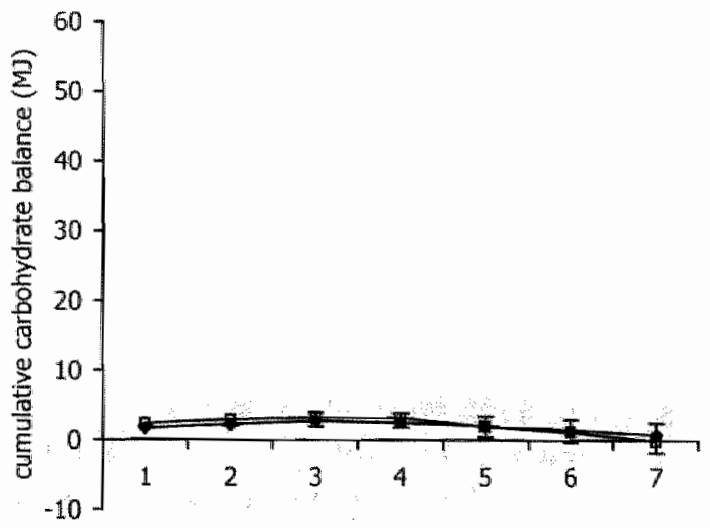

(c) $\quad d a y$

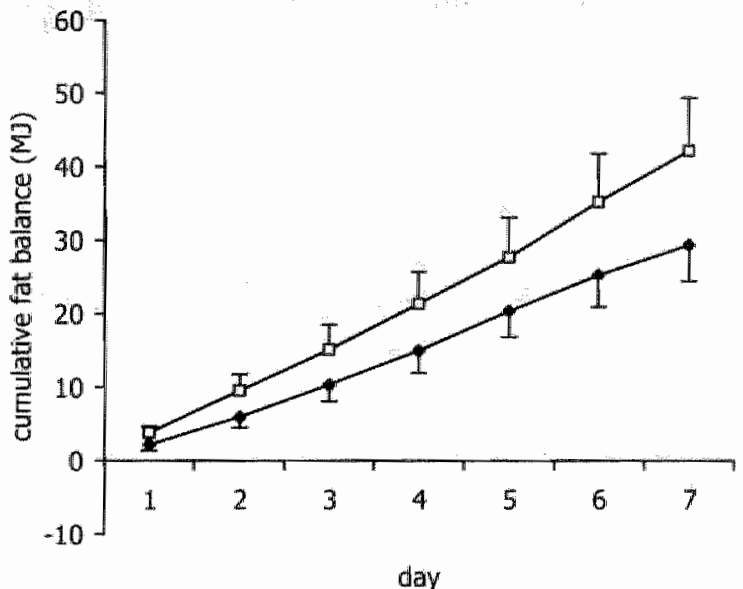

Figure 2 Mean ( $(S E)$ cumulative protein (a), carbohydrate (b) and fatt (c) balances (MI) for the placebo ( ) and rosiglitazone (D) groups on days $1-7$. 


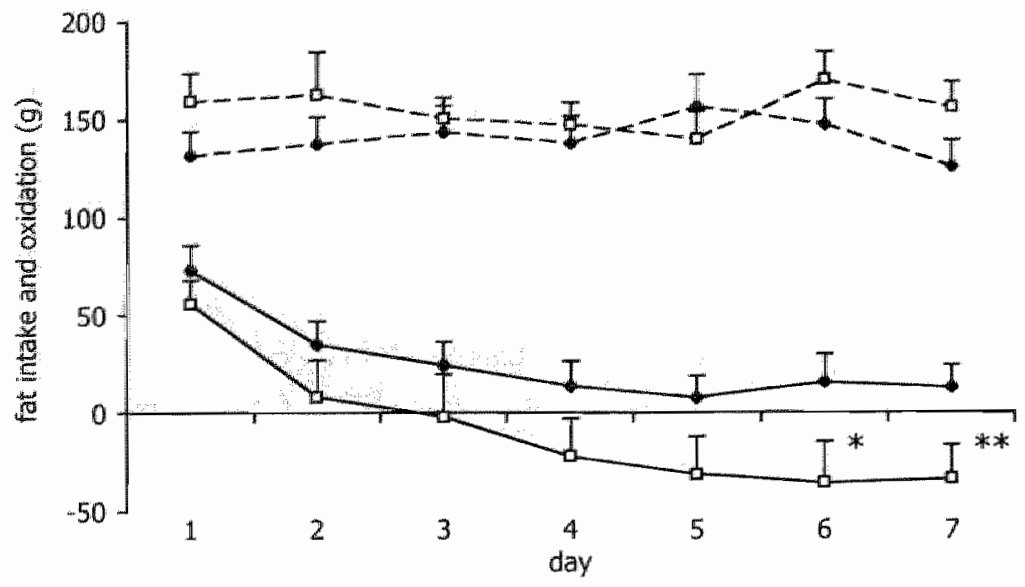

Figure 3 Mean ( $₫$ SE) fat intake (dotted lines) and fat oxidation (solid lines) (g) for placebo ( $)$ and rosiglitazone (C) groups on days $1-7$.

$* P=0.05, * * P<0.05$ oxidation between groups

Individual fat ballances all increased similarly in the placebo group, independent of the classification normal weight (BMl $<25 \mathrm{~kg} / \mathrm{m}^{2}$, solid lines) or overweight (BMI $\geq 25 \mathrm{~kg} / \mathrm{m}^{2}$, dotted lines) (Figure 4a). However, there was a significant interaction between body weight class and treatment $(\mathrm{P}<0.001)$. As can be seen in Figure $4 \mathrm{~b}$, during treatment with rosiglitazone overweight subjects stored more fat than normal weight subjects.

\section{Blood parameters}

Table 2 shows the mean fasting plasma concentrations of glucose, insulin, leptin and TAG. In the placebo group, plasma glucose was decreased and TAG were increased after overfeeding, other parameters did not change significantly. In the rosiglitazone group, plasma insulin and TAG were increased after overfeeding, plasma glucose and leptin did not change significantly. There was a significant treatment effect on changes in plasma glucose $(P=0.02)$ and TAG $(P=0.03)$, but not on plasma insulin $(P=0.07)$ and leptin $(P=0.15)$. 
(a)

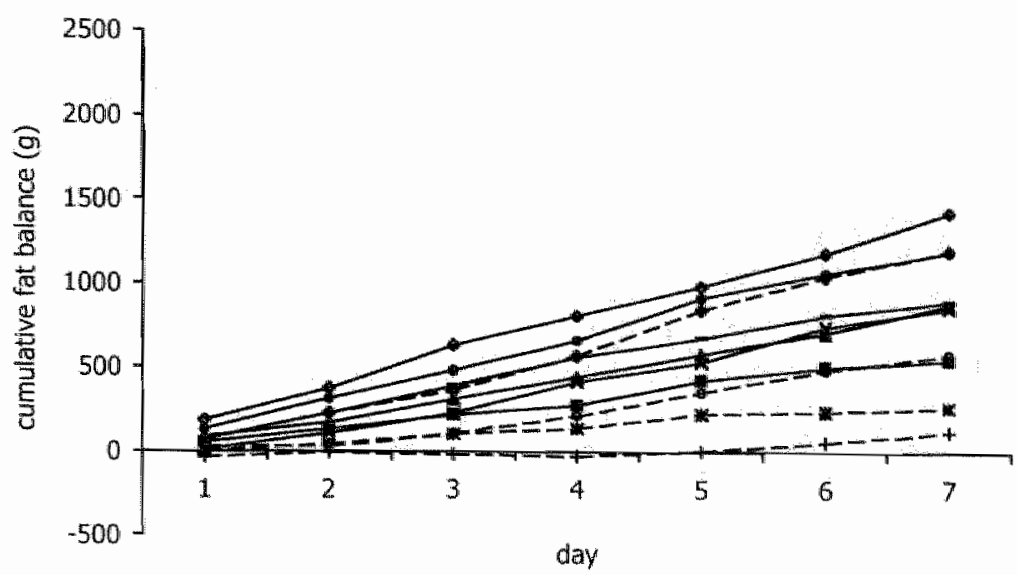

(b)

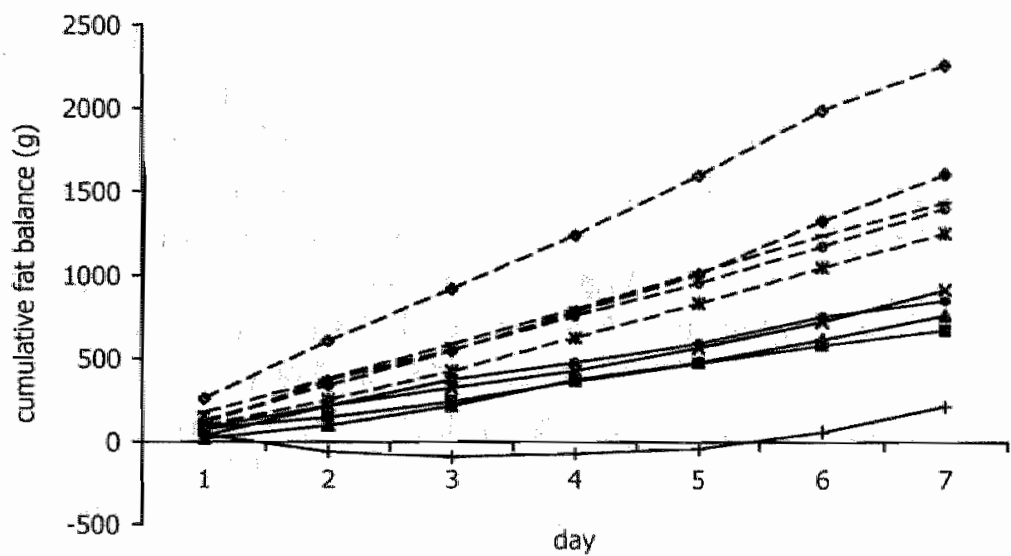

Figure 4 Individual cumulative fat balances (g) for the placebo (a) and rosiglitazone (b) groups. Solid lines represent subjects with $B M I<25 \mathrm{~kg} / \mathrm{m}^{2}$, dotted lines represent subjects with $B M I I=25 \mathrm{~kg} / \mathrm{m}^{2}$.

\section{DISCUSSION}

The increasing prevalence of obesity is related to changing dietary habits and a sedentary lifestyle (22). The contribution of environmental factors is apparent, but genetic factors are also involved (23). 
Table 2 Fasting plasma parameters a baseline and after self-induced overfeeding for the placebo and rosighitazone treated groups

\begin{tabular}{|c|c|c|c|c|c|c|c|c|}
\hline & \multicolumn{4}{|c|}{ Placelbo in=10) } & \multicolumn{4}{|c|}{ Rosiglitazone $(n=10)$} \\
\hline & \multicolumn{2}{|c|}{ Baseline } & \multicolumn{2}{|c|}{ Overfeeding } & \multicolumn{2}{|c|}{ Baseline } & \multicolumn{2}{|c|}{ Overfeeding } \\
\hline & mean & SE & mean & $S E$ & mean & SE & mean & SE \\
\hline Glucose (mmol/) & 5.0 & 0.1 & $4.6^{11}$ & 0.1 & 4.8 & 0.1 & 4.9 & 0.2 \\
\hline Insulin $(\mu \cup / \mathrm{m})$ & 7.8 & 0.6 & 8.5 & 0.5 & 6.0 & 0.8 & $8.2^{2}$ & $\mathbb{1} 1$ \\
\hline Leptin (ng/ml) & 5.4 & 1.1 & 5.6 & 1.0 & 5.6 & 1.4 & 5.3 & 1.4 \\
\hline TAG (rimmol/y & 0.6 & 0.04 & $12^{1}$ & 0.2 & 0.8 & 0.1 & $2.5^{1}$ & 0.7 \\
\hline
\end{tabular}

TAC = triacyiglycerol

"Significantly different from baseline (within-group) $P<0.01,{ }^{2} P=0.01$

PPARy is a key regulator of fat metabolism, therefore a high PPARy activity could form a predisposing factor for the excess of fat mass characteristic for obesity. The present study aimed to investigate the influence of the PPARY ligand rosiglitazone on substrate usage, EE and El. Twenty males were studied during a 7 -d stay in the respiration chamber. During this period, PPAR $y$ activity was stimulated with rosiglitazone in ten males, the control group received a placebo treatment. As shown before $(24,25)$, the sedentary lifestyle imposed by the restrictions of the small environment in the respiration chamber together with an ad libitum food intake resulted in a significant positive EB by the end of day 7 in both groups. Though not statistically significant, there was a trend towards an effect of PPARY stimulation on $E B$ regulation. El tended to be higher in the rosiglitazone treated group, similar to results observed in lean rats, in diet-induced obese rats, and in insulin-resistant fatty Zucker rats treated with TZD, where an increased weight gain was associated with increased food intake and feed efficiency (13-15). Theoretically, PPARY can influence food intake through a direct effect on the central nervous system or indirect through effects on peripheral tissues. In humans, PPAR $y$ is most abundantly expressed in adipose tissue and at lower levels in skeletal muscle, liver and heart $(2,3)$. It is therefore most likely that the tendency to increase food intake with rosiglitazone is due to the PPARy activity in adipose tissue. The adipokine leptin is known to be a regulator of $\mathrm{El}$ and $\mathrm{EE}$ (1), and plasma leptin concentrations can be decreased in lean and diet-induced rats with PPARy stimulation (13). However, plasma leptin was not decreased in ad libitum-fed rats treated with rosiglitazone and could thus not explain the observed hyperphagia (13). Similarly, plasma leptin did not change on either treatment and 
is therefore unlikely to have influenced food intake or thermogenesis in our subjects.

There was no statistical significant effect of PPARY stimulation on EE, indicating no thermogenic dissipation of the excess energy. However, when we look at nutrient oxidation, there was an effect on fat oxidation after 6 days of rosiglitazone treatment. Both groups could not adjust their fat oxidation to fat intake during the 7 -d treatment period, but treatment with rosiglitazone worsened the adaptation of fat oxidation to fat intake. Independent of treatment, the majority of excess energy was stored as fat, as can be expected from the limited storage capacity for carbohydrates which forces an increase in carbohydrate oxidation to maintain carbohydrate balance. In addition, the positive fat balances seen in the majority of the subjects developed faster in overweight subjects compared to normal weight subjects treated with rosiglitazone. Smith et al. (26) found similar results in obese type 2 diabetic patients treated with another TZD, pioglitazone (45 mg/d), for 24 weeks. Though not statistically significant, substrate oxidation after a meal tended towards fat storage and an increased carbohydrate oxidation. Pioglitazone treatment resulted in fat gain, but this change could not be accounted for ${ }_{*}$ as measurements of $24 \mathrm{~h} \mathrm{hE}$ and $\mathrm{El}$ were not included. In contrast Füllert et al. (27) did not find an increase in body weight in overweight, nondiabetic patients with arterial hypertension treated with $45 \mathrm{mg} / \mathrm{d}$ pioglitazone for 16 weeks.

Furthermore, overfeeding resulted in increased fasting plasma TAG concentrations in both groups, but this increase was significantly higher with PPARy stimulation. As fasting plasma TAG and fat oxidation have been shown to predict weight gain in diet-induced prone and resistant rats $(28)$, this indicates an insufficient fat oxidation and a tendency to retain TAG in the plasma until storage in the adipose tissue. However, PPARy activation during ad libitum feeding, initiating a positive energy balance, resulted in lower plasma TAG in $\mathrm{db} / \mathrm{db}$ mice, fatty Zucker rats (10), ob/ob mice (29) and diet-induced obese mice (14) but not in lean mice (29), which suggests that fat storage upon PPARy activation is only accompanied by a decrease in plasma TAG if baseline values are already elevated.

The favourable effects of TZD treatment on plasma glucose and insulin concentrations in type 2 diabetic patients are attributed to their ability to stimulate PPARY (9). However, in our group of healthy, normal to overweight men, overfeeding induced a significant increase in plasma insulin concentrations with PPARY stimulation. Probably, TZD treatment is only associated with decreased insulin in patients already showing elevated plasma concentrations. This was also seen in patients with type 1 diabetes, where the greatest improvements in glycemic control with combined rosiglitazone and insulin treatment were seen in those patients with more pronounced markers of insulin resistance (30). 
Though PPARy activity in adipose tissue is necessary to convert an energy surplus into fat mass, PPARy does play an important role in liver and muscle fat metabolism as well. Adipose-specific PPARy knockout mice are lipodystrophic, leading to decreased plasma leptin and increased plasma TAG concentrations, storage of fat in skeletal muscle and liver, and increased hepatic PPARy MRNA (31). Hepatic PPARy plays a critical role in the regulation of TAG content, blood glucose homeostasis and insulin resistance as liver-specific PPARY knockout mice have a diabetic phenotype including an increased adiposity $(32,33)$. PPARy knockout in muscle, the major site of fat oxidation, causes an impaired ability of muscle to use fat and thus shunting of fat to the liver, increased adiposity and hepatic insulin resistance. Our results indicate that healthy men treated with rosiglitazone develop an insulin resistant state, with increased plasma TAG and insulin concentrations, which facilitates the development of a positive fat balance. The observation that overweight subjects develop a positive fat balance faster than do normal weight subjects supports this hypothesis, as overweight subjects are generally considered to be obesity prone. We expect that these effects will be more pronounced when rosiglitazone treatment continues for longer periods as it might take more than 7 days for full effects on plasma parameters to develop. In addition, fat oxidation gradually became more suppressed compared to placebo from day 6 , which might have been earlier if rosiglitazone treatment was already started before the respiration chamber measurements. Yet, TBW was significantly increased in the rosiglitazone group, which indicates that rosiglitazone exerted effects on metabolism within 7 days.

In summary, our results suggest a shift in substrate usage during PPAR stimulation leading to a preference for fat storage, especially in subjects with a higher BMI.

\section{ACKNOWLEDGEMENTS}

We thank Paul Schoffelen for technical assistance with the respiration chambers, Wendy Sluijsmans for nitrogen analyses and Sander Kersten for TAG analyses. 


\section{REFERENCES}

1. Rajala MW, Schener PE. Minireview: The adipocyte-at the crossroads of energy homeostasis, inflammation, and atherosclerosis. Endocrinology $2003 ; 1 / 443765-73$.

2. Mukherjee $R$, Jow $L$, Croston $G E$, Paterniti $\mid R$, Ir. Identification, characterization, and issue distribution of human peroxisame proliferator-activated receptor (PPAR) isoforms. PPARY2 versus PPARY 1 and activation with retinoid $X$ receptor agonists and antagonists. I Biol Chem $1997,272: 8071-6$.

3. Vidal Puig Al, Considine RV, Jimenez-Linan $M_{3}$ et al. Peroxisome prolfferatoractivated receptor gene expression in human tissues. I Cin lnvest 1997;99:2416-22.

4. Savage $\mathrm{DB}$, $\operatorname{Tan} \mathrm{GD}$, Acerini $\mathrm{CL}$, et al. Human metaholic syndrome resulting from dominantnegative mutations in the nuclear receptor peroxisome proliferator-activated receptor- $\gamma$. Diabetes $2003 ; 52: 910-7$.

5. Ristow M, Muller-Wieland D, Pteiffer A, Krone W, Kahn CR. Obesity associated with a mutation in a genetic regulator of adipocyte differentiation. N Engl J Med 1998;339:953-9.

6. Rosen $E D$, Sarraf $P$, Troy AE, et al. PPARY is required for the differentiation of adipose tissue in wivo and in witro. Mol Cell 1999;461:7.

7. Rosen $\mathbb{E D}$, Walkey $\mathrm{C}$, Puigserver $\mathrm{P}$, Spiegeiman BM. Transcriptional regulation of adipogenesis. Genes Dev 2000; 14:1293-307.

8. Kllewer $S A$, Sundseth $S S$, lones $S A$, et al. Fatty acids and eicosanoids regulate gene expression through direct interactions with peroxisome proliferatoractivated receptors $\alpha$ and $p$. Proc Natl Acad SCI USA 1997;94:4318-23.

9. Lehmann $J M$, Moore LB, Smith-Oliver TA, Wilkison WO, Willson TM, Kliewer SA. An antidiabetic thiazolidinedione is a high affinity ligand for peroxisome proliferator-activated receptor y (PPAR ). I Biol Chem 1995:270:12953-6.

10. Chaput E, Saladin R, Silwestre M, Edgar AD. Fenofibrate and rosiglitazone lower serum triglycerides with opposing effects on body-weight. Biochem Biophys Res Commun 2000;271:445-50.

11. Asnani S, Richard BC, Desouza C, Fonseca V. Is weight loss possible in patients treated with thiazolidinediones? Experience with a low-calorie diet. Cur Med Res Opin 2003;19:609-13.

12. Lebovitz HE Differentiating members of the thiazoldinedione class: a foc us on safety. Diatbetes Metab Res Rev 2002:18 Suppl 2:523-9.

13. Pickavance LC, Buckingham RE, Wilding IP. Insulin-sensitizing action of rosiglitazone is enhanced by preventing hyperphagia. Diabetes Obes Metab 2001;3:171-80.

14. Larsen $P \|_{\text {, lensen } P B}$, Sorensen $R V$, et al. Differential influences of peroxisome proliferatoractivated receptors $\gamma$ and $-a$ on food intake and energy homeostasis. Diabetes 2003,52:2249-59.

15. Warg Q, Dryden $S$, Frankish $H M$, et al. Increased feeding in fatty Zucker rats by the thiazolidinedione BRL 49653 (rosiglitazone) and the possible involvement of leptin and hypothalamic neuropeptide $Y$. Br / Pharmacol 1997;122:1405-10.

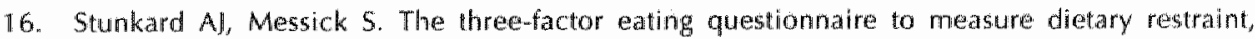
disinhibition and hunger. I Psychosom Res 1985:29:71-83.

17. Westerterp KR, Wouters L, Marken Lichtenbelt WDV. The Mastricht protocol for the measurement of body composition and energy expenditure with labeled water, Obes Res $1995 ; 3: 49-57$. 
10. Siti WE Body composition from fluid spaces and density: analysis of methods. 1961. Nutrition 1993:9:480-91; discussion, 92 .

19. Schoffelen PF, Westerterp KR, Saris WH, Ten Hoor F. A dual-respiration chamber system with atutomated calibration. J Appl Physiol 1997,83:2064-72.

20. Brouwer $\mathbb{E}$. On simple formulae for calculating the heat expenditure and the quantities of carbohydrate and fat oxidized in metabolism of men and animals, from gaseous exchange

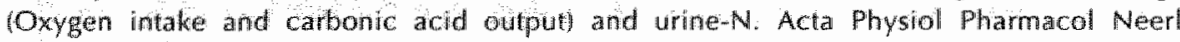
$1957 ; 6: 795-802$.

21. Lamment $O$, Girunnet $N$, Faber $P$, et al. Effects of isoenergetic overfeeding of either carbohydrate or fat in young men. Brit I Nutr 2000;84:233-45.

22. Weinsier RL, Hunter GR, Hein AF, Goran MI, Sell SM. The etiology of obesity: relative cortribution of metabolic factors, diet, and physical activity. Am J Med 1998:105:145-50.

23. Bouchard C. Heredity and the path to overweight and obesity. Med Sci Sports Exerc $1991 ; 232851-91$.

24. Larson DE, Rising R, Ferraro RT, Ravussin E. Spontaneous overfeeding with a "cafeteria diet." in men: effects on 24- hour energy expenditure and substrate oxidation. Int J Obes Relat Metab Disord $1995,19 \div 331-7$.

25. Murgatroyd PR, Gollberg GR, Leahy FE, Gilsenan MB, Prentice AM. Effects of inactivity and diet composition on human energy balance: Int J Obes Relat Metab Disord 1999;23:1269-75.

26. Simith $S R$, De Jonge L, Volaulova J, Lij $Y$, Xie $H_{3}$ Bray GA. Effect of pioglitazone on body composition and energy expenditure: a randomized controlled trial. Metabolism 2005:54:24-32.

27. Fullert $S$, Schneider $F$, Hakk $E$, et al. Effects of pioglitazone in nondiabetic patients with arterial hypertension: a double-blind, placebo-controlled study. I Clin Endocrinol Metab 2002;87:5503. 6.

28. If $\mathrm{H}$, Friedman Ml. Fasting plasma triglyceride levels and fat oxidation predict dietary obesity in rats. Physiol Behav 2003;78:767-72.

29. Sell H, Berger JP, Samson P, et al. PPAR agonism increases the capacity for sympatheticallymediated thermogenesis in lean and oblob mice. Endocrinology 2004.

30. Strowig SM, Raskin P. The effect of rosiglitazone on overweight subjects with type 1 diabetes. Diabetes Care $2005 ; 28: 1562 \times 7$

31. Jones $\rrbracket R_{2}$ Barrick $C$, Kim KA, et al. Deletion of PPARy in adipose tissues of mice protects against high fat diet-induced obesity and insulin resistance. Proc Nat Acad Sci U S A 2005;102:620712.

32. Gavrilova $\mathrm{O}$, Haluzik Matsusue $K$, et al. Liver peroxisome proliferator-activated receptor $\gamma$ contributes to hepatic steatosis, triglyceride clearance, and regulation of body fat mass. I Biol Chem 2003:278:34268-76.

33. Matstsue K, Haluzilk M, Lambert $\mathrm{G}$, et al. Liver-specific distuption of PPARy in leptin-deficient mice improves fatty liver but aggrawates diabetic phenotypes. I Cin Invest 2003;111:737-47. 


\section{The short-term effect of the PPAR ligand}

rosiglitazone on fat mass regulation during a positive energy balance in healthy, non-obese males

Annemiek M.C.P. Joosen, Arjen H.F. Bakker, Sander Kersten and Klaas R. Westerterp

Submitted for publication 


\section{ABSTRACT}

Objective The peroxisome proliferator-activated receptor $\gamma$ (PPARy) is obligatory for fat mass generation and is thought to determine the amount of triacylglycerol (TAC) stored per fat cell. We investigated whether the PPARy ligand rosiglitazone influences fat storage during overfeeding by increasing the PPARY activity in adipose tissue.

Design and measurements 20 healthy men $(20-29 y)$ were randomly assigned to receive rosiglitazone $(8 \mathrm{mg} / \mathrm{d})(\mathrm{n}=10)$ or a placebo $(n=10)$ during a stay of $7 \mathrm{~d}$ in a respiration chamber. Food intake was ad libitum, resulting in positive energy balances of $32.2 \mathrm{M}$ (placebo) and $44.7 \mathrm{MJ}$ (rosiglitazone). Fat cell size and expression of PPARY, aP2, adipsin, adiponectin, and fasting-induced adipose factor (FIAF) were determined in subcutaneous abdominal fat biopsies.

Results The total amount of fat stored and the amount of TAG per fat cell were not different between groups. For the entire group, fat cell size was decreased after overfeeding ( $P=0.02)$. FIAF mRNA levels were decreased after overfeeding in the rosiglitazone group $(P=0.01)$, with a trend towards a decrease in the placebo group. Unexpectedly, rosiglitazone treatment did not influence aP2 gene expression on group level. In addition, changes in plasma glucose and TAG were worse on rosiglitazone.

Discussion These results suggest that in healthy, non-obese males ligand availability is not rate limiting for PPARy activity. Alternatively, rosiglitazone seems to induce a response opposite to its effects in diabetic patients, as it does not prevent the metabolic consequences of a positive energy balance on the short term. 


\section{INTRODUCTION}

The increasing prevalence of obesity is a major health problem as obesity is associated with chronic diseases, which include type 2 diabetes and cardiovascular disease (1). An excessive adipose tissue mass, the main feature of obesity, is the result of an energy intake that exceeds energy expenditure for longer periods. Yet, the molecular mechanisms contributing to the development of obesity remain ill defined. Fat mass generation depends on an increased volume of adipocytes (hypertrophy), the recruitment of new adipocytes (hyperplasia), decreased apoptosis of adipocytes or a combination of these processes (2). Obesity accompanied by metabolic disturbances (including insulin resistance, increased production of free fatty acids, leptin and TNFa) is typically associated with hypertrophy of the fat cells (3).

The peroxisome proliferator-activated receptor $\gamma$ (PPAR $\gamma$ ), a member of the nuclear hormone receptor superfamily of transcription factors, is required for adipogenesis, which involves the differentiation of preadipocytes into fat-storing mature adipocytes (4). PPARy regulates the expression of numerous genes involved in fat storage, including aP2, lipoprotein lipase and CD36. In addition, PPAR $\gamma$ is involved in the regulation of insulin sensitivity $(4,5)$. The importance of PPAR activity in the regulation of fat mass is emphasized by PPAR $\gamma$ mutations. Dominant-positive PPARY mutations are associated with severe obesity (6), while dominant-negative PPAR $\gamma$ mutations are associated with partial lipodystrophy (7). Activation of DNA transcription by PPARy requires the binding of a ligand, as well as the presence of several transcriptional regulators and cofactors (8). Natural ligands for PPARy include polyunsaturated fatty acids and eicosanoids (9); synthetic ligands include the antidiabetic thiazolidinedione (TZD) class of drugs, which are widely and effectively used in the treatment of type 2 diabetes mellitus for their insulin-sensitizing effects (10). Treatment with TZD is accompanied by weight gain in rodents $(11,12)$ and obese, diabetic patients (13). In rats this is due to an increased food intake and an increased feed efficiency (12). However, the molecular and metabolic basis for the weight gain in obese diabetic patients is not completely clear. The central role of PPARy in fat mass generation suggests that a high PPARY activity could form a predisposing factor for human obesity. As PPARY activity depends on ligand binding, the availability of ligand might be involved.

We hypothesized that the PPARY ligand rosiglitazone would influence fat storage, the amount of triacylglycerol stored per fat cell, adipose gene expression, hormones involved in fat storage (insulin, leptin) and substrate avallability (glucose, triacylglycerol) by increasing the PPARY activity in adipose tissue. To address this question, healthy, non-obese males were exposed to an obesigenic environment while receiving either a placebo or rosiglitazone. 


\section{SUBJECTS AND METHODS}

\section{Subjects}

Subjects were recruited through notice boards in the university and in the university hospital. Subjects had to be male, between the age of 18 and 40 years; Caucasian, healthy and have a BMI between 20 and $32 \mathrm{~kg} / \mathrm{m}^{2}$. They had to be unrestrained eaters, as indicated by the Three-Factor Eating Questionnaire (14) with scores 59 on Factor 1 (cognitive restraint). Subjects completed a medical questionnaire before entering the study; only subjects in good health were included. Subjects who followed a dietary regime with the aim to lose or gain weight within a year prior to the study were excluded. The study design required that the subjects were not fully informed about the adipogenic effect of the PPARY agonist rosiglitazone as this could influence self selected food and energy intake and activity-induced energy expenditure. Therefore subjects were informed that they would receive either a substance that influences fat metabolism or a nonactive substance (placebo) in a double-blind manner (i.e. neither the subject nor the investigator knew what the subject received during the experiment). The study was approved by the Ethics Committee of Maastricht University. All subjects received verbal and written information and signed a written consent form. Twenty men between the age of 20 and 29 y participated in the study. Characteristics of the subjects are shown in Table 1.

Table 1 Baseline characteristics of the subjects.

\begin{tabular}{lllll}
\hline & \multicolumn{2}{c}{ Placebo $(n=10)$} & \multicolumn{2}{c}{ Rosiglitazone $(\mathrm{n}=10)$} \\
& mean & SE & mean & SE \\
\hline Age $(y)$ & 22 & 1 & 24 & 1 \\
Height $(\mathrm{m})$ & 1.83 & 0.02 & 1.84 & 0.02 \\
Body weight $(\mathrm{kg})$ & 80.2 & 3.5 & 85.7 & 3.6 \\
BMl $\left(\mathrm{kg} / \mathrm{m}^{2}\right)$ & 24.0 & 1.3 & 25.1 & 0.7 \\
Body fat $(\%)$ & 19.6 & 1.9 & 20.3 & 2.4 \\
Cognitive restraint score & 5 & 1 & 4 & 1 \\
\hline
\end{tabular}

"Factor th of the Three Factoi Eating Questionnaire (14)

\section{Experimental design}

Subjects were studied during a stay in the respiration chamber for 7 consecutive days for energy expenditure measurements calculated from oxygen consumption, carbon dioxide production and urinary nitrogen excretion according to the 
formula of Brouwer (15). The respiration chamber measures $14 \mathrm{~m}^{3}$ and is furnished with a bed, chair, table, TV, radio, telephone, computer, washbowl and tollet facilities (16).

Following a double-bind, placebo-controlled design, subjects were randomly assigned to receive either $8 \mathrm{mg} / \mathrm{d}$ rosiglitazone (Avandia, GlaxosmithKline BV, The Netherlands) or placebo orally. Drugs were dosed twice daily for the total stay of $7 \mathrm{~d}$ in the respiration chamber. Subjects were asked to eat ad libitum from an excess of food supplied at each mealtime and as snacks to induce a positive energy balance. No exercise protocol was imposed, but sleeping during daytime and strenuous physical activity were not allowed. Subjects were woken up between 08:00 and 08:30h, they were free to choose their bedtimes in the evening. Body composition was determined by underwater weighing and deuterium dilution (day 1) or by deuterium dilution alone (day 8). On the same days blood samples and fat biopsies were taken. Fat storage was calculated as the difference between fat intake and fat oxidation.

\section{Dietary intake}

Meals consisting of typically Dutch food items were provided three times per day, breakfast between 08:30 and 09:00h, lunch between 12:30 and 13:00h and dinner between 18:00 and 18:30h. Breakfast and lunch consisted of bread, savoury and sweet condiments, fruit, yogurt, milk, fruit juice, instant coffee (decaffeinated) and tea. For dinner, subjects could choose between readyprepared potato-, pasta- or rice-based meals with only vegetables or with vegetables plus meat or fish. They were allowed two alcoholic consumptions, white or red wine or beer, per day. A wide variety of snacks was continuously available in the chamber in packages that were refreshed every moming. Snacks consisted of savoury items (crisps, nuts), sweet items (chocolate bars, sweets). various biscuits, fruit (apple, orange, banana), instant soup, fruit juice, instant coffee (decaffeinated) and tea. Meals and snacks were supplied in excess to be eaten ad libitum; extra food items were readily avallable on request. All foods and drinks entering and leaving the respiration chamber were weighed to the nearest gram. Energy content and macronutrient composition of the diets were calculated using the Dutch food composition table (17).

\section{Procedures}

Anthropometry and body composition Measurements were carried out in the morning after voilding and before breakfast. Body weight and height were measured to the nearest $0.01 \mathrm{~kg}$ and $0.1 \mathrm{~cm}$ respectively. Body mass index $(B M)$, $\mathrm{kg} / \mathrm{m}^{2}$ ) was calculated as body weight $(\mathrm{kg}$ ) divided by height ( $\mathrm{m}$ ) squared. Body density was determined by underwater weighing with simultaneous measurement 
of resiclual lung volume with the helium dilution technique. Total body water (TBW) was determined with deuterium dilution following the Maastricht protocol (18). Body composition was calculated from body density and TBW using the three-compartment model of Siri (19).

Blood parameters After an overnight fast blood samples were obtained and mixed with citrate to prevent clotting. Plasma was obtained by centrifugation $\left(4^{\circ} \mathrm{C}, 3000\right.$ $\mathrm{rpm}, 10 \mathrm{~min}$ ), frozen in liquid nitrogen and stored at $-80^{\circ} \mathrm{C}$ until analysis of concentrations of glucose (hexokinase method; Glucose HK 125 kit, $A B X$ diagnostics, Montpellier, France), insulin (ELISA, Mercodia, Uppsala, Sweden), leptin (double-antibody RIA, human leptin specific RIA kit, Linco Research inc., St Charles, USA), triacylglycerols (TAC) (Triglycerides liquicolor kit, Instruchemie, Delfzijl, The Netherlands), free fatty acids (FFA) (Wako NEFA C-kit, Wako chemicals, Neuss, Germany) and HDL cholesterol (HDL cholesterol liquicolor kit, Instruchemie, Delfzijl, The Netherlands).

Adipose tissue and RNA isolation Abdominal subcutaneous fat biopsies were obtained by needle liposuction under local anesthesia (lidocain $2 \%$, AstraZeneca BV, Nederland) after an overnight fast. The tissue was immediately washed in cold phosphate-buffered saline, homogenized in $1 \mathrm{ml}$ Trizol (Invitrogen Life Technologies, Carlsbad ${ } \mathrm{CA}$ ) in a mini-beadbeater (Biospec Products, Bartlesville, OK), frozen in liquid nitrogen and stored at $-80^{\circ} \mathrm{C}$ until RNA extraction. Total RNA was isolated using the method of Chomczynski and Sacchi (20) and $10 \mu \mathrm{g}$ glycogen (Roche Diagnostics GmBH, Mannheim, Germany) was added to each sample. Extracted RNA was quantified and assessed for purity using the NanoDrop (NanoDrop Technologies, Wilmington, DE) and gel electrophoresis (Agilent Technologies).

Quantification of mRNA expression by real-time RT-PCR CDNA was synthesized from $500 \mathrm{ng}$ RNA in a volume of $20 \mu \mathrm{l}$ containing $2 \mu \mathrm{l} \mathrm{RT}$ buffer, $2 \mu \mathrm{lNTPs}, 1 \mu l$ oligo (dT) primer, $0.25 \mu \mathrm{l}$ RNase inhibitor and $1 \mu \mathrm{l}$ reverse transcriptase (iScript kit, Biorad). The RT reaction was performed at $37^{\circ} \mathrm{C}$ for $60 \mathrm{~min}$.

PCR reactions were performed in a final volume of $25 \mu \mathrm{l}$ containing $0.2 \times$ SYBR Green/fluorescein in DMSO (5X SYBR Green / $0.25 \mu \mathrm{M}$ fluorescein), $1 X$ Taq buffer, $0.02 \mathrm{U} / \mu \mathrm{l} \mathrm{Taq}$ polymerase, $0.2 \mathrm{mM}$ dNTPs, $3 \mathrm{mM} \mathrm{MgCl}, 0.6 \mathrm{pmol} / \mu \mathrm{l}$ of each primer and $25 \mathrm{ng} / \mu \mathrm{l}$ CDNA. The PCR program was $94^{\circ} \mathrm{C}$ for $2 \mathrm{~min}$, followed by 45 cycles of $94^{\circ} \mathrm{C}$ for $15 \mathrm{sec}$ and $60^{\circ} \mathrm{C}$ for $1 \mathrm{~min}$. After every cycle the fluorescence of SYBR Green was measured, which represents the amount of double-stranded DNA amplified to that point in the PCR. Subsequently, melt curve analysis $\left(45^{\circ} \mathrm{C}\right.$ for $5 \mathrm{~min}, 100$ cycles of $65^{\circ} \mathrm{C}$ for $10 \mathrm{sec},+0.3^{\circ} \mathrm{C}$ after cycle 
2) indicated specific product for each pair of primers. The primer sequences were as follows: PPAR $y$ forward 5'-TCCATGCTGTTATGGGTGAA-3', reverse 5"TCAAAGGAGTGGGAGTGGTC-3;; aP2 forward 5'-GCATTCCACCACCAGTTT ATC-3', reverse 5'-CAGGAAAGTCAAGAGCACCAT-3; FIAF forward 5'- CACAGCCTGCAGACACAACTC-3', reverse 5'-GGAGGCCAAACTGGCTTTGC-3'; adipsin forward 5'- TAGCGCGACTCCATCTCTACAA-3', reverse 5'-GCCTCCTGAGTAGCTGGAACT-3'; adiponectin forward 5'-TATCCCCAACATGCCCATTCG-3', reverse 5'-TGGTAGGCAAAGTAGTACAGCC-3'; ATGL forward 5'-ATGAGGGGACTCACAGTTGC-3', reverse 5"-CAGGGGAGGGAAGATTAAGG-3'; 36B4 forward 5'-CGGGAAGGCTGTGGTGCTG-3', reverse 5'-GTGAACACA AAGCCCACATTCC-3'; $\beta$-actin forward 5'-AGAAAATCTGGCACCACACC-3", reverse 5'-AGAGGCGTACAGGGATAGCA-3". For target and housekeeping genes, standard curves were created from a specific PCR product. To account for differences in RNA loading, target mRNA was expressed relative to $\beta$-actin and relative to $36 \mathrm{~B} 4 \mathrm{mRNA}$. The PCR amplification efficiencies of the target and housekeeping genes were similar and therefore the normalized amount of target mRNA in each sample was calculated as follows: $\Delta C_{T}=C_{T}$ (target) $-C_{T}$ (housekeeping), relative expression level $=2^{-A C T}$, where $C_{T}$ is the threshold cycle at which the fluorescence is first recorded statistically significant above background. As both housekeeping genes gave the same normalized quantities, target mRNA levels are presented after normalization to $\beta$-actin.

Adipocytes were isolated from the fat biopsies as described before (21). Briefly, fat tissue was collected in cold phosphate-buffered saline and cut into pieces with a scalpel. The pieces of fat tissue were digested in $5 \mathrm{ml}$ Dulbecco's modified Eagle's medium (DMEM)/F12 (Invitrogen Life Technologies) containing 4\% bovine serum albumin (BSA) (Sigma-Aldrich $\mathrm{CO}$, St Louis, MO) and $2 \mathrm{mg} / \mathrm{ml}$ collagenase II (Sigma) in an incubator $\left(37^{\circ} \mathrm{C}, 5 \% \mathrm{CO}_{2}\right.$ ) on a shaking platform (200 rpm) for 120 min. The digest was transferred to a $5 \mathrm{ml}$ syringe and gently pressed over a $500-$ $\mu \mathrm{m}$ sterile disposable filter (Schleicher \& Schuell MicroScience, Dassel, Germany). The syringe was rinsed with $5 \mathrm{ml} \mathrm{DMEM/F12}$ containing $4 \%$ BSA, which was added to the digest. After centrifugation (1000 rpm, $1 \mathrm{~min})$, the layer of adipocytes floating on top was removed, frozen in liquid nitrogen and stored at $80^{\circ} \mathrm{C}$ until analysis of cell size.

For determination of adipocyte cell size, circa $40 \mathrm{mg}$ of adipocytes was incubated in a volume of $160 \mu \mathrm{l}$ containing $0.1 \mathrm{M} \mathrm{NaCl}, 0.02 \mathrm{M}$ Tris pH 7.4, $0.01 \mathrm{M} \mathrm{EDTA}$ $\mathrm{pH} 7.5,100 \mu \mathrm{g} / \mathrm{ml}$ protein kinase $\mathrm{K}$ and $0.05 \%$ Triton $\mathrm{X}-100$ for $60 \mathrm{~min}$ at $65^{\circ} \mathrm{C}$, followed by $10 \mathrm{~min}$ at $95^{\circ} \mathrm{C} .10 \mu \mathrm{l}$ of this solution was $100 x$ diluted before determination of triacylglycerol (GPO-trinder 337, Sigma). For DNA determination, the remaining solution was mixed with SDS, RNase A and protein 
kinase $\mathrm{K}$ to make final concentrations of $0.5 \%, 20 \mu \mathrm{g} / \mathrm{ml}$ and $100 \mu \mathrm{g} / \mathrm{ml}$ respectively. After an overnight incubation at $37^{\circ} \mathrm{C}$, DNA was precipitated using ethanol precipitation and a high-salt solution (KAC), rinsed with $70 \%$ ethanol and resuspended in $20 \mu 1 \mathrm{H}_{2} \mathrm{O}$. DNA was quantified and assessed for purity using the NanoDrop (NanoDrop Technologies, Wilmington, DE). The mean adipocyte cell size was calculated as $\mu \mathrm{g}$ TAG / cell (mean DNA content per cell is $6 \mathrm{pg}$ ).

\section{Statistical analysis}

Results are presented as mean \pm standard error (SE) unless otherwise stated. Measurements on the morning of day 1 before entering the respiration chamber are referred to as baseline; measurements on the morning of day 8 after the $7-d$ respiration chamber stay are referred to as overfeeding. Effects of overfeeding within groups were analyzed with Student's paired t-test (two-sided) or Wilcoxon's paired signed rank test (two-sided) where appropriate. Effects of rosiglitazone treatment (between-group effects) were analyzed with the MannWhitney U-test (two-sided). Significance of correlations was tested with the Spearman rank correlation $\left(r_{s}\right) . P<0.05$ was considered statistically significant. SPSS 11 for Macintosh (SPSS Inc., Chicago, IL, 2002) was used for the analysis.

\section{RESULTS}

\section{Energy balance}

Self-selected diets contained $15.9 \pm 0.9 \mathrm{MJ} / \mathrm{d}$ in the placebo group and $18.9 \pm 1.2$ $\mathrm{Ml} / \mathrm{d}$ in the rosiglitazone group. Diets provided $13 \%$ of energy from protein, $54 \%$ from carbohydrates and 33\% from fat in both groups. Energy expenditure was $11.3 \pm 0.3 \mathrm{M} / / \mathrm{d}$ and $12.5 \pm 0.5 \mathrm{MJ} / \mathrm{d}$ for placebo and rosiglitazone respectively. For both groups, this resulted in a positive energy balance, which was calculated as the difference between energy intake and energy expenditure. By the end of day 7 , the cumulative energy balance was $32.2 \pm 5.1 \mathrm{M}$ J for placebo and $44.7 \pm$ $6.9 \mathrm{Ml}$ for rosiglitazone, which was not statistically significant different between groups due to the high inter-individual variation in both groups. The positive $\mathrm{EB}$ was reflected in changes in body weight. Body weight increased by $1.39 \pm 0.37$ $\mathrm{kg}(\mathrm{P}<0.01)$ in the placebo group and by $2.54 \pm 0.53 \mathrm{~kg}(\mathrm{P}=0.001)$ in the rosiglitazone group. Changes in body weight did not differ significantly between treatments $(P=0.09$ ). However, body weight change on rosiglitazone was accompanied with an increase in TBW of $1.6 \pm 0.6 \mathrm{I}(\mathrm{P}<0.05)$, whereas TBW did not significantly change in the placebo group $(-0.2 \pm 0.7 \mathrm{I}, \mathrm{P}=0.79)$. 


\section{Blood parameters}

Table 2 shows the mean fasting plasma concentrations of glucose, insulin, leptin, TAG, FFA and HDL cholesterol. In the placebo group, plasma glucose and FFA were decreased and TAG were increased after overfeeding, other parameters did not change significantly. In the rosiglitazone group, plasma insulin and TAG were increased and FFA decreased after overfeeding; plasma glucose, leptin and HDL cholesterol did not change significantly. Rosiglitazone affected changes in plasma glucose $(P=0.02)$ and TAG $(P=0.03)$, but not in plasma FFA $(P=0.94)$, insulin $(P=0.07)$, leptin $(P=0.15)$ and $\mathrm{HDL}$ cholesterol $(P=0.97)$.

Table 2 Fasting plasma parameters at baseline and after self-induced overfeeding for the placebo and rosiglitazone treated groups.

\begin{tabular}{|c|c|c|c|c|c|c|c|c|}
\hline & \multicolumn{4}{|c|}{ Placebo $(n=10)$} & \multicolumn{4}{|c|}{ Rosiglitazone $(\mathrm{n}=10)$} \\
\hline & \multicolumn{2}{|c|}{ Baseline } & \multicolumn{2}{|c|}{ Overfeeding } & \multicolumn{2}{|c|}{ Baseline } & \multicolumn{2}{|c|}{ Overfeeding } \\
\hline & mean & $\mathrm{SE}$ & mean & SE & mean & SE & mean & SE: \\
\hline Glucose $(\mathrm{mmol} / \mathrm{l})$ & 5.0 & 0.1 & $4.6^{1}$ & 0.1 & 4.8 & 0.1 & 4.9 & 0.2 \\
\hline Insulin $(\mu \mathrm{U} / \mathrm{ml})$ & 7.8 & 0.6 & 8.5 & 0.5 & 6.0 & 0.8 & $8.2^{2}$ & 1.1 \\
\hline Leptin (ng/ml) & 5.4 & 1.1 & $5: 6$ & 1.0 & 5.6 & 1.4 & 5.3 & 1.4 \\
\hline TAG (mmol/n) & 0.6 & 0.04 & $1.2^{1}$ & 0.2 & 0.8 & 0.1 & $2.5^{1}$ & 0.7 \\
\hline FFA (mmol/l) & 0.2 & 0.03 & $0.1^{3}$ & 0.02 & 0.2 & 0.02 & $0.1^{3}$ & 0.03 \\
\hline HDL (mmol/l) & 1.2 & 0.03 & 1.2 & 0.02 & 12 & 0.1 & 1.3 & 0.1 \\
\hline
\end{tabular}

$\mathrm{TAG}=$ triacylglycerol $\mathrm{FFA}=$ free fatty acids, HDL $=$ HDL cholesterol

${ }^{1}$ Significantly different from basel ine (withim-group) $P<0.01,{ }^{2} P=0.01,{ }^{3} P<0.05$

\section{Adipose tissue mRNA expression}

The measured mRNA levels represent genes involved in adipogenesis, lipogenesis and lipolysis, i.e. PPARY, aP2, adipsin, adiponectin and FIAF. The pattern of gene expression as a result of self-induced overfeeding shows a large inter-individual variation (Figure 1).

MRNA levels were not statistically significant affected by treatment. In the rosiglitazone group, FIAF MRNA levels were significantly decreased after overfeeding (median fold change $0.30, P=0.01$ ), with a trend towards a decrease in the placebo group. 
(a)

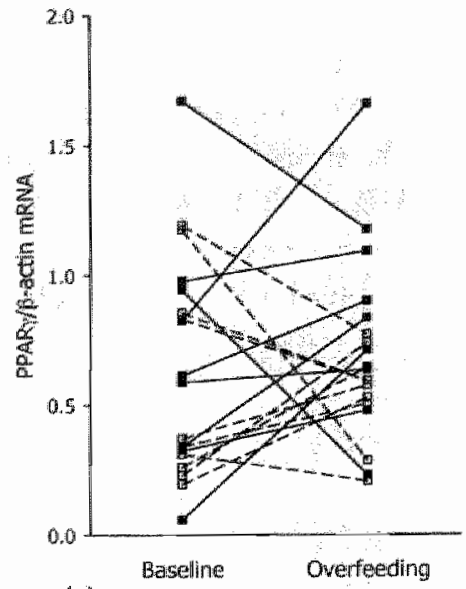

(c)

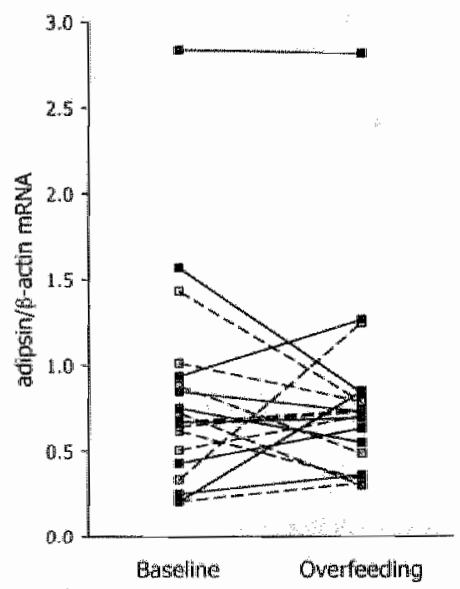

(e)

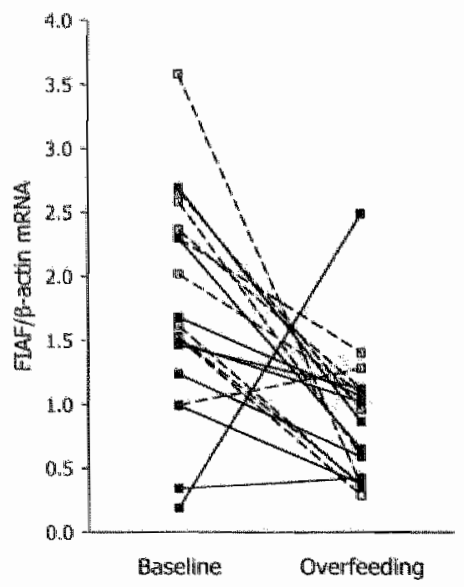

(b)

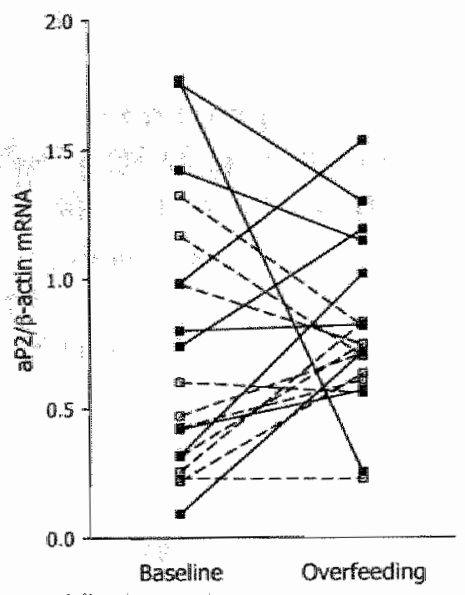

(d)

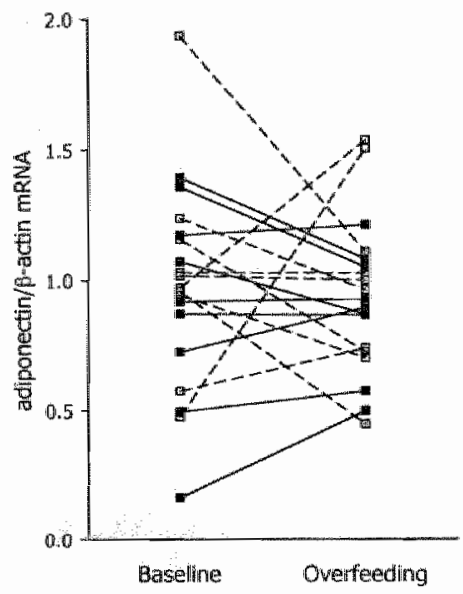

Figure 1 Individual mRNA levels at baseline and after overfeeding for PPAR (a), aP2 (b), adipsin (c), adiponectin (d), and FLAF (e). Solid lines represent the placebo group. dotted lines represent the rosiglitazone group. 
In both groups, there were strong correlations between PPARy and aP2 MRNAs at baseline, after overfeeding and between changes in expression $r_{S}=0.83-0.97, \mathrm{P}$ $<0.01$ ), indicating that PPARy mRNA levels are related to PPARy activity. There were no significant correlations between changes in PPARy or aP2 mRNA levels and fat storage. Changes in adiponectin mRNA levels were positively correlated with changes in PPARY or aP2 mRNA levels in both groups $\left(r_{5}=0.64-0.93, P<\right.$ $0.05)$.

\section{Fat cell size}

The mean fat cell size for the placebo group was $0.51 \pm 0.10 \mu \mathrm{g} \mathrm{TAG} / \mathrm{cell}$ at baseline and $0.31 \pm 0.06 \mu \mathrm{g}$ TAG/cell after overfeeding (difference $P=0.11$ ). The rosiglitazone group had a mean fat cell size of $0.67 \pm 0.17 \mu \mathrm{g}$ TAG/cell at baseline and $0.28 \pm 0.04 \mu \mathrm{TAG} /$ cell (difference $P=0.08$ ). There was no statistically significant difference in changes in fat cell size between treatments; for the entire group, fat cell size was decreased after overfeeding $(P=0.02)$. There were no differences in gene expression or plasma parameters between subjects that showed fat cell hypertrophy or hyperplasia after overfeeding for both groups.

(a)

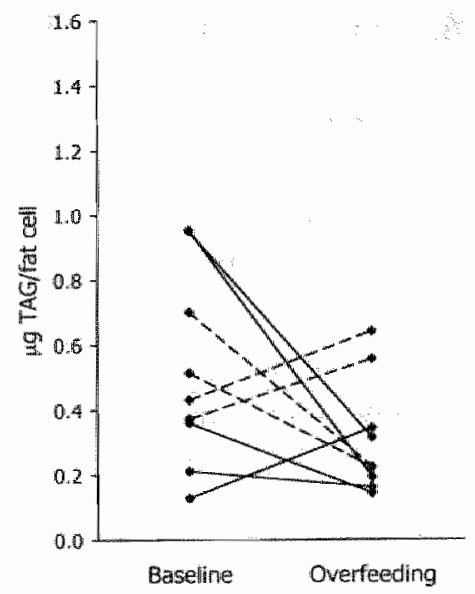

(b)

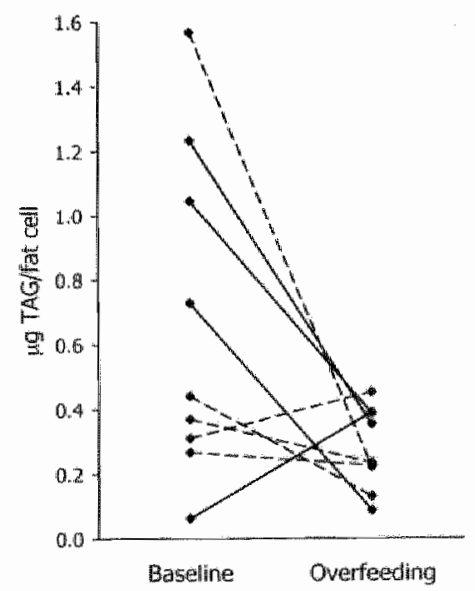

Figure 2 Fat cell size in subcutaneous abdominal adipose tissue at baselline and after self-induced overfeeding for the placebo (a) and rosiglitazone (b) treated groups. Solid lines represent subjects with $B M I<25 \mathrm{~kg} / \mathrm{m}^{2}$, dotted lines represent subjects with $B M I \geq 25 \mathrm{~kg} / \mathrm{m}^{2}$. 


\section{DISCUSSION}

Obesity is characterized by an excessive adipose tissue mass. The adipocyte is not only an important mediator of energy metabolism by storing excess energy as fat, but also by secreting adipokines involved in energy metabolism, like leptin and adiponectin (22). The efficiency of fat storage in the presence of an energy excess might be reflected in the gene expression in the adipocyte. This is likely due to interactions between genotype and diet as rats can be selectively bred to be obesity-prone or obesity-resistant on a high-fat, high-energy diet (23). In humans, the importance of genetic background in fat storage is demonstrated by the overfeeding of monozygotic twins, where variation between pairs was at least three times higher than variation within pairs for gains in body weight and fat mass (24). PPARy is the key regulator of adipose gene expression, whose activity depends on transcriptional regulators and cofactors as well as ligand availability (8). We investigated the effect of the PPARy ligand rosiglitazone on several PPARy dependent processes, including fat storage, fat cell size, adipose gene expression, hormones involved in fat storage and substrate usage during (self-induced) overfeeding.

Though not statistically significant, there was a trend towards a stimulation of energy intake and thus energy balance and weight gain with rosiglitazone. Changes in fat cell size were not different between groups; for the entire group, fat cell size was decreased after overfeeding suggesting that fat was stored in newly recruited fat cells.

In both the placebo and rosiglitazone groups, PPAR $\gamma$ and $\mathrm{PP} 2$ were correlated, which indicates that PPAR mRNA reflected PPAR $\gamma$ activity as aP2 is primary a PPARy response gene $(25,26)$. However, aP2 gene expression was not influenced by rosiglitazone, which suggests that PPAR $\gamma$ ligand availability is not rate limiting for PPAR $\gamma$ activity in healthy male subjects.

Adiponectin and adipsin are respectively early and late markers of adipocyte differentiation $(27,28)$. While plasma adipsin concentrations are increased in obesity and correlate with plasma insulin and TAG, adipsin mRNA in subcutaneous fat tissue decreases with increasing BMI (28). In contrast, plasma adiponectin and mRNA expression are decreased in obesity and in insulinresistant patients, independent of obesity (27) and can be increased by TZD treatment (29). These observations suggest an impaired fat cell functioning due to a diabetic state, which is typically associated with fat cell hypertrophy (3). Indeed, fat cell size was shown to be negatively correlated with adiponectin mRNA (30). However, we found no effect of rosiglitazone or overfeeding on adiponectin and adipsin mRNA expression, suggesting that rosiglitazone has no, or at least an insignificant effect on adipose tissue in healthy, non-obese males. 
Whole-body fat oxidation was more suppressed in the rosiglitazone group $(31)$, which suggests an indirect effect of rosiglitazone on lipolysis. This is also seen in the expression of the fasting-induced adipose factor (F/AF), which is strongly upregulated in adipose tissue and liver during fasting, while plasma FIAF concentrations decrease in mice fed a high-fat diet (32). Our results suggest that FIAF responds similarly in humans. Adipose FIAF expression decreased in the rosiglitazone group, with a tendency towards a decrease in the placebo group. FIAF has been shown to increase plasma TAG concentrations, probably by inhibiting lipoprotein lipase (LPL) activity. Accordingly, lower FIAF mRNA levels during overfeeding may stimulate the uptake of TAG by the adipose tissue through increased LPL activity $(32,33)$.

In conclusion, our results show that in non-obese, healthy subjects PPAR $\gamma$ activity in adipose tissue is not influenced by rosiglitazone. This suggests that PPAR $\gamma$ ligand avallability is not rate limiting for PPAR $y$ activity in healthy males. Alternatively, rosiglitazone seems to induce a response opposite to its effects in diabetic patients, as it does not prevent the metabolic consequences of a positive energy balance on the short term. We can speculate that the fat mass itself might be involved in ligand availability and ligand binding, which might explain why rosiglitazone has different effects in non-obese, healthy subjects compared to obese, diabetic patients.

\section{ACKNOWLEDGEMENTS}

We thank Maarten Gering for help in data collection and Gabby Hul for obtaining the fat samples. 


\section{REFERENCES}

1. Silwentoinen $K$, Sans $S$, Tolonen $H$, et all. Trends in obesity and energy supply in the WHO MONUCA Project. Int J Obes Relat Metab Disord. 2004;28:710-8.

2. Frins IB and O'Rahilly S. Regulation of adipose cell number in man. Clinical Science. $1997 ; 92: 3-11$.

3. Farnier $\mathrm{C}$, Krief $\mathrm{S}$, Blache $\mathrm{M}$, ef al. Adipocyte functions are modulated by cell size change: potential involvemeryt of an integrin/ERK signalling pathway. Int J Obes Relat Metab Disord. $2003 ; 27: 1178-86$

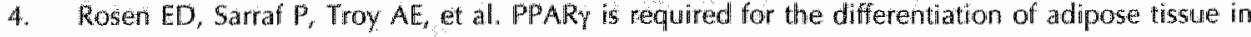
vivo and in vitro. Mol Cell. 1999;4:611-17.

5. Evans RM, Barish GD and Wang YX. PPARs and the complex journey to obesity. Nat Med. $2004 ; 10: 355-61$.

6. Ristow Muller-Wieland $D$, Pfeiffer $A$, Krone $W$ and Kahn $C R$. Obesity associated with a mutation in a genetic regulator of adipocyte differentiation. N Engl J Med. 1998;339:953-9.

7. Savage $\mathrm{DB}$, Tan $\mathrm{GD}$, Acerini $\mathrm{CL}$, et al. Human metabolic syndrome resulting from dominantnegative mutations in the nuclear receptor peroxisome proliferator-activated receptor- $y$. Diabetes. 2003;52:910-7.

8. Miard S and Fajas L. Atypical transcriptional regulators and cofactors of PPARy. Int I Obes Relat Metab Disord. 2005;29 5upp/ 1:510\%2.

9. Kliewer SA, Sundseth SS, Jones SA, et al. Fatty acids and eicosanoids regulate gene expression through direct interactions with peroxisome proliferator-activated receptors $\alpha$ and $\gamma$. Proc Nat: Acad SCI USA. 1997;94:4318-23.

10. Lehmann IM, Moore LB, Smith-Oliver TA, Wilkison WO, Willson TM and Kliewer SA. An antidiabetic thiazolidinedione is a high affinity ligand for peroxisome proliferator-activated receptor $\%$ (PPAR $\gamma$ ). I Biol Chem. 1995;270:12953-6.

11. Chaput $\mathbb{E}$, Saladin $\mathbb{R}$, Silvestre $M$ and Edgar $A D$. Fenofibrate and rosiglitazone lower serum triglycerides with opposing effects on body weight. Biochem Biophys Res Commun. 2000;271:44:5-50.

12. Larsen $P$, Jensen $P B$, Sorensen $R V$, et al. Differential influences of peroxisome proliferatoractivated receptors y and $\alpha$ on food intake and energy homeostasis. Diaberes. 2003;52:2249.59.

13. Asnani $S$, Richard BC, Desouza $C$ and Fonseca $\mathrm{V}$. Is weight loss possible in patients treated with thiazolidinediones? Experience with al low-calorie diet. Curr Med Res Opin. 2003;19:609-13.

14. Stunkard $\mathrm{A}$ and Messick $\mathrm{S}$. The three-factor eating questionnaire to measure dietary restraint, disinhibition and hunger. J Psychosom Res. 1985;29:71-83.

15. Brouwer E. On simple formulae for calculating the heat expenditure and the quantities of carbohydrate and fat oxidized in metabolism of men and animals, from gaseous exchange (Oxygen intake and carbonic acid output) and urine N. Acta Physiol Pharmacol Neerl. $1957 ; 6: 795-802$.

16. Schoffelen PF, Westerterp KR, Saris WH and Ten Hoor F. A dual-respiration chamber system with automated calibration. J Appi Physiol. 1997;83:2064-72.

17. Stichting Nederlands Voedingsstoffenbestand. NEVO tabel. Den Haag, 1996.

18. Westerterp KR, Wouters L and Marken Lichtenbelt WDV. The Maastricht protocol for the measurement of body composition and energy expenditure with labeled water. Obes Res. 1995:3:49-57. 
19. Siri WE. Body composition from fluid spaces and diensity: analysis of methods. 1961. Nutrition. 1993;9:480-91; discussion 80, 92.

20. Chomczynski $P$ and Sacchi $N$. Single-step method of RNA isolation by acid guanidinium thiocyanate-phenol-chloroform extraction. Anal Biochem. 1987;162:156-9.

21. Bakker AH, Van Dielen FM, Greve W, Adam IA and Buurman WA. Preadipocyte number in omental and subcutaneous adipose tissue of obese individuals. Obes Res. 2004;12:488-98.

22. Rajala MW and Scherer PE. Minireview: The adipocyte-at the crossoads of energy homeostasis, inflammation, and atherosclerosis. Endocrinology. 2003;144:3765-73.

23. Levin BE, Dunn-Meynell AA, Balkan B and Keesey RE. Selective breeding for dietinduced obesity and resistance in Sprague-Dawdey rats. Am / Physiol. 1997;273:R725-30.

24. Bouchard $C_{n}$ Tremblay $A$, Despres JP, et al. The response to long-term overfeeding in identical twins. N Eng / Med. 1990;322:1477-82.

25. Ross $S R$, Graves $R A$, Greenstein $A$, et al. A fat-specific enthancer is the primary determinant of gene expression for adipocyte $P 2$ in vivo. Proc Natl Acad Sci U SA. 1990;87:9590-4.

26. Sen A, Lea-Currie YR, Sujkomska D, et al. Adipogenic potential of human adipose derived stromal cells from multiple donors is heterogeneous. ) Cell Biochem. 2001:81:312-9.

27. Gustafison B, Jack MM, Cushman SW and Smith U. Adiponectin gene activation by thiazolidinediones requires PPAR 2 , but not C/EBPa-evidence for differential regulation of the aP2 and adiponectin genes. Biochem Biophys Res Commun. 2003;308:933-9.

28. Xia $Z$ and Cianflione K. Acylation-stimulating protein precursor proteins in adipose tissue in human obesity. Metabolism. 2003:52:1360\%6.

29. Maeda $N$, Takahashi $M$, Funahashi $T$, et al. PPARy ligands increase expression and plasma concentrations of adiponectin, an adipose-derived protein. Diabetes. 2001;50:2094-9.

30. Yang $X$, Jansson PA, Nagaev 1, et al. Evidence of impaired adipogenesis in insulin resistance. Biochem Biophys Res Commun. 2004;317:1045-51.

31. Joosen AMCP, Bakker AHF, Gering MIA and Westerterp KR. The effect of the PPARY ligand rosiglitazone on energy balance regulation. Dïabetes Metab Res Rev. 2005 (in press).

32. Kersten $S$, Mandard $S$, Tan NS, et al. Characterization of the fasting-induced adipose factor FIAF, a novel peroxisome proliferator-activated receptor target gene. J Biol Chem. 2000;275:28488-93.

33. Mandard $S$, Zandbergen F, Tan NS, et al. The direct peroxisome proliferatomativated receptor target fasting-induced adipose factor (F/AF/PGAR/ANGPTL4) is present in blood plasina as a truncated protein that is increased by fenofibrate treatment. I Biol Chem. 2004:279:34411-20. 



\section{Genetic analysis of physical activity in twins}

Annemiek M.C.P. Joosen, Marij Gielen, Robert Vlietinck and Klaas R. Westerterp

American Journal of Clinical Nutrition (in press) 


\section{ABSTRACT}

Background The reduced contribution of physical activity (PA) to daily energy expenditure contributes to the increased prevalence of obesity. If activity-induced energy expenditure (AEE) is genetically controlled, this may contribute to a genetic susceptibility to obesity.

Objective To investigate the relative contribution of genetic and environmental factors to the (co)variation in AEE and PA.

Design 12 monozygotic $(M Z)$ and 8 same-sex dizygotic $(D Z$, including 2 same-sex sibling pairs, age differences 2 and $2.5 y$ ) twin pairs, aged between 18 and $39 y_{\text {* }}$ participated. AEE was measured in a respiration chamber and with doubly labeled water in daily life for 2 weeks. PA was recorded simultaneously with a tri-axial accelerometer. Structural equation modeling was used to separate and quantify the observed variance into sex-adjusted additive genetic common $_{s}$ and unique environmental contribution.

Results Within the respiration chamber, common and unique environmental factors explained the variance of AEE and PA and no genetic contribution was found. In daily life, genetic factors explained $72 \%$ of the variance of AEE and $78 \%$ of the variance of PA. Unique environmental factors explained the remaining variance. The same additive genetic factors explained $67 \%$ of the covariance of AEE and PA in daily life.

Conclusion In this exploratory study using golden standard measurements of AEE and $\mathrm{PA}$, but with a limited sample size, genetic influence explained a large part of the variation in AEE and PA in daily life, while both AEE and PA were influenced by environment only within the confined area of the respiration chamber. 


\section{INTRODUCTION}

Epidemiological data show that a sedentary lifestyle is associated with severall diseases such as cardiowascular disease, type 2 diabetes mellitus and obesity (1). The link between physical inactivity and obesity is likely to be causal as overweight and obesity are determined by the long-term imbalance between energy intake and energy expenditure (2). Both environmental and genetic factors can influence the energy balance. In this view, if activity-induced energy expenditure is genetically controlled, this may contribute to a genetic susceptibility to obesity. This can have important implications in the prevention and treatment of obesity.

Total energy expenditure (TEE) consists of four components: sleeping metabolic rate (SMR), energy cost of arousal, diet-induced thermogenesis (DIT) and activityinduced energy expenditure (AEE). Of these components, AEE is the most variable between persons (3). AEE is determined by the amount of physical activity (PA), the intensity of the activities, body characteristics (size, composition) and indirectly by physical fitness $(4,5)$.

In daily life, the contribution of AEE to TEE can range from $25 \%$ in sedentary persons to $75 \%$ in extreme situations during heavy, sustained exercise (6). PA includes a spontaneous component, such as fidgeting, sitting, standing and walking, an obligatory component, such as occupation, household and activities of daily living, and a voluntary component such as sports (7). In a respiration chamber, without an exercise protocol, PA is limited to the spontaneous component because of the limited space available. Even within this confined environment, PA and AEE are highly variable between subjects and contribute substantially to energy expenditure emphasizing the important contribution of activities of low to medium intensity to total daily activity level $(7,8)$. In addition, high levels of PA and AEE in the respiration chamber predict high levels of PA and AEE in daily life with correlation coefficients of $0.30-0.57$ and $0.50-0.53$ for PA and AEE respectively $(8,9)$, which could be the result of a genetic basis. To test for genetic contribution we used a twin design, which allows us to separate the genetic and environmental variance components of AEE and PA when measured in the respiration chamber and in daily life. The classical twin design is based on the comparison of monozygotic $(\mathrm{MZ})$ twins, which are genetically identical, with dizygotic (DZ) twins, which share (on average) $50 \%$ of their genes like sibs. Intrapair difference in $M Z$ twins is due to environmental factors and measurement errors, while intra-pair difference in $D Z$ twins is additionally affected by genetic factors. 
We hypothesized that genetic factors would contribute to a predisposition of being physically active and have a high AEE and that these genetic factors are shared for $\mathrm{PA}$ and $\mathrm{AEE}$.

\section{SUBJECTS AND METHODS}

\section{Subjects}

Twin pairs were recruited through advertisements in the university, the university hospital and the local press, and through the City Council of Maastricht and the Dutch Twin Register (10). Selection criteria included being a same-sex twin or sib pair, between the age of 18 and 40 years (for sib pairs with an age difference $<3$ y), Caucasian, non-smoking or only occasionally smoking, and not following a dietary regimen with the aim to lose or gain weight. Subjects were medically screened by a detailed health questionnaire; only twins in good health without physical limitations were included. The study was approved by the Ethics Committee of Maastricht University. All subjects received verbal and written information and signed a written consent form. Twelve $M Z$ ( 5 male and 7 female) and six DZ (1 male and 5 female) same-sex twin pairs and two (female) same-sex sibling pairs with age differences of 2 and 2.5 y participated in the study. Since $D Z$ twins are like sibs, but with no age difference, the sibs were included in the $D Z$ group, making a total of eight DZ twin pairs. Zygosity of the twins was established using nine polymorphic DNA markers. Both $M Z$ and DZ twin pairs were studied in equal distributions over the seasons.

\section{Experimental design}

Individual study periods covered 17 consecutive days. Both members of a twin pair were measured on the same days. In the evening of day 1 each member of a twin pair entered one of two respiration chambers for a period of $36 \mathrm{~h}$. No exercise protocol was imposed. Meals were served at fixed hours. Energy intake was calculated from SMR during the first night, which was multiplied with an activity level of 1.4 to reach energy balance ( 8 ). The macronutrient composition of the diets reflected that of the average Dutch diet $15 \%$ of energy from protein, $50 \%$ from carbohydrates, $35 \%$ from fat). After leaving the respiration chamber on the morning of day 3 , body weight and body composition were measured. A fasting blood sample was drawn for analysis of zygosity. Consecutively, twins went home where total free-living energy expenditure was measured with doubly labeled water (DLW) for 15 days (10 MZ AND $8 \mathrm{DZ}$ pairs due to availability of the DLW). Subjects wore an accelerometer for the entire study period to measure plrysical activity. 


\section{Procedures}

Anthropometry and body composition Measurements were cartied out the morning after voiding and before breakfast. Body weight and height were measured to the nearest $0.01 \mathrm{~kg}$ and $0.1 \mathrm{~cm}$ respectively. Body mass index (BM), $\mathrm{kg} / \mathrm{m}^{2}$ ) was calculated as body weight $(\mathrm{kg})$ divided by height (m) squared. Body density was determined by underwater weighing with simultaneous measurement of residual lung volume with the helium dilution technique. Total body water (TBW) was determined with deuterium dilution following the Maastricht protocol (11). Body composition was calculated from body density and TBW using the three-compartment model of Siri (12).

Respiration chamber Total energy expenditure (TEE) was measured over the last $24 \mathrm{~h}(7: 30 \mathrm{am}-7: 30 \mathrm{am})$ of a $36 \mathrm{~h}$ stay $(7: 30 \mathrm{pm}-7: 30 \mathrm{am})$ in a respitation chamber from oxygen consumption and carbon dioxide production according to the formula of Weir (13). The respiration chamber measures $14 \mathrm{~m}^{3}$ and is furnished with a bed, chair, table, TV, radio, telephone, computer, washbowl and toilet facilities (14). During daytime subjects were allowed to move freely, sit, lie down, study, telephone, listen to the radio, watch television and use the computer; only sleeping and strenuous exercise were not allowed. SMR was defined as the lowest observed energy expenditure for three consecutive hours during the night, generally between 3:00 and 6:00 am. The SMR of the second night was used for further calculations. AEE was calculated as (0.9 TEE) - SMR with a diet-induced thermogenesis of $10 \%$ assumed (3).

Daily life Average daily metabolic rate (ADMR) was measured with the DLW technique following the Maastricht protocol (11). Briefly, isotopes were administered as a mixture of $5 \mathrm{At} \%{ }^{2} \mathrm{H}_{2} \mathrm{O}$ and $10 \mathrm{At} \% \mathrm{H}_{2}{ }^{13} \mathrm{O}$ resulting in an initial excess body water enrichment of $150 \mathrm{ppm}$ for deuterium and $300 \mathrm{ppm}$ for oxygen-18, leaving a sufficient excess enrichment at the end of the observation period. The volume of the isotope mixture was $80-160 \mathrm{ml}$. Subjects collected a background urine sample immediately before isotope consumption to correct for isotopic backgrounds, subsequent urine samples were collected from the second and the last voiding on the first, mid and last day of the $15 \mathrm{~d}$ observation period. Isotope enrichments of the urine samples were analyzed with isotope ratio mass spectrometry (Optima, VG, UK). Theoretical considerations and calculations of energy expenditure by the DLW method are described in detail elsewhere by Westerterp et all. (11). AEE was calculated as $(0.9 *$ ADMR) - SMR with a dietinduced thermogenesis of $10 \%$ assumed (3). 
Physical activity (PA) was registered with a tri-axial accelerometer for movement registration (Tracmor, Philips Research, Eindhoven, The Netherlands), which measures body accelerations in anterioposterior, mediolateral and vertical directions. PA was expressed as Mcounts per day by summing the minute values of all axes per day. The tri-axial accelerometer has been validated against DLW (15) and has been used before in our department $(16,17)$. Subjects wore the accelerometer on al belt at the lower back during waking hours, except during water activities.

\section{Statistical analysis}

\section{Descriptive analysis}

Twins were considered as individuals for this analysis. Results are presented as mean \pm SE. A F-test followed by Student's unpaired t-test (two-sided) was used to compare two groups. $P<0.05$ was considered statistically significant.

Intra-pair correlations for $M Z$ and $D Z$ twins were calculated with the Pearson correlation coefficient (r). From these correlations the heritability was calculated, as $h^{2}=2 *(r M Z$-rDZ $)$. The comparison of $r_{\text {aee }}$ and $r_{p a}(=$ intra-pair correlation; AEE in twin 1 correlated with AEE in twin 2, $r_{\text {aee }}$ same for $\left.P A, r_{p a}\right)$ between $M Z$ and $D Z$ twins gives an indication of additive genetic $\left(a^{2}\right)$, common environmental $\left(c^{2}\right)$ and unique environmental influence $\left(\mathrm{e}^{2}\right)$ on AEE and PA respectively (18).

\section{Univariate analysis}

Structural equation modeling was used to separate and quantify the observed phenotypic variance $\left(V_{\text {tot }}\right)$ in AEE and PA into its different components: additive genetic contribution ( $a^{2}=V_{a} / V_{\text {lot }}$, heritability), common (or shared, equal to both members of the twin pair) environmental contribution $\left(c^{2}=V_{d} / V_{t a t}\right)$ and unique (or specific, different for each member of the twin pair) environmental contribution $\left(e^{2}=V / V_{\text {pol }}\right)$. This additive model assumes no dominant genetic effects, no interaction between genes, no interaction between genes and environment, and that $M Z$ and $D Z$ twins share common environmental factors to the same extent.

Based on the results from the descriptive analysis, correlation matrix and sexdifferences in absolute parameter levels, alternative univariate models (ACE, CE, $\mathrm{AE}$ and $\mathrm{E}$ ) with sex as an explanatory variable were fitted to the raw data using a maximum likelihood approach with accompanying Akaike's information criterion (AIC) (18). The ACE model and sub-models were compared to one another with the AIC. The model with the lowest AIC reflects the best model in which the pattern of variances and covariance is explained by as few parameters as possible. The goodness-of-fit of the sub-models was also evaluated by hierarchical $\chi^{2}$ tests. 
Note that only nested models can be compared with this test, which is therefore unable to compare the AE and CE models.

\section{Bivariate analysis}

Structural equation modeling Based on the univariate structural equation models we tested in a bivariate model whether there was a genetic, common environmental or unique environmental correlation between AEE and PA. The bivariate heritability (the part of the phenotypic correlation that is due to shared

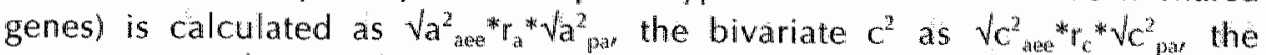
bivariate $\mathrm{e}^{2}$ as $\mathrm{Ve}^{2}{ }_{\text {aee }}{ }^{*} \mathrm{r}_{\mathrm{e}}{ }^{*} \sqrt{ } \mathrm{e}^{2}$ pa . SPSS 11 for Macintosh (SPSS Inc., Chicago, IL, 2002) was used for descriptive analysis, Mx (19). was used for correlations and structural equation modeling.

\section{RESULTS}

Descriptive analysis Characteristics of the 40 subjects are shown in Table 1. Data were normally distributed. Overall, $M Z$ twins were slightly older than $D Z$ twins ( $P$ $<0.05$ ); other physical characteristics were not significantly different between $M Z$ and $D Z$ twins. As can be expected from the general population, males were significantly taller $(P<0.0001)$ and had a higher fat-íree mass $(F F M, P<0.0001)$ and a lower fat mass ( $F M, P=0.01)$ than females.

There were no significant differences between $M Z$ and $D Z$ twins for $A E E$ and PA, both in the respiration chamber and in daily life. Except for PA in daily life, males showed significantly higher values for $A E E$ and $P A$ than females $P<0.05\rangle$. AEE and $P A$ in daily life were significantly higher than in the confined area of the respiration chamber $\left(\mathrm{P}^{2}<0.001\right)$.

Intra-pair correlations Figure 1 shows the twin $1 \times$ twin 2 plots for AEE and PA, Table 2 shows the accompanying intra-pair correlations and heritabilities. In the confined area of the respiration chamber, the ratio between $M Z$ and $D Z$ correlations is $<2$ for both AEE and PA, which suggests not only genetic but also common and unique environmental influences on AEE and PA separately. In daily life, the ratio between $r_{\text {aee }} M Z$ and $r_{\text {aee }} D Z$ is $<2$ as well. Contrary to the respiration chamber, the $r_{p a} M Z$ is equal to $2^{*} r_{p a} D Z$ in daily life, which suggests that $P A$ in daily life is determined by additive genetic and unique environmental influences, without common environmental influences.

The overall correlation between $\mathrm{PA}$ and AEE, calculated with one random selected member of each twin pair, in the respiration chamber was 0.46 ( $\mathrm{P} \ll$ $0.05)$, in daily life this correlation was $0.65(\mathrm{P}<0.001)$. 
Table 1 Characteristics of the 40 swbjects, divided by zygosity and sex?

\begin{tabular}{|c|c|c|c|c|c|c|c|c|c|}
\hline$\therefore$ & $\begin{array}{l}\text { Total } \\
(n=40)\end{array}$ & $\begin{array}{l}M Z \\
\text { Males } \\
(n=10)\end{array}$ & & $\begin{array}{l}\text { Female } \\
(n=14)\end{array}$ & & $\begin{array}{l}\mathrm{DZ} \\
\text { Males } \\
(\mathrm{n}=2)\end{array}$ & & $\begin{array}{l}\text { Female } \\
(\mathrm{n}=14)\end{array}$ & $e^{2}$ \\
\hline & mean & mean & SE & mean & $S E$ & mean & SE & mean & $\mathrm{SE}$ \\
\hline Phosical characteristios & & & & & & & & & \\
\hline Age $(y)$ & 25 & 25 & 2.5 & 28 & 2.1 & 20 &.$^{7}$ & $21.6^{3}$ & 0.5 \\
\hline Height (m) & 1.72 & 1.81 & 0.04 & $1.67^{7}$ & 0.02 & 1.83 & $=$ & $1.69^{6}$ & 0.01 \\
\hline $\left.\mathrm{BM} / \mathrm{kg} / \mathrm{m}^{2}\right)$ & 23.4 & 22.9 & 0.8 & 24.2 & 1.6 & 21.0 & 0.3 & 23.1 & 1.3 \\
\hline $\mathrm{BW}(\mathrm{kg})$ & 68.9 & 75.2 & 3.4 & 67.2 & 4.3 & 70.2 & 0.4 & 65.9 & 3.4 \\
\hline$F F M(k g)$ & 49.9 & 60.6 & 2.3 & $44.3^{4}$ & 1.1 & 60.7 & 1.1 & $46.3^{16}$ & 1.6 \\
\hline FM (kg) & 19.0 & 14.6 & 1.9 & 22.8 & 3.8 & 9.5 & 1.5 & 19.6 & 2.3 \\
\hline$S M R(M) / d)$ & 6.3 & 7.1 & 0.3 & 6.1 & 0.2 & 6.9 & 0.1 & $6.0^{6}$ & 0.2 \\
\hline Respiration chamber & & . & & & & & & & \\
\hline TEE $(M / / d)$ & 8.9 & 10.1 & 0.4 & $8.5^{4}$ & 0.2 & 9.5 & 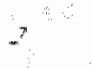 & 8.4 & 0.3 \\
\hline $\operatorname{AEE}(\mathrm{M} / \mathrm{d})$ & 1.7 & 2.0 & 0.2 & $1.6^{5}$ & 0.1 & 1.6 & 0,1 & 1.5 & 0.1 \\
\hline AEEBWW (MU/kg/d) & 0.024 & 0.027 & 0.002 & 0.024 & 0.002 & 0.023 & 0.002 & 0.024 & 0.001 \\
\hline PA (Mcounts/d) & 149 & 170 & 11 & 143 & 10 & 136 & 7 & 140 & 7 \\
\hline Daily life & & & 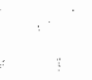 & & & & 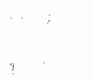 & $\cdots$ & \\
\hline ADMR $(M \mathrm{M} / \mathrm{d})$ & 11.5 & 14.0 & 0.8 & $9.9^{4}$ & 0.3 & 12.6 & 0.1 & 10.7 & 0.6 \\
\hline AEt: (MU/d) & 4.11 & 5.5 & 0.5 & $3.1^{4}$ & 0.3 & 4.4 & 0.2 & 3.7 & 0.4 \\
\hline AEE/BW $(M / / / k g / d)$ & 0.060 & 0.073 & 0.005 & $0.052^{4}$ & 0.006 & 0.063 & 0.003 & 0.055 & 0.005 \\
\hline $\mathrm{PA}(\mathrm{Mcounts} / \mathrm{d})$ & 368 & 419 & 19 & $318^{5}$ & 37 & 387 & 105 & 381 & 36 \\
\hline
\end{tabular}

$A D M R=$ average dally metabolic rate, $A E E=$ activity-induced energy expenditure, $B W=$ body weight, $\mathrm{DZ}=$ dizygotic hwins, $F F M=$ fat free mass, $\mathrm{FM}=$ fat mass, $M Z=$ monozygotic twins, $\mathrm{PA}=$ physical activity, $S M R=$ sleeping metabolic rate

I Twins were considered as individuals for comparison of characteristics using a F-test followed by Student's t-test (unpaired, bwo-sided).

${ }^{2}$ DZ female group includes two sanne-sex sibling pairs (age difference $\leq 2.5$ years)

${ }^{3} \mathrm{P}<0.01, \mathrm{MZ}$ fenales compared to DZ females

${ }^{4} \mathrm{P}<0.01$ and ${ }^{5} \mathrm{P}<0.05, \mathrm{MZ}$ males compared to $M Z$ females

${ }^{5} \mathrm{P}<0.05, \mathrm{DZ}$ males compared to $\mathrm{DZ}$ females

"No vartation was observed tor the thwo individuals of the one $\mathrm{DZ}$ male twin pair 
(a)

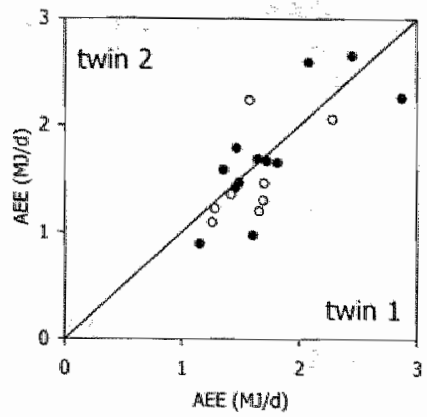

(C)

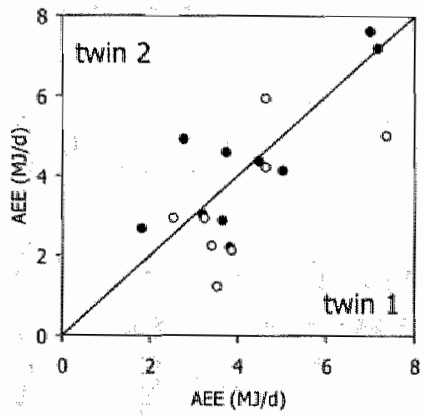

(b)

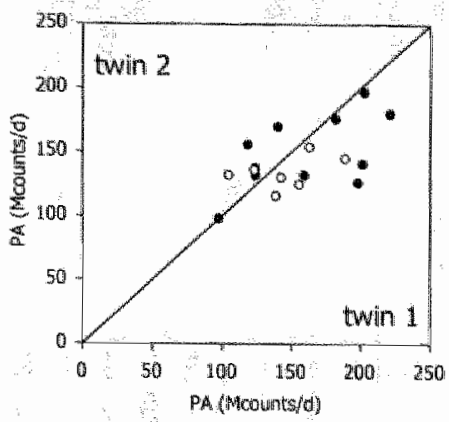

(d)

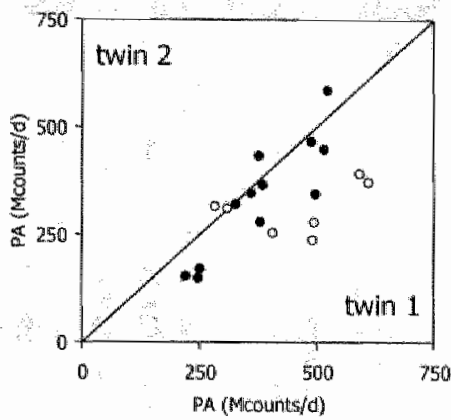

Figure 1 Twin $1 \times$ twin 2 plots of $M Z(-)$ and DZ (O) twins for AEE in the respiration chamber (as, $P A$ in the respiration chamber (b), AEE in daily life (c) and PA in daily life (d). Members of a twin pair were randomly assigned to be twin 1 or twin 2.

$\mathrm{AEE}=$ activity-induced energy expenditure, $\mathrm{DZ}=$ dizygotic, $M Z=$ monozygotic $c_{\gamma} \mathrm{PA}=$ physical activity

Table 2 : Intra-pair correlations and heritabilities in $M Z$ and $D Z$ twins. ${ }^{5,2}$

\begin{tabular}{|c|c|c|c|c|}
\hline$\ldots$ & & $M M Z$ & $r D Z$ & $h^{2}$ \\
\hline \multirow[t]{2}{*}{ Respiration chamber } & AEE & $0.78^{13}$ & $0.60^{\circ}$ & 0.36 \\
\hline & $P A$ & $0.56^{8}$ & 0.43 & 0.26 \\
\hline \multirow[t]{2}{*}{ Daily lite } & AEE & $0.82^{3}$ & 0.64 & 0.36 \\
\hline & $P A$ & $0.88^{9}$ & 0.42 & 0.92 \\
\hline
\end{tabular}

$A E E=$ activity $-i n d u c e d$ energy expenditure, $D Z=$ dizygotic, $M Z=$ monozygotic, $P A=$ physical activity 'using Pearson's correlation coefficient and heritability, calculated as $h^{2}=2 *(\mathrm{MZ}-\mathrm{r} D \mathrm{D})$

${ }^{2}$ differences between $\mathrm{rMZ}$ and $\mathrm{rDZ}$ were not statistically significant for all variables

${ }^{3} \mathrm{P}<0.001,{ }^{4} \mathrm{P}<0.05$ 


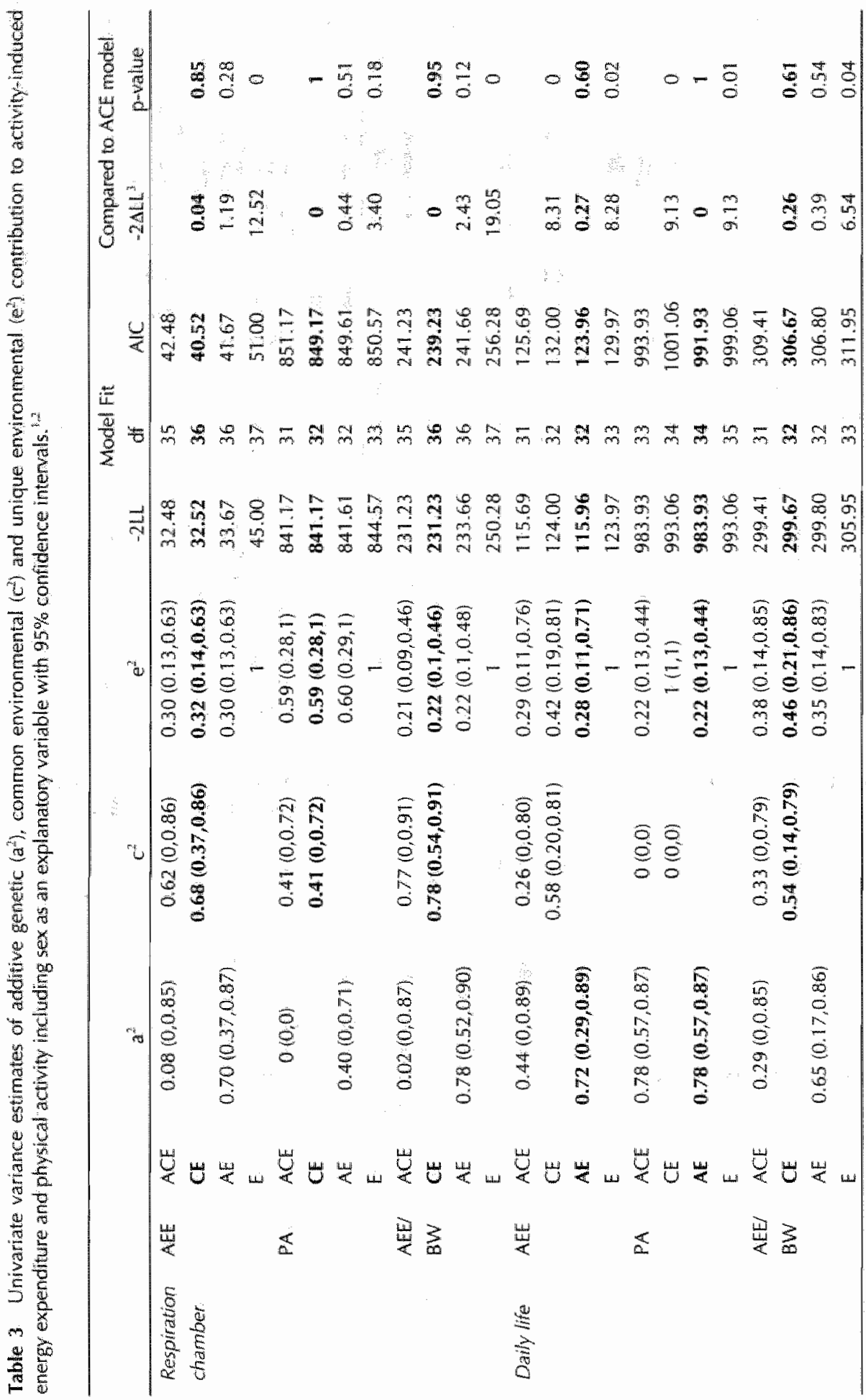


Table 3 (continued)

$\mathrm{AEE}=$ activity-induced energy expenditure, $\mathrm{BW}=$ body weight, $\mathrm{DZ}=$ dizygotic, $\mathrm{MZ}=$ monozygotic, $\mathrm{PA}=$ physical activity

"using the goodness-of-fit and the parsimony of the models

${ }^{2}$ the best-fitting and most parsimonious models (lowest AlC are in bold

${ }^{3}-2 \Delta L L$ follows a $x^{2}$ distribution with df degrees of freedom

\section{Univariate analysis}

Structural equation modeling As absolute levels of AEE and PA (except for PA in daily life) were significantly higher for males than females, sex was added as an explanatory variable into the analyses. Variance estimates of additive genetic, common environmental and unique environmental influences were derived from the best-fitting and most parsimonious (lowest $\mathrm{AIC}$ ) univariate structural equation model, although the difference between models was not always large (Table 3). In the confined area of the respiration chamber the common environment accounted for $68 \%$ of the total variance in $\mathrm{AEE}$, whereas in daily life genetic factors were the main contributors $(72 \%)$. Unique $(59 \%)$ and common $(41 \%)$ environmental factors explained the variance in PA in the respiration chamber, whereas in daily life mainly genetic factors $(78 \%)$ accounted for the total variance in $P A$ as measured with accelerometry.

\section{Bivariate analysis}

Structural equation modeling Since univariate structural equation modeling showed that genetic factors played only a role in daily life and not in the respiration chamber, we focused on the correlation between PA and AEE in daily life. From the correlations and the variance estimates of the individual variables we calculated the percentage of the variance in both phenotypes that was explained by the same genes or the same environment. A bivariate model with only additive genetic factors provided the most appropriate fit for the data as determined by the goodness-of-fit and the parsimony of the model (Figure 2). The correlation between additive genetic effects on AEE and PA in daily life was 0.90 $(95 \% \mathrm{Cl} 0.56,1)$. In this model, $67 \%$ of the phenotypic covariance was accounted for by shared genetic factors.

\section{DISCUSSION}

The aim of this study was to determine the relative contribution of genetic and environmental factors to AEE and PA and to the covariance of these parameters. 


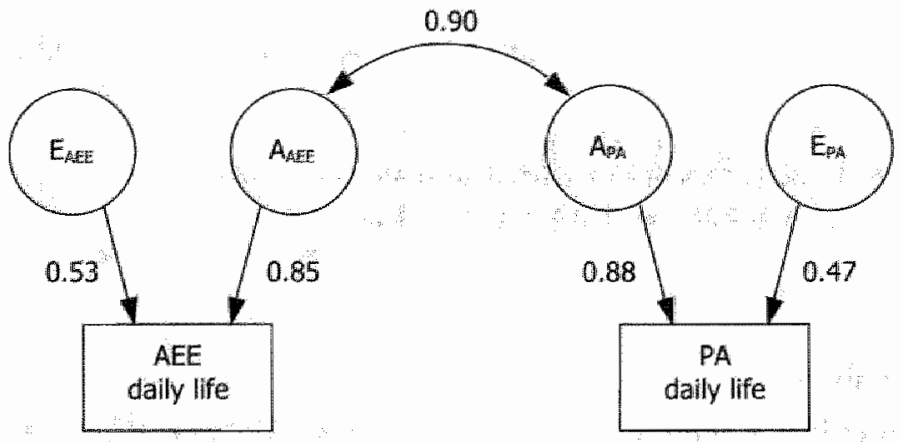

Figure 2 Correlation and path coefficients for the best-fitting bivariate model for AEE and PA in daily life: $1 / 2$

$\mathrm{AEE}=$ activity-induced energy expenditure, $\mathrm{PA}=$ physical activity, $\mathrm{A}=$ additive genetic influence on $A E E\left(A_{A S B}\right)$ or $P A\left(A_{P A}\right), E=$ snique environmental influence on $A E E\left(E_{A F E}\right)$ or $P A\left(E_{P A}\right)$

the presented model has the lowest $A I C$ and is therefore the best-fitting and most parsimonious one

2 The square of the path coefficients reflects the amount of the total variance accounted for by additive genetic or unique environmental factors to AEF and PA.

AEE is not only highly correlated with the amount of PA, but also with body characteristics (size, composition), physical fitness and intensity of the activities, factors that can influence AEE directly and indirectly through PA. We hypothesized that genetic factors would contribute to a predisposition of being physically active and have a high AEE. High levels of PA and AEE in the respiration chamber predicted high levels of PA and AEE in daily life $(8,9)$, which shows the major contribution of low-intensity activities to total PA and suggests a genetic basis. Therefore, we compared measurements in the confined area of the respiration chamber and measurements in daily life in twins.

We did not find genetic influences on the variation in AEE and PA in the respiration chamber. The restrictions of the small environment, limiting activities to the spontaneous component of PA (essentially non-weight-bearing and of low intensity) seemed to dominate the genetic basis of a person in the respiration chamber. However in daily life, where PA not only includes a spontaneous component but also obligatory and voluntary components (both weight-bearing and non-weight-bearing activities and a wide range of intensities, we found a high genetic contribution to the variation in AEE and PA. As hypothesized, the correlation between AEE and PA in daily life was largely due to shared genetic factors affecting both AEE and PA. This suggests that genes determine whether a person is prone to engage in activities and how much energy is expended for these activities. The combination of results from the confined, controlled area of 
the respiration chamber and the self-selected environment in daily life suggests that the genetic influence is more pronounced on the obligatory and voluntary components of PA than on the spontaneous component. Therefore, we also analyzed AEE normalized for body weight. In the respiration chamber, results for AEE and AEE/BW were the same. However, in daily life the AE model was favorable for the uncorrected AEE whereas there was almost no difference between the CE and $A E$ models for $A E E / B W$, with $C E$ as the best-fitting model for $A E E / B W$. This suggests that body weight contributes to the genetic influence on AEE but that there are additional genetic factors involved. Additional analyses of genetic and environmental influences on body composition, SMR, TEE and ADMR showed a large contribution of genetic factors ( $a^{2}$ between 0.79 and 0.87 , data not shown). As reported earlier (20), SMR and FFM were highly heritable, and the genetic contribution found in the components of TEE were reflected in TEE and ADMR, which confirms the results found for AEE and PA.

In this study we used golden standard techniques for measurements of energy expenditure (respiration chamber and DLW) and PA (accelerometry). The tri-axial accelerometer used (Tracmor) measures frequencies of activities of daily living, which are mainly between 0.3 and $3.5 \mathrm{~Hz}$ (21). When placed on a belt at the lower back, the accelerometer can clearly distinguish small body movements: the output of an accelerometer positioned on a belt at the lower back of a subject performing low-intensity activities such as computer work, writing or reading (e.g. static work) is significant higher than the output of an accelerometer lying still on a table (22). To our knowledge; the only other study investigating genetic influence on AEE using objective measurements was by Goran (23). After adjusting the ADMR, measured with DLW in 37 young $(5-9 y)$ sib pairs, for resting metabolic rate; he still found a significant sib-pair correlation suggesting separate génetic influences on resting metabolic rate and non-resting energy expenditure (23). However, this family study did not include MZ twin pairs and could therefore not quantify genetic contribution. Epidemiological twin studies have investigated PA using activity questionnaires. Results, including those from a review on genetic determinants on $\mathrm{PA}$, show that $\mathrm{PA}$ is genetically influenced with heritability coefficients between 0.29 and $0.68(24-27)$, still leaving a considerable influence of shared environmental factors (28). However, questionnaires rely on subjective interpretation of PA, which depends on how the question is asked, and the type of responses offered as options (27).

The classical twin design used in this study requires some remarks. First, a major assumption of the twin design is that $M Z$ twins share a common environment to the same extent as $D Z$ twins. If $M Z$ twin pairs have a more similar environment compared to DZ twin pairs, as adults or when growing up as children, then heritability estimates are overestimated and common environmental influence is underestimated. The more obvious common environments of the present study, 
i.e. living in the same house (with parents) and the amount of contact within pairs; were similar for $M Z$ and $D Z$ twins. Second, the twin design assumes that the twins studied represent the general young adult population. In our subjects the mean value for the physical activity level (PAL, calculated as ADMR/SMR) was 1.81 . range 1.39-2.29, which is comparable to the value of 1.75 , range $1.2-2.5$, (lower because PAL was calculated by dividing ADMR by BMR instead of SMR) reported for the general population (29). Third, the strict measurement protocol, the high costs of the measurement techniques, but mainly the difficulty of recruiting twin pairs of which both members were willing to participate have limited the numbers of twins and thus the power of this study. Therefore, it can be difficult to distinguish between additive genetic and common environmental factors. We can not rule out the possibility of a small common environmental factor in the other coefficients. In addition, with this sample size there is not enough power to test for sex-differences in path-coefficients, especially because of the low numbers of male twins. However, statistical analyses including only the female twins yielded the same results.

Though the numbers of twins in our study was limited, we were able to detect a significant genetic contribution to PA and AEE and these results were confirmed with other measurements of energy expenditure and body composition. The use of a longitudinal study design and objective measurements (DLW and accelerometers) in larger and more diverse populations will provide more information about the genetic determinants of AEE and PA. Quantification of genetic factors that contribute to AEE and PA gives direction to the identification of genes involved. Finding those genes may identify persons at risk for obesity, since PA contributes to energy balance regulation. Furthermore, this allows prevention and treatment strategies for obesity to be personalized based on a person"s genetic background.

In conclusion, in this exploratory study using golden standard measurements of $A E E$ and $P A$, but with a limited sample size, genetic influence explained a large part of the variation in AEE and PA in daily life, while both AEE and PA were influenced by environment only within the confined area of the respiration chamber.

\section{ACKNOWLEDGEMENTS}

We thank Loek Wouters for the analysis of the doubly labeled water samples, Paul Schoffelen for technical assistance with the respiration chambers, Rob Janssen for zygosity determination and Patrick Lindsey for statistical advise. We thank the City Council of Maastricht and the Dutch Twin Register for their help with recruiting the twins. 


\section{REFERENCES}

1. Booth FW, Chakravarthy MV; Gordion SE, Spangenburg EE. Waging watr on physical inactivity: using modern molecular armmuntion against an ancient enemy. I Appl Playsiol 2002;93:3-30.

2. Jebb SA, Moore MS. Contribution of a sedentary lifestyle and inactivity to the etiology of overweight and obesity: current evidence and research issues. Med Sol Sponts Exerc $1999 ; 31: 5534-4 \%$.

3. Westerterp KR. Energy metabolism and body composition: genteral principles. Eur Respir Mon $2003 ; 24: 1-10$.

4. Prentice $\mathrm{AM}_{x}$ Black $\mathrm{AE}_{n}$ Coward WA, at. High levels of energy expenditure in obese women. BrMed I (Clin Res Ed) 1986:292:983-7.

5. Sharp TA, Reed GW, Sun M, Abumrad NN, Hill 1O. Rellationship between aenobic finess level and daily energy expenditure in weight-stable humans. Am / Physiol 1992;263:E121-8.

6. Westerterp KR. Alterations in energy balance with exercise. Am / Clin Nutr 1998;68:9705-4S.

7. Levine IA, Schleustver SI, Jensen MD. Energy expenditure of nonexercise activity. Am I Clin Nutr $2000 ; 72: 1451-4$.

8. Westerterp KR, Kester AD. Physical activity in confined conditions as an indicator of free-hiving physical activity. Obes Res 2003;11:865-8.

9. Snitker S, Tataranni PA, Ravussin E. Spontaneous physical activity in a respiratory chamber is correlated to habitual physical activity. Int J Obes Relat Metab Disord 2001;25:1481-6.

10. Willemsen $C$, Boomsma DI, Beem AL, Vink IM, Slagboom PE, Posthuma D. QTLs for height: results of a full genome scan in Dutch sibling pairs. Eur I Hum Cenet 2004:12:820-8.

11. Westerterp KR, Wouters L, Marken Lichtenbell WDV. The Maastricht protocol for the measurement of body composition and energy expendifure with labeled water. Obes Res $1995 ; 3: 49-57$.

12. Siri WE. Body composition from fluid spaces and density: analysis of methods. 1961 . Nutrition 1993:9:480-91; discussion, 92.

13. Weir JdV. New methods for calculating metabolic rate with special reference to protein metabolism. J Phyiol 1949;109:1-9

14. Schoffelen PF, Westerterp $K R_{s}$ Saris WH, Ten Hoor F. A dual-respiration chamber system with automated calibration. I Appl Physiol 1997;83:2064-72.

15. Bouten CVC, Verboeket-Van De Venne WPHC, Westerterp KR, Verduin M, Janssen JD. Daily physical activity assessment: comparison between movement registration and doubly labeled water. J Appl Physiol 1996;81:1019-26.

16. Goris AHC, Meijer EP, Westerterp KR. Repeated measurement of habitual food intake increases under-reporting and induces selective under-reporting. Brit I Nutr 2001;85:629-34.

17. Goris AHC, Meijer EP, Kester A, Westerterp KR. Use of a triaxal accelerometer to validate reported food intakes. Am I Cin Nutr 2001;73:549.53.

18. Neale MC, Cardon LR. Methodology for genetic studies of twins and families. Dordrecht, The Netherlands: Kluwer Academic, 1992.

19. Neale MC, Boker SM, Xie G, Maes HH. Mx: Statistical Modeling. 6 ed. VCu Box 900126 , Richmond, VA 23298: Department of Psychiatry, 2002.

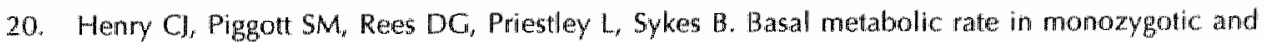
dizygotic (wins. Eur J Clin Nutr 1990;44:717-23. 
21. Sun $\mathrm{M}, \mathrm{H}$ H 1O. A method for measuring mechanical work and work efficiency during human activitues. J Biomech $1993 ; 26: 229-41$.

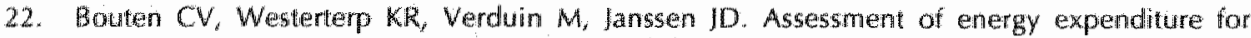
physical activity using a tridxial acceterometer. Med Sci Spoirs Exerc 1994:26:1516-23.

23. Goran MI. Genetic influences on human energy expenditure and substrate utilization. Behav Cenet $1997,27389999$.

24. Beunen $\mathrm{C}$, Thomis $\mathrm{M}$. Genetic determinants of sports participation and daly physical activity. Irit J Obes Relat Metab Disord 1999,23 suppl 3:555-63.

25. Lauderdale DS, Fabsitz R, Meyer IM, Sholnsky P, Ramaknishnan V, Coldberg J. Familiall determinants of moderate and intense physical actiwity: a twin study. Med Sci Sports Exerc $1997,29: 1062 \% 8$.

26. Maia IA, Thomis $M$. Betnen $G$. Genetic factors in physicall activity levels. A twin study. Am J Prev Med $2002 ; 23: 87,91$.

27. Perusse $\mathrm{L}$, Tremblay $A$, Leblanc $C$, Bouchard $C$. Cenetic and environmental influences on level of habitual physical activity and exercise participation. Am J Epidemiol 1989:129:1012-22.

28. Aarnio M, Winter T, Kujala UM, Kaprio I. Familial aggregation of leisure-time physical activity -a three generation study. lint I Sports Med 1997;18:549-56.

29. Black AE, Coward WA, Cole T], Prentice AM. Human energy expenditure in affluent societies: an analysis of 574 doubly-labelled water measurements. Fur ) Clin Nutr 1996;50:72-92. 
Discussion 


\section{GENERAL DISCUSSION}

The aim of the research presented in this thes is was to identify factors that regulate energy metabolism and fat mass, i.e. determinants of weight gain. Body weight maintenance requires a long-term balance between energy intake (EI) and energy expenditure (EE). A positive energy balance, caused by an increased $\mathrm{El}$, a decreased $\mathbb{E}$ or both, results in energy storage and thus weight gain. Overfeeding experiments show that some subjects increase their EE during overfeeding. As this might be due to adaptive changes in EE during overfeeding, adaptive thermogenesis as a mechanism to resist weight gain was investigated.

Excess energy is stored in the main energy storing tissue, the adipose tissue, thus changes in body mass are mainly changes in fat mass. The adipose tissue is not

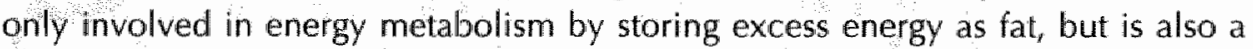
mediator of energy metabolism by secreting adipokines. In principle, differences in fat mass regulation could predispose to obesity. Therefore the influence of overfeeding on adipose gene expression, as well as the influence of adipose gene expression on energy balance regulation and fat mass gain was investigated.

Direct evidence for a genetic predisposition to obesity can be obtained from studying twins. Regarding energy metabolism, activity-induced energy expenditure (AEE) is the most variable component of daily EE and a reduced physical activity (PA) contributes to the increased prevalence of obesity. The relative contribution of genetic and environmental factors to the (colvariation in AEE and PA was tested using a twin design.

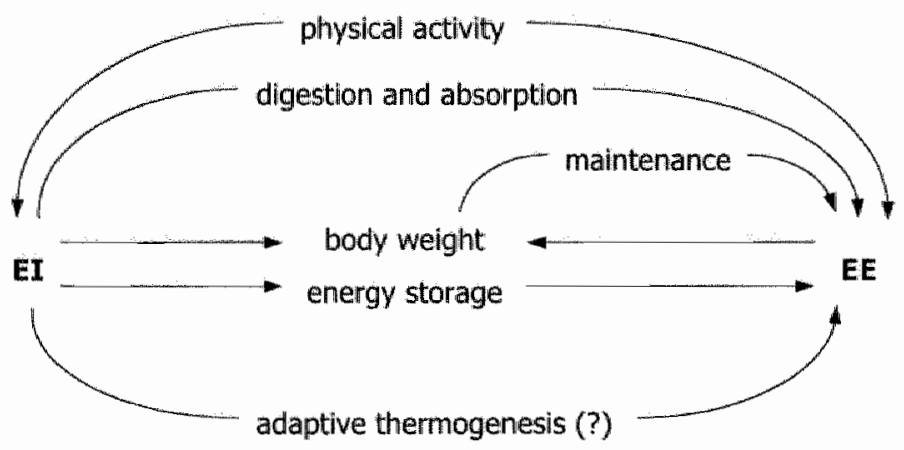

Figure 1 Energy balance regulation. 


\section{ENERGY BALANCE REGULATION}

The maintenance of a balance between $\mathbb{E}$ and $E E$ (Figure 1 ) is achieved when changes in one side of the ballance lead to adaptations in the other side. If there are no or only partial adaptations, changes in energy stores, and hence body weight occur.

\section{Factors influencing energy expenditure}

The maintenance cost of the body, represented by the basal metabolic rate (BMR), is the main determinant of total energy expenditure (TEE). The BMR accounts for $\sim 60 \%$ of daily $\mathrm{EE}$ in moderately active persons and is mainly a function of body weight, in particular the fat-free mass (FFM) (1). For a given weight, women have a lower FFM than men, resulting in a lower mean BMR, but when corrected for body composition, there is no difference in BMR between males and females (2). During weight gain, the BMR will increase in proportion to the change in FFM (3). Leibel et al. (3) showed that maintaining a body weight at a level $10 \%$ above the usual weight, which was induced by overfeeding, was associated with a higher BMR per kilogram of FFM. Similarly, BMR per kilogram FFM decreased during maintenance of a body weight at a level $10 \%$ below the usual weight (3). This indicates that at least some persons can regulate their EE beyond the obligatory costs associated with weight change in response to changes in energy balance. However, most overfeeding studies did not find evidence for the existence of adaptive thermogenesis (chapter 2), mainly because increases in BMR could be fully explained by an increased body size and tissue gain (4-8). Yet, there are large differences between subjects in the amount of energy stored per kilogram body weight during overfeeding, but they seem to be unrelated to adaptive changes in EE (chapter 3).

El stimulates EE as the diet-induced thermogenesis (DIT) increases proportionally with the amount of food eaten (9). The DIT is additionally affected by the macronutrient composition of the diet (10) and especially the poor regulation of fat oxidation in response to fat intake is thought to affect the susceptibility to weight gain by reducing the thermogenic response (11, 12). However, fat oxidation did not seem related to adaptive changes in EE during overfeeding (6, 7). Instead, a low fat oxidation may promote the preference to store fat independent of TEE (chapter 5). In addition, overfeeding healthy subjects with a relatively low-protein diet as a tool to maximize DIT (13) revealed no evidence for adaptive thermogenesis (chapter 3 ). Therefore, it is likely that the capacity for DIT influences energy balance regulation through effects on satiety, in particular by dietary protein (14), instead of through adaptive thermogenesis. 
A reduced physical activity (PA) results in a decrease in TEE. This is mainly the result of decrease in activities of daily living, as, with the exception of endurance athletes, this is the largest component of activity-induced energy expenditure (AEE) (15, 16). Low levels of spontaneous PA, which includes fidgeting, sitting, standing and walking $(17)$, are associated with weight gain in obesity-prone Pima Indians (18). PA is clearly influenced by environmental factors, including season (19), family habits (20) and availability and costs of exercise facilities (21): In addition, depending on the environment, genetic factors explain a large part of the variation in PA and AEE (chapter 7). In rodents, the functioning of specific areas of the central nervous system seems to predict PA (22-24). Similar associations were reported in patients with attention deficit hyperactivity disorder (ADHD), which is characterized by high levels of physical activity (22). However, the biological determinants of PA in humans are still largely unknown.

The energy stores, the adipose tissue, can influence EE through leptin. Leptin is synthesized in and secreted by the adipose tissue and plasma leptin concentrations are strongly correlated to the size of the adipose tissue (25). Central administration of leptin in rodents leads to an increase in EE consistent with activation of the autonomic nervous system (26). However, the role of leptin in human EE regulation is still controversial $(27)$.

\section{Factors influencing energy intake}

PA not only affects TEE, it is also shown that physical inactivity does not result in a compensatory reduction of $\mathrm{El}_{\mathrm{W}}$ resulting in a positive energy balance $(28,29$ ) (chapter 5). This effect was less pronounced when an activity protocol was implied $(28,29)$. This suggests that $\mathrm{El}$ is adjusted according to an increased PA, but is less or not sensitive to a decrease in PA. The motivation to eat was not related to the physical activity level (29) indicating that PA unconsciously influences $\mathrm{El}$. One explanation might be that sensitivity to the energy density of the diet is influenced by the physical activity level $(30,31)$.

In addition to the stimulation of EE, leptin influences food intake by serving as an afferent signal from the adipose tissue to those regions of the central nervous system that regulate hunger and satiety (26). Central administration of leptin reduces food intake in rodents (26). Treatment of leptin deficient patients with leptin injections reduces the extreme hunger associated with leptin deficiency, resulting in reduced food intake and weight loss (32), which emphasizes the relevance of leptin in normal human metabolic function. 


\section{FAT MASS REGULATION}

In adults, an increase in fat mass depends on the differentiation of preadipocytes into mature adipocytes, and on the accumulation of triacylglycerol in adipocytes, resulting in an increased cell volume. Genetic, nutritional and hormonal factors influence these processes (Figure 2).

\section{Genetic contribution}

Fat mass is influenced by environmental factors like dietary habits (33), but there is a considerable genetic contribution as well. Twin studies show heritabilities between 60 and $78 \%$ for fat mass $(34,35)$, although there was a decreasing tendency seen with advancing age (35). Monogenic human obesity syndromes are rare, but made a major contribution to the study of metabolic pathways involved in human obesity. Mutations in the leptin, leptin receptor, POMC and MC4R genes revealed critical components of energy intake and expenditure, and hence fat mass, regulation (36). A dominant-positive mutation in the PPARY2 gene, a gene highly expressed in adipose tissue (37), reduces the inactivation of PPAR 2 . resulting in a more active protein and extreme obesity (38). On the other hand, dominant-negative mutations in the PPARY gene lead to partial lipodystrophy (39).

Different genetically inbred rat strains differ widely in their susceptibility to dietinduced obesity (DIO) (40), suggesting an important contribution of genetic factors to the susceptibility to obesity. Even within strains, differences in predisposition occur. Levin et al. (41) selectively bred rats, descended from one strain, that were either prone or resistant to DIO. Comparison of chow-fed DIOprone and DIO-resistant rats showed $44 \%$ more fat mass in the DIO-prone rats despite having a similar body weight, energy intake and feed efficiency. But for real obesity to develop, predisposed rats needed a high-energy, high-fat diet (41). Thus, interactions between genes and environment (diet) are essential for a predisposed genotype to result in obesity. This was confirmed in humans, where overfeeding monozygotic twins resulted in at least three times more variance between than within pairs for gains in body weight and fat mass (4).

\section{Factors regulating adipocyte differentiation}

An increase in adipocyte number starts with the recruitment and replication of cells, preadipocytes, that have the potential to become adipocytes (42). Adults can acquire new fat cells throughout life, as preadipocytes are still present in the adipose tissue (43). However, the numbers of preadipocytes differ between persons (44) as well as the capacity to differentiate in response to an optimal adipogenic stimulus in vitro (45). 
Loss-of-function studies in mice show that the peroxisome proliferator-activated receptor $y$ (PPAR $y$ ) is required to stimulate adipocyte differentiation (46). PPARy activity depends on an appropriate level of PPAR $\mathrm{mRNA}$ expression, leading to sufficient PPARy protein, and on the sensitivity to external factors, one of which is the availability and binding of a ligand to the PPARY/RXR heterodimer ( 47 ). Natural ligands include unsaturated free fatty acids, components of oxidized llowdensity lipoproteins and eicosanoids (48). Most of these natural ligands bind with relatively low affinities compared to affinities of most ligands for nuclear receptors and are present at low concentrations. This questions their physiological significance $(47)$, though recently, naturall occurring nitroalkene derivates of fatty acids were found to be potent endogenous PPARy ligands (49). High-affinity synthetic ligands include the thiazolidinediones (TZD), which are used for their insulin-sensitizing effects in the treatment of type 2 diabetes mellitus (50). Treatment with TZD is associated with weight gain in diet-induced and genetically obese rodents (51-54) and in most, but not all diabetic and healthy obese subjects $(55-57)$. As weight gain will only occur in the presence of a positive energy balance, this suggests a specific interaction between PPARy activity and energy balance regulation. Indeed, fat mass gain during overfeeding was associated with the induction of PPAR $\gamma$ activity in healthy subjects (chapter 4). This suggests that the potential to gain fat depends on the capacity to optimize the conditions for fat mass gain, which might involve a high ability to change PPARy activity. The common Pro12Ala polymorphism in the PPAR 2 gene results in a mutant protein with an impaired ability to mediate TZD-induced adipogenesis compared to the wild-type (Pro/Pro) gene $(58,59)$, though Kolehmainen et al. (60) did not observe an effect of the Pro12Ala polymorphism on the mRNA expression of PPAR 2 target genes in adipose tissue of morbid obese subjects. In addition, both negative (58) and positive (61) correlations between the Pro12Ala polymorphism and BMI are found, which indicates that environmental factors, like diet, may contribute to role of genotype in the development of obesity. This is emphasized by Luan et al. (62) who found an interaction between the ratio of dietary polyunsaturated fat to saturated fat and the Pro12Ala polymorphism in relation to differences in BMI. The availability of ligand seems to be of minor importance compared to the ligand-binding affinity in a normal weight $\mathrm{BMI}$ range, as treatment of healthy, non-obese subjects with either rosiglitazone or a placebo resulted in similar PPARY activity in subcutaneous abdominal adipose tissue (chapter 6).

Different hormonal and nutritional factors are able to influence PPAR $\gamma$ activity. The adipogenic effect of insulin is shown by the stimulation of preadipocyte differentiation by insulin (43). Insulin acutely upregulates the expression of PPARY in human adipocytes, in both lean and obese nondiabetic subjects and type 2 diabetic patients, indicating that the pathway involved in the regulation of PPARY 
mRNA expression is not resistant to the insulin (63). This might explain the positive correlation between PPARy expression and BMI. (64), though such a correlation was not always observed (63). In addition, fatty acids formed after the hydrolization of TAG by LPL, can stimulate preadipocyte differentiation by acting as ligands for transcription factors (48).

\section{Factors regulating adipocyte size}

Adipocytes function uniquely as an energy depot that can store and release energy, i.e. fat, in response to the body's energy demands. PPARY is involved in fat storage by regulating the expression of lipogenic genes, including aP2, LPL and CD36 (47). Interestingly, heterozygous PPAR $\gamma$-deficient mice are protected against high-fat diet-induced adipocyte hypertrophy and insulin resistance, which indicates that both PPAR $\gamma$ alleles are required for full obesity (65).

Large et al. (66) showed that a decreased expression and function of HSL in subcutaneous adipocytes of obese subjects might impair the lipolytic capacity of the adipocytes. In addition, insulin has an anti-lipolytic effect by decreasing HSL function (67). Furthermore, plasma concentrations of TAG have been shown to stimulate TAG accumulation in adipocytes (68).

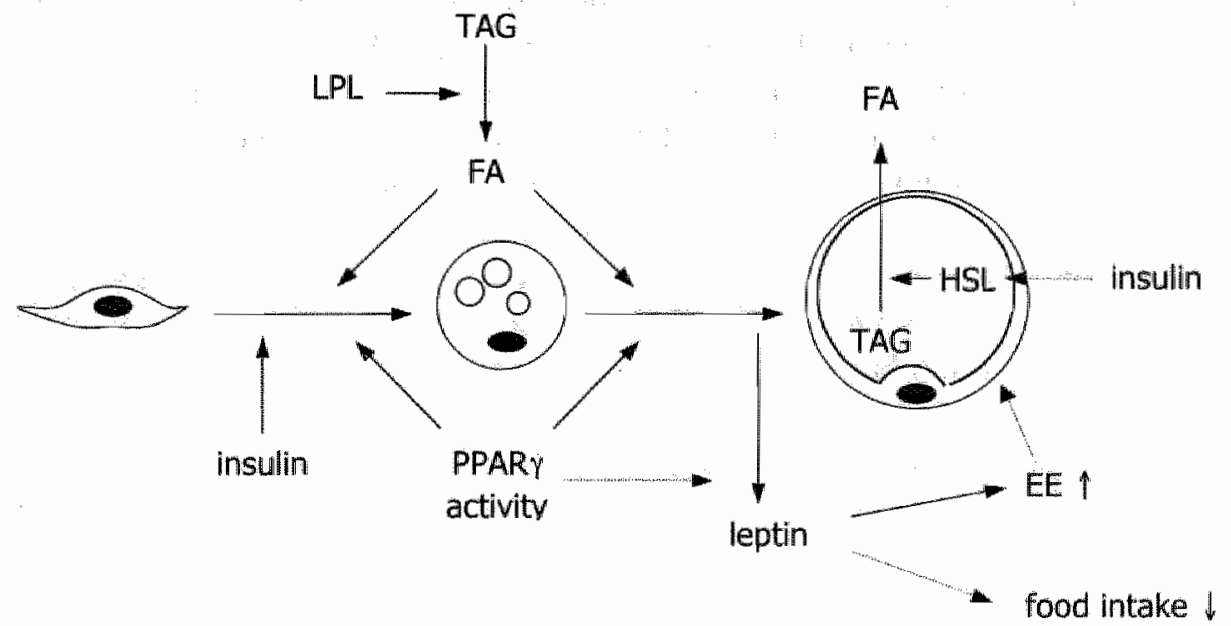

Figure 2 Factors influencing fat mass generation (- stimulation, ........ inhibition). 


\section{Adipocyte function and fat mass regulation}

In addition to their function as a fat storage depot, adipocytes are active mediators of energy regulation, as adipose tissue metabolism influences whole-body metabolism. For example, a selectively reduced insulin-stimulated uptake of glucose into the adipocyte results in insulin resistance in rodents (69). Adipocyte size is an important factor for fat cell function; metabolic disturbances (including insulin resistance and overproduction of FFA, TNF-a and leptin) in obese subjects are typically associated with adipocyte hypertrophy (70).

Adipocytes from ob/ob-mice treated with rosiglitazone showed enhanced fatty acid oxidation and oxygen consumption in vitro $(71)$. In contrast, whole-body fat oxidation gradually became more suppressed during treatment with rosiglitazone compared to placebo in healthy subjects, which facilitates the development of a positive fat balance (chapter 5). However, PPARy activity in adipose tissue and fat cell functioning did not seem to be influenced (chapter 6), suggesting that this was a result of PPAR $y$ activity in liver and muscle. But adipocyte function might be critically involved in fat mass regulation when normal function is disturbed, as is the case in hypertrophic obesity.

\section{CONCLUSIONS}

Differences in genotype may contribute significantly to energy balance regulation. At least at the energy expenditure side of the energy balance equation, genetic factors are likely to play an important role, i.e. in physical activity and activityinduced energy expenditure, which might be reflected in body weight and body composition. Even in healthy, non-obese subjects there are large differences in the metabolic efficiency of weight gain. However, they do not seem to be due to the existence of adaptive thermogenesis. Fat mass gain during overfeeding is associated with the induction of PPAR $y$ activity in subcutaneous abdominal adipose tissue in non-obese subjects. Similarly, stimulation of PPARy activity by rosiglitazone facilitates the development of a positive fat balance as it decreases fat oxidation in non-obese subjects, independent of TEE. Though this effect of rosiglitazone was more pronounced in subjects with a higher $\mathrm{BMI}$, it does not seem directly related to the PPARY activity in the adipose tissue.

\section{FUTURE RESEARCH}

The question remains whether energy intake drives fat mass gain or whether metabolic changes lead to energy intake and thus stimulate fat mass gain. Based on the results described in this thesis, the fat mass should be considered as an 
active mediator of a positive energy balance and hence a predisposition to obesity. On the one hand, the induction of PPARy activity in the adipose tissue seems to be involved in the ability to gain fat mass during overfeeding, on the other hand, stimulation of the PPARy activity reduces fat oxidation and facilitates the development of a positive fat balance. Likewise, this is indicated by the significant increase in energy expenditure and fat oxidation in response to acute overfeeding in lipodystrophic patients, who lack functional adipocytes, in contrast to healthy, non-obese subjects (72). This suggests that information of the adipose tissue on its potential to expand is central in the regulation of energy metabolism. The adipose tissue secretes adipokines involved in several processes, including appetite, EE, insulin sensitivity and lipid metabolism, and has receptors to respond to nutritional and hormonal changes, thereby communicating locally and with other organs. However, the pathways, for instance the regulation of adipose gene expression, remain to be identified. Furthermore, it is important to define a metabolic predisposition to obesity, for instance by testing whether the fat mass of metabolically efficient and inefficient subjects provides different information to the brain on the regulation of energy intake. 


\section{REFERENCES}

1. Ravussin E Bogardus C. Relationship of genetics, age, and physical fitness to daily energy expenditure and fuel utization. Am/ Cl in Nutr 1989,49:968-75.

2. Westerterp KR. Energy metabolism and body composition. general principles. Eur Respir Mon $2003 ; 24: 1-10$.

3. Leibel RL, Rosenbaum M, Hirsch I. Changes in energy expenditure resulting from altered body weight. N Engl I Med 1995;332:621-8.

4. Bouchard $C_{\text {, Tremblay } A}$. Despres JP; et al. The responise to long-term overfeeding in identical twins. N Eng J Med 1990;322:1477-82.

5. Tremblay $A$, Despres JP, Theriaut $G$ foumier $G$, Bouchard $C$. Overfeeding and energy expenditure in humans. Am I Clin Nutr 1992,56:857-62.

6. Diaz EO, Prentice AM, Goldberg, GR, Murgatroyd PR, Coward WA. Metabolic response to experimental overfeeding in lean and overweight healthy volunteers. Am I Clin Nutr $1992,56,641.55$.

7. Horton TJ, Drougas A, Brachey A, Reed GW, Peters JC, Hill JO. Fat and carbohydrate overfeeding in humans different effects on energy storage. Am J Clin Nutr 1995;62:19-29.

3. Norgan $N G$, Dumin IV. The effect of 6 weeks of overfeeding on the body weight, body composition, and energy metabolism of young men. Am / Clin Nutr 1980;33:978-88.

9. Ravussin $E$, Schutz $Y$, Acheson $K I$, Dusmet $M$, Bourquin $L$, Jequier $E$. Short-term, mixed-diet overfeeding in man: no evidence for "luxuskonsumption". Am II Physiol 1985;2,49:E470-7.

10. Westerterp $K R$, Wilson SA), Rolland V. Diet induced thermogenesis measured over $24 \mathrm{~h}$ in a respiration chamber: effect of diet composition. Int J Obes 1999;23:287-92.

11. Zurlo F, Lillioja $S$, Esposito-Del Puente $A$, et all. Low ratio of fat to carbohydrate oxidation as predictor of weight gain: study of 24-h RQ. Am I Physiol 1990;259:E650-7.

12. Seidell $I C$, Muller $D C$, Sorkin $D D$, Andres $R$. Fasting respiratory exchange ratio and resting metabolic rate as predictors of weight gain: the Baltimore Longitudinal Study on Aging. Int I Obes Relat Metab Disord 1992;16:667-74.

13. Dulloo $A G$, Jacquet ). Low-protein overfeeding: a tool to unmask susceptibility to obesity in humans: Int J Obes 1999;23:1118-21.

14. Westenterp-Plantenga MS, Rolland V, Wilson SA, Westerterp KR. Satiety related to $24 \mathrm{~h}$ diet. induced thermogenesis during high protein/carbohydrate ws high fat diets measured in a respiration chamber. Eur / Clin Nutr 1999;53:495-502.

15. Westerterp KR, Plasqui G. Physical activity and human energy expenditure. Curr Opin Clin Nutr Metab Care 2004:7:60\% 13 .

16. Levine \A, Schlewsner S|, Jensen MD. Energy expenditure of nonexercise activity. Am I Clin Nutr $2000: 72: 1451 \times 4$.

17. Levine 1, Melanson $\mathbb{E L}$, Westerterp $\mathrm{KR}$, Hill JO. Measurement of the components af nonexercise activity thermogenesis. Am I Physiol Endocrinol Metab 2001;281:E670-5.

18. Zurlo F, Ferrafo RT, Fontvielle AM, Rỉsing. R, Bogardus C. Ravussin E. Spontaneous physical activity and obesily: cross-sectional and longitudinal studies in Pima Indians. Am I Physiol 1992;263:E296-300

19. Plasqui $G_{*}$ Westerterp $K R$. Seasonal variation in total energy expenditure and physical activity in Dutch young adults. Obes Res 2004; 12:688-94. 
20. Perusse $L$, Tremblay $A_{r}$ Leblanc $C$, Bouchard $C$. Genetic and environmental influences on level of habitual physical activity and exercise participation. Am J tepidemiol 1989,129:1012-22.

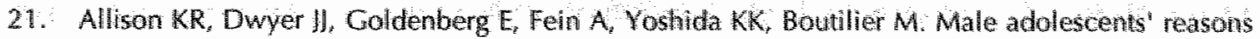
for participating in physical activity, barriers to participation, and stiggestions for increasing participation. Adolescence $2005 ; 40: 155-70$.

22. Rowland TW. The biological basis of physical activity. Med Sci Sports Exerc 1998;30;392-9.

23. Thorburn AW, Proietto J. Biological determinants of spontaneous physical activity. Obes Rev 2000;1:87-94.

24. Tou JC, Wade CE. Determinants affecting physical activity levels in animal modelś. Exp Biol Med (Maywood) $2002,227: 587-600$.

25. Considine RV, Sinha MK, Heiman ML, ef al. Serum immunoreactive-leptin concentrations in normal-weight and obese humans. N Engl J Med 1996;334:292-5.

26. Campfield LA, Smith FI, Burn P. The OB protein (leptin) pathway--a link between adipose fissue mass and central neural networks. Horm Metab Res 1996,28:619-32.

27. Hukshorn Cl, Saris WH. Leptin and energy expenditure. Curr Opin Clin Nutr Metab Care 2004;7:629-33.

28. Murgatroyd PR, Goldberg GR, Leahy FE, Gilsenan MB. Prentice AM. Effects of inactivity and diet composition on human energy balance. Int J Obes Relat Metab Disord 1999;23:1269-75.

29. Stubbs RJ, Hughes DA, Johnstone AM, Horgan GW, King N, Blundell JE. A decrease in physical activity affects appetite, energy, and nutrient balance in lean men feeding ad libitum. Am I Clin Nutr 2004;79:62-9.

30. Stubbs R], Ritz $\mathbb{P}$, Coward WA, Prentice AM. Cowert manipulation of the ratio of dietary fat to carbohydrate and energy density: effect on food intake and energy balance in free-living men eating ad libitum. Am J Clin Nutr 1995;62:330-7.

31. Stubbs R], Harbron CG, Murgatroyd PR, Prentice AM. Covert manipulation of dietary fatt and energy density: effect on substrate flux and food intake in men eating ad libitum. Am I Clin Nutr 1995;62:316-29.

32. Williamson DA, Ravussin $E_{\text {, Wong }}$ ML, et al. Microanalysis of eating behavior of three leptin deficient adults treated with leptin therapy. Appetite 2005;45:75-80.

33. Hakala $P$, Rissanen $A$, Koskenvuo $M$, Kaprio J, Ronnemaa $T$. Environimental factors in the development of obesity in identical wins. Int J Obes Relat Metal Disord 1999;23:746-53.

34. Carey DG, Nguyen TV, Campbetl LV, Chisholm DI, Kelly P. Genetic influences on central abdominal fat: a twin study. Int I Obes Relat Metab Disord 1996;20:722-6.

35. Schousboe $K$, Visscher PM, Erbas $B$, et al. Twim study of genetic and environmental influences on adult body size, shape, and composition. Int I Obes Relat Metab Disord 2004;28:39 48.

36. ORahilly $S$, Farooqi $\| S$, Yeo CS, Challis BG. Minireview: human obesity-tessons from monogenic disorders. Endocrinology 2003; 144:3757-64.

37. Mukherjee R, Jow L., Croston GE, Paternit JR, Ir. Identification, characterization, and tissue distribution of human peroxisome proliferator-activated receptor (PPAR) isoforms PPARy2 versus PPARY 1 and activation with retinoid $X$ receptor agonists and antagonists. I Biol Chem $1997 ; 272: 8071 \times 6$.

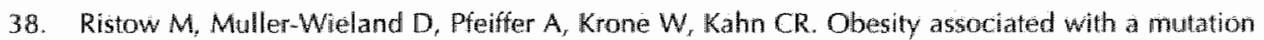
in a genetic regulator of adipocyle differentiation. N Engl I Med 1998;339:953-9.

39. Savage $\mathrm{DB}$, Tan $\mathrm{CD}$, Acerini $\mathrm{CL}$, et al. Human metabolic syndrome resulting from dominantnegative mutations in the nuclear receptor peroxisome proliferator-activated recepitor- $\gamma$. Diabeles $2003 ; 52: 910-7$. 
40. Schemmel $R$, Mickelsen $O$, Gill IL. Dietary obesity in rats: Body weight and body fat accretion in seven strairs of rats. I Nutr 1970; 100:1041-8.

41. Levin BE, Dunn-Meynell AA, Balkan B, Keesey RE. Selective breeding for diet-induced obesity and resistance in 5prague-Dawley rats. Am I Physiol 1997;273:R725-30.

42. Kras KM, Hausman DB, Hausman Cl. Martin RI. Adipocyte development is dependent upon stem cell recruitment and proliferation of preadipocytes. Obes Res 1999,7:491-7.

43. Hauner $H$, Entenmann $G_{\text {, }}$ Wabuttsch $M$, et al. Promoting effect of glucoconticoids on the differentiation of human adipocyte precursor cells cultured in a chemically defined medium. I Clin Inwest $1989 ; 84: 1663-70$.

44. Bakker AH, Van Dielen FM, Gireve IW, Adam IA, Buuman WA. Preadipocyte number in omental and subcutaneous adipose tissue of obese individuals. Obes Res 2004;12:488-98.

45. Sen A, Lea-Currie YR, Sujkowska D, et al. Adipogenic potential of humam adipose derived stromal cells from multiple donors is heterogeneous. I Cell Biochem 2001;81:312-9.

46. Rosen ED, Sarraf P, Troy AE, et al PPARy is required for the differentiation of adipose tissue in vivo and in witro. Mol Cell 1999;4:611-7.

47. Rosen ED, Walkey CI, Puigserver $\mathrm{P}$, Spiegelman BM. Transcriptional regulation af adipogenesis. Cenes Dev $2000141293-307$.

48. Kliewer $S A$, Sundseth $S S_{*}$ Jones $S A$, et all. Fatty acids and eicosanoids regulate grene expression through direct interactions with peroxisome proliferatorackivated receptors $\alpha$ and $y$. Proc Natl Acad Sci USA 1997;94:4318-23.

49. Schopfer $\mathrm{F}$, Lin $Y$, Baker PR, et al. Nitrolinoleic acid: an endogenous peroxisome proliferatoractivated receptor $\gamma$ lligand. Proc Natl Acad Sci U S A 2005;102:2340-5.

50. Lehmann IM, Moore LB; Smith-Oliver TA, Wilkison WO, Willson IM, Kliewer SA. An antidiabetic thiazolidinedione is a high affinity ligand for peroxisome proliferator-activated receptor y (PPARY). I Biol Chem 1995;270:12953-6.

51. Wang $Q$, Dryden $S$, Frankish $H M$, al, Increased feeding in fatty Zucker rats by the thiazolidinedione BRL 49653 (rosiglitazone) and the possible involvement of leptin and hypothalamic neuropeptide $Y$. Br I Pharmacol 1997;122:1405-10.

52. Chaput E, Saladin R, Silvestre M, Edgar AD. Fenofibrate and rosiglitazone ower serum Iriglycerides with opposing effects on body weight. Biothem Biophys Res Commun $2000,271: 445-50$.

53. Pickavance LC, Buckingham RE, Wilding JP. Insulin-sensitizing action of rosiglitazone is enhanced by preventing hyperphagia. Diabetes Obes Metab 2001;3:171-80.

54. Larsen $\mathrm{PJ}$, Jensen $\mathrm{PB}$, Sorensen RV, et al. Differential influences of peroxisome proliferatoractivated receptors $y$ and $-a$ on food intake and energy homeostasis. Dilabetes 2003;52:2249-59.

55. Will SM, Kennedy A, Wallace P, Ganaway E, Rogers, NL, Garvey Wr. Troglitazone antagonizes metabolic effects of glucocorticoids in humans: effects on glucose tolerance insulin sensilivity, suppression of free fatty acids, and leptin. Diabetes 2002;51:2895-902.

56. Snith $S R$; De Jonge L, Volatova , Li $Y$, Xie $H$, Bray GA. Effect of pioglitazone on body composition and energy expenditure: a vandomized controlled trial. Metabolism 2005;54:24-32.

57. Fullert $S$, Schneider $F$, Haak $E$, et al. Effects of pioglitazone in nondiabetic patients with arterial hypertension: a double-blind, placebo-controlled study. I Clin Endocrinol Metab 2002;87:55036.

58. Deeb SS, Fajas $L$, Nemoto $M_{*}$ et all. A Pro12Alla substitution in PPAR 2 associated with decreased receptor activity; lower body mass index and improved insulin sensitivity. Nat Genet $1998,20: 284-7$. 
59. Masugi J, Tamori $Y$, Mori $H$, Koike T. Kasuga $M$. Inhibitory effect of a proline-to-alanine substitution at codon 12 of peroxisome proliferator-activated receptor- $\gamma 2$ on thiazolidinedioneinduced adipogenesis. Biochem Biophys Res Commun 2000; $268: 17882$.

60. Kolehmainen $M$, Uusitupa $M$, Alhava $E$, Laakso $M$, Viddal $H$. Effect of the ProtzAla polymorphism in the peroxisome proliferator-actiwated receptor (PPAR) $\gamma^{2}$ gene on the expression of PPARy target genes in adipose tissue of massively obese subjects. I Cin Endocrinol Metab 2003;88:1717-22.

61. Beamer $B A$, Yen $C$, Andersen RE, et al. Association of the Pro12Ala wariant in the peroxisome proliferator-activated receptor- $\gamma 2$ gene with obesity in two caucasian populations Diabetes $1998 ; 47: 1806-8$.

62. Luan, , Browne PO, Harding AH, et al. Evidence for gene-nutrient interaction at the PPARY locus. Diabetes 2001;50:686-9.

63. Rieusset ], Andreelli F, Auboeuf $D$, et al. Insulin acutely regulates the expression of the peroxisome proliferator-activated receptorwy in human adipocytes. Diabetes 1999;48:699-705.

64. Redonnet $A_{*}$ Bonilla $S_{n}$ Noel-Suberville $C_{n}$ et al. Relationship between peroxisome proliferatoractivated receptor $\gamma$ and retinoic acid receptor $\alpha$ gene expression in obese human adipose tissue. Int J Obes Relat Metab Disord 2002;26:920-7.

65. Kubota $N$, Terauchi $Y$, Miki $H_{\text {; }}$ et al. PPARy mediates high-fat diet-induced adipocyte hypertrophy and insulin resistance. Mol Cell 1999;4:597-609.

66. Large $V$, Reynisdottir $S$, Langin $D$, et al. Decreased expression and function of adipocyte hormone-sensitive lipase in subcutaneous fat cells of obese subjects. / Lipid Res 1999;40:2059 66.

67. Holm C. Molecular mechanisms regulating hormone-sensitive lipase and lipolysis. Biochem Soc Trans 2003;31:11:120-4.

68. Sypniewska $G$, Karlsson $M$, Bjorntorp P. Adipogenic activity in human plasma effects of feeding state and obesity. Int J Obes 1986;10:265-76.

69. Abel ED, Peroni $\mathrm{O}$, Kim $\mathrm{KK}_{\text {, }}$ et al. Adipose-selective targeting of the GLUT4 gene impairs insulin action in muscle and liver. Nature 2001;409:729-33.

70. Farnier $C$, Krief $S$, Blache $M$, et al. Adipocyte functions are modulated by cell size change: potential involvement of an integrin/ERK signalling pathway. Int J Obes Relat Metab Distord 2003:27:1178\%86.

71. Wilson-Fritch $L_{i}$ Nicoloro $S_{\text {; }}$ Chouinard $M$, al. Mitochondrial remodeling in adipose tissue associated with obesity and treatment with rosiglitazone. I Clin Invest 2004:114:1281-9.

72. Savage DB, Murgatroyd PR, Chatterjee WK, O'Rahilly S. Energy expenditure and adaptive responses to an acute hypercaloric fat load in humans with lipodystrophy. I Clin Endocrinol Metab 2005:90:1446-52. 



\section{Summary}

In many countries, the prevalence of obesity has increased over the past decades showing an increased disability to maintain a balance between energy intake and energy expenditure. The increasing prevalence of obesity coincides with changing dietary habits and lifestyles, which might indicate a causal link. However, within the same obesigenic environment there are persons that maintain a stable body weight seemingly without any effort. They seem to regulate their energy balance unconsciously, suggesting that the susceptibility to become obese is at least in part genetically determined.

There are still many questions regarding the determinants of weight gain, not only in obese persons but in a normal weight population as well. The ability to convert excess energy into heat or to store the excess in the body may be involved in the efficiency of weight gain and hence a predisposition to obesity. As the main energy storing tissue, the adipose tissue and thus adipocyte functioning is likely to be an important factor in the ability to gain weight as well. The aim of the research presented in this thesis was to identify factors that regulate energy metabolism and fat mass as determinants of weight gain.

Energy expenditure consists of the basal metabolic rate (BMR), diet-induced thermogenesis (DIT) and activity-induced energy expenditure (AEE). The BMR is mainly a function of body mass, in particular fat-free mass (FFM). During weight gain, the BMR will increase in proportion to the change in FFM. When more energy is ingested, the DIT will increase due to the extra amount of food to be digested and absorbed. In addition, the DIT is influenced by the composition of the diet, and thereby seems to affect the energy cost of weight gain during overfeeding.

A positive energy balance, caused by an increased energy intake, a decreased energy expenditure or both, results in energy storage and thus weight gain. Subjects were overfed with a low-protein diet to investigate whether humans can adapt their heat production and thus their energy expenditure to an increased energy intake, thereby reducing the efficiency of weight gain. Excess energy is mainly stored in the adipose tissue. Therefore the influence of overfeeding on adipose gene expression was determined. Subsequently, the influence of adipose gene expression on energy balance regulation and fat mass gain was investigated. Subjects continuously stayed in a respiration chamber with ad libitum food intake for measurement of substrate oxidation and energy expenditure. With respect to energy metabolism, AEE is the most variable component of daily energy expenditure and a reduced physical activity (PA) results in a decrease in energy expenditure leading to a positive energy balance when the energy intake is not 
adjusted. The relative contribution of genetic and environmental factors to the tcolvariation in AEE and PA was investigated in twins.

Results showed that even in a normal weight population there were large differences in the metabolic efficiency of weight gain during overfeeding. However, there was no relation with changes in BMR and PA. The fat mass increased during overfeeding due to energy storage. In adults, an increase in fat mass depends on the differentiation of preadipocytes into mature adipocytes, and on the accumulation of triacylglycerol in adipocytes, resulting in an increased cell volume. The peroxisome proliferator-activated receptor $\gamma(\mathbb{P P A R} \gamma)$ is a key mediator of both processes. Indeed, treatment with PPAR ligands is associated with weight gain. As weight gain only occurs in the presence of a positive energy balance, there might be an interaction between PPARY activity and energy balance regulation. During overfeeding, fat mass gain was associated with the induction of PPARy activity. Stimulation of the PPARy activity with the PPARy ligand rosiglitazone resulted in a shift in substrate usage, i.e. a decrease in fat oxidation, without changes in energy expenditure. Though this effect of rosiglitazone was more pronounced in persons with a higher $\mathrm{BMI}$, or a higher fat mass, it did not seem directly related to the PPARy activity in the adipose tissue.

The study of twins showed that the majority of the variation in PA and AEE in daily life could be explained by genetic factors.

In conclusion, there was no evidence for the existence of adaptive thermogenesis as a mechanism to resist weight gain during overfeeding. At the energy expenditure side of the energy balance equation, genetic factors are likely to play an important role, i.e. in PA and AEE, which might be reflected in body weight and body composition. The potential to gain fat seems a function of the capacity to optimize the conditions for fat mass gain, which might involve the ability to change PPARY activity. In non-obese persons, the availability of PPARY ligand does not seem to be rate limiting for PPARy activity. However, stimulation of the PPARY activity with a PPARy ligand does facilitate the development of a positive fat balance. 


\section{Samenvatting}

In veel landen is de prevalentie van obesitas de laatste decennia sterk toegenomen. Dit laat zien dat er toegenomen problemen zijn om een balans tussen de energie inname en het energiegebruik te behouden. De stiigende prevalentie van obesitas gaat samen met veranderingen in eet- en leefgewoonten, wat mogelijk wijst op een oorzakelijk verband. Toch zijn er, in dezellde obesilasbevorderende omgeving, mensen die schijnbaar zonder moeite een stabiel lichaamsgewicht behouden. Zij lijken hun energiebalans onbewust te reguteren; wat er op wijst dat de neiging om obesitas te ontwikkelen tenminste voor een deel genetisch bepaald is.

Er zijn nog altijd veel vragen wat betreft de factoren die van invloed zijin op gewichtstoename, niet alleen bij obese personen, maar ook in een populatie met een normaal lichaamsgewicht. De mogelijkheid om een overmaat aan energie om te zetten in warmte danwel op te slaan in het lichaam speelt mogelijk een rol bij de efficiëntie van gewichtstoename en daarmee een aanleg om obesitas te ontwikkelen. Als primair weefsel voor energieopslag, is het vetweefsel en dus het functioneren van vetcellen waarschinlijk een belangrijke factor voor de mogeligkeid om in gewich toe te nemen. Het onderzoek beschreven in dit proefschrift had tot doel om determinanten van gewichtstoename, dus factoren die het energiemetabolisme en de vetmassa reguleren, op te sporen.

Het energiegebruik bestaat uit het basaal metabolisme (BMR), de energiekosten voor het verteren en absorberen van voedsel (DIT) en het energiegebruik als gevolg van lichamelijke activiteit (AEE). De BMR is sterk gerelateerd aan het lichaamsgewicht, met name aan de vetvrije massa. Tijdens gewichtstoename stijgt de BMR evenredig met de vetvrije massa. Wanneer de energie innanie toeneemt, stijgt de DIT vanwege de grotere hoeveelheid voedsel die verteerd en geabsorbeerd moet worden. Daarnaast wordt de DIT beïnvloed door de samenstelling van de voeding, wat effect lijkt te hebben op de energiekosten van gewichtstoename tijdens overvoeding.

Een positieve energiebalans, veroorzaakt door een verhoogde energie inname, een verlaagd energiegebruik of beide, resulteert in energie opslag en dus gewichtstoename. Proefpersonen werden overvoed met een laag eiwit dieet om te onderzoeken of mensen hun warmteproductie en dus hun energiegebruik kunnen aanpassen aan een verhoogde energie inname en daarmee de efficiëntie van gewichtstoename kunnen verlagen. Een overmaat aan energie wordt hoofdzakelijk opgeslagen in het vetweefsel. Daarom werd het effect van overvoeding op de genexpressie in het vetweefsel onderzocht. Vervolgens werd ook de invloed van de genexpressie in het vetweefsel op de regulatie van de 
energiebalans en de vetmassa bepaald. Proefpersonen verbleven gedurende het onderzoek in een respiratiekamer waar ze ad libitum konden eten, en substraatgebruik en energiegebruik continu gemeten werden. De meest variabele component van het dagelijks energiegebruik is de AEE. Een verlaagde lichamelijke activiteit (PA) resulteert in een verlaagd energiegebruik en een positieve energiebalans wanneer de energie inname niet aangepast wordt. De relatieve bijdrage van genetische en omgevingsfactoren aan de (co)variatie in AEE En PA werd bepaald in een onderzoek met tweelingen.

De resultaten van overvoeding lieten zien dat er zelfs binnen een groep personen met een normaal lichaamsgewicht grote verschillen zijn in de metabole efficiëntie van gewichistoename. Deze waren echter niet gerelateerd aan veranderingen in BMR en PA. De vetmassa nam toe gedurende overvoeding als gevolg van de opslag van energie. Bij volwassenen hangt een toename van de vetmassa af van de differentiatie van voorloper vetcellen in rijpe vetcellen en van de ophoping van triacylglycerol in de vetcellen, wat zorgt voor een stijging van het volume van de vetcellen. Voor beide processen is de peroxisome proliferator-activated receptor $\gamma$ (PPARy) noodzakelijk. Behandeling met PPAR y liganden gaat inderdaad gepaard met gewichtstoename. Omdat een positieve energiebalans noodzakelijk is voor een toename in gewicht, zou er een interactie kunnen zijn tussen de PPAR $\gamma$ activiteit en de regulatie van de energiebalans. De toename in vetmassa gedurende overvoeding was gerelateerd aan de mate waarin de PPARy activiteit toenam. Stimulatie van de PPAR $\gamma$ activiteit met de PPAR $\gamma$ ligand rosiglitazon zorgde voor een verschuiving van het substraatgebruik, dat will zeggen een verlaging van de vetoxidatie, zonder verandering in het energiegebruik. Dit effect van rosiglitazon leek niet direct gerelateerd aan de PPAR $\gamma$ activiteit in het vetweefsel, hoewel het wel meer uitgesproken was bij personen met een hogere $B M$, ofwel een hogere vetmassa.

Het tweelingonderzoek liet zien dat het grootste deel van de variatie in PA en AEE in het dagelijks leven verklaard kon worden door genetische factoren.

Samenvattend leverden de beschreven onderzoeken geen bewijs voor het bestaan wan adaptieve thermogenese als een mechanisme om gewichtstoename tijdens overvoeding tegen te gaan. Aan de energiegebruik kant van de energiebalans vergelijking, namelijk wat betreft de $P A$ en $A E E$, spelen genetische factoren waarschijnlijk een belangrijke rol. Dit wordt mogelijk weerspiegeld in het lichaamsgewicht en de lichaamssamenstelling. De toename in vetmassa tijdens overvoeding lijkt een functie van de capaciteit om de condities die hiervoor nodig zijh te optimaliseren, zoals de mogelijkheid om de PPARy activiteit te veranderen. Bij niet-obese personen lijkt de beschikbaarheid van een ligand voor PPARY niet de beperkende factor voor de PPAR $\gamma$ activiteit. Aan de andere kant verhoogt stimulatie van de PPARY activiteit het risico op een positieve vetbalans. 


\section{Dankwoord}

Beste proefpersonen, jullie verdienen de eerste regel van het dankwoord. Zonder jullie bereidheid om enorme hoeveelheden eten weg te werken en daarmee dikker te worden of om te worden opgesloten in een respiratiekamer zou het nooit zo ver ziinn gekomen met dit proefschrift!

Klaas, dankzij jou heb ik misschien niet altijd het makkelijkste maar wel het leukste uit twee vakgebieden kunnen halen. Bedankt dat ik dit vaak op mijn eigen manier heb kunnen doen en dat je altijd bereikbaar was wanneer ik je nodig had. Jouw efficiënte begeleiding heeft er zeker aan bijgedragen dat dit proefschrift binnen afzienbare tijd voltooid is.

Arjen, jij voldoet helemaal aan het stereotype wetenschapper. Maar zie het als een compliment. Je hebt je op voor jou onbekend fysiologisch terrein begeven met dit project. Bedankt voor alle momenten dat jouw enorme hoeveelheid kennis van pas kwam. Ik hoop dat ik er wat van meegenomen heb.

I would like to thank Prof. dr. E. Mariman, Prof. dr. M. Hofker, Prof. dr. M. Müller, Prof. dr. ir. A. Schols and Prof. dr. Y. Schutz for your critical evaluation of this thesis.

Geen artikelen zonder mede-auteurs, daarom Antoine, Arjen, Bob, Klaas, Maarten, Marij, Patrick en Sander bedankt voor jullie bijdrage. Antoine, bedankt voor al het werk dat je achter de schermen hebt verzet tijdens de overvoedingsstudie. Maarten, jij had je stage vast iets anders voorgesteld! Bedankt voor de goede zorgen voor onze kinders in de respiratiekamer, ook buiten normale werktijden. Marij, statistiek zal nooit mijn vak worden, maar dankzij jou was het wel erg gezellig.

Chris, Erwin en Gabby, bedankt voor alle vroege uurtjes waarop jullie klaarstonden om vetbiopten af te nemen.

Esther, Joan, Jos en Wendy, analyseren is een vak. I ben blij dat ik het aan jullie heb kunnen overlaten. Jos, jouw vertrouwde gemopper en vers gezette koffie waren onmisbaar tijdens de weekenden op de uni.

Loek en Paul, het is goed dat jullie meer computerproblemen op kunnen lossen dan ik kan maken. Loek, bedankt ook voor de vele deuteriumbepalingen. Paul, zonder jouw deskundigheid zouden er geen respiratiekamerproeven zijn en, niet te vergeten, zou mijn laptop nog altijd vastzitten.

Belangrijker nog dan het plannen van experimenten is het plannen van ontspanning tussen de experimenten door. Gelukkig waren Astrid, Freddy, Guy, Joost, Kristel, Lydia, Manuela, Marieke, Mirjam, Natalie, Neeltje en Tanja altijd bereid tijdens de koffie en de rest van de dag de grootste onzin met me te delen. 
Jullie zijn stuk voor stuk het bewijs dat wetenschappers net mensen (of eigenlijk erger...) zijn! Natuurlijk verdienen ook Ananda, Andrea, Arie, Claudia, Eva, Gijs, Hanneke, llona, Ilse, Johan J, Johan R, Joris, Kaatje, Kristof, Larisa, Luc, Mandy, Marcel, Margriet V, Margriet W, Marije, Niels, Pascal, Ralph", Rene, Roy, Stefan, Stijn en alle anderen hier een plaatsje.

Myriam, bedankt voor de overheerlijke maaltijden die in drukke tijden voor me klaarstonden. Gert-Jan, bedankt voor de keren dat we de afwas voor jou konden laten staan. De afstand is wat groter, de vriendschap blijt.

Vier jaar geleden kwam ik niét in Maastricht, maar in Belgie terecht. Maar Guy, ik had me geen betere kamergenoot kunnen wensen. Zowel tijdens werktijd (aan een half woord genoeg) als daarbuiten (in de pub) was het een feest. En je reist de halve wereld af om op tijd achter me te kunnen staan. Guytje, bedankt!

Edcly, Gert-Jan, Janette en Renate, met jullie was (en is) het gezellig tijdens de studie, de (vet)feestjes en de etentjes in Wageningen! Jullie begrijpen als geen ander wat het onderzoek' inhoudt, bedankt dat ik bij jullie altijd mijn verhaal kwijt kon. Laten we de weekendjes weg en de dagjes uit nog lang in ere houden. En ik kijk al uit naar jullie promotiefeestjes! Floor, jij weet precies de goede momenten uit te zoeken om langs te komen. Succes met jouw laatste loodjes. Jessica, het geheim van een goede vriendschap ken ik niet, maar jij bent de beste persoon om ' $m$ mee te delen! Zou het kunnen dat het de herkenning van onze rare gewoonten is? Uiteraard kan ik ook de HEMA-meiden niet vergeten. Het is heerlijk af en toe weer de brabantse gezelligheid te voelen.

Wat moet je zonder familie, die eigenlijk geen idee heeft wat je doet, maar toch altijd weer interesse toont, bedankt! Jammer dat opa er niet meer bij is.

Lieve papa en mama, jullie hadden en hebben het maar druk met ons (alleen al met verhuizen!), maar er is altijd liefde en aandacht genoeg voor iedereen. Als er lets is wat jullie ons geleerd hebben, dan is het wel nooit half werk af te leveren. Ik heb mijn best gedaan, deze is voor jullie. Helma en Marc, het is toch wel erg fijn om jullie kleine zus te zijn (ook al valt dat niet altijd mee)! Helma en Harry (Br. B.), jullie zullen een geweldige mama en papa worden voor jullie ukkies. Marc, of het nu hier is of aan de andere kant van de wereld, een logeerplekje heb je gelukkig altijd. Last, maar zeker niet least: lieve Dorién, jou hoef ik niets te zeggen, als tweeling begrijp je elkaar zonder woorden. $1 k$ ben blij dat jij achter me staat (en vergeet niet, jij bènt de dokter). 


\section{Publications}

\section{FULL PAPERS}

1. Joosen AMCP, Westerterp KR. Energy expenditure during overfeeding. Submitted for publication.

2. Joosen AMCP, Bakker AHF, Westerterp KR. Metabolic efficiency and energy expenditure during short-term overfeeding. Physiol Behav 2005;85:593-7.

3. Joosen AMCP, Bakker AHF, Zorenc AHG, Kersien $S$, Schrauwen $P$, Westerterp KR. PPAR $y$ activity in subcutaneous abdominal fat tissue and fat mass gain during short-term overfeeding. Int / Obes (in press).

4. Joosen AMCP, Bakker AHF, Gering MIA, Westerterp KR. The effect of the PPAR $y$ ligand rosiglitazone on energy balance regulation. Diabetes Metab Res Rev (in press).

5. Joosen AMCP, Bakker AHF, Kersten S, Westerterp KR. The short-term effect of the PPARY ligand rosiglitazone on fat mass regulation during a positive energy balance in healthy, non-obese males. Submitted for publication.

6. Joosen AMCP, Gielen M, Vlietinck $R$, Westerterp KR. Genetic analysis of physical activity in twins. Am I Clin Nutr (in press).

7. Plasqui $\mathrm{C}$, Joosen AMCP, Kester AD, Gorts AHC, Westerterp KR. Measuring free-living energy expenditure and physical activity with tri-axial accelerometry. Obes Res 2005;13:1363-9.

\section{ABSTRACTS}

1. Al Dieri R, Joosen AMCP, Carlo A, Béguin S, Hemker HC. The thrombogram in twins, influence of oral contraceptive and intercurrent infection. J Thromb Haemost 2005;3 Suppl 1:P1483.

2. Joosen AMCP, Bakker AHF, Westerterp KR. Metabolic response to short-term overfeeding. Proc Nutr Soc 2002;61:167A.

3. Joosen AMCP, Bakker AHF, Westerterp KR. Evidence for no change in nonexercise activity thermogenesis during short-term overfeeding. Int I Obes 2003;27 Suppl 1:5133.

4. Joosen A, Bakker A, Zorenc A, Kersten S, Schrauwen P, Westerterp K. Gene expression in subcutaneous abdominal fat tissue after short-term overfeeding. Int 』 Obes 2004;28 Suppl 1:\$99. 
5. Joosen AMCP, Gielen M, Vlietinck R, Westerterp KR. Twin study of genetic influence on physical activity. Obes Rev 2005;6 Suppl 1:39.

6. Plasqui $\mathrm{G}_{r}$ Joosen AMCP, Kester AD, Goris AHC, Westerterp KR. Measuring free-living energy expenditure and physical activity with tri-axial accelerometry. Obes Res 2004; 12 Suppl:A76. 


\section{Curriculum vitae}

Annemiek Joosen was born on 3 July 1978 in Breda. In 1996, she graduated from the atheneum at the Newmancollege in Breda. The same year she started at the former Wageningen Agricultural University, where she studied Human Nutrition and Health. As part of this study, she completed a graduation project in dietetics at the Department of Human Nutrition and Epidemiology, WU/Department of Dietetics, UMC Utrecht-Wilhelmina Children's Hospital; a research training in human nutrition at the Dunn Human Nutrition Unit, Cambridge (UK); and a graduation project in physiology at Numico Research B.V., Wageningen/ Department of Human and Animal Physiology, WU. She graduated in March 2001, and started in May 2001 as a PhD student at the Department of Human Biology, Maastricht University.

Annemiek Joosen werd geboren op 3 juli 1978 in Breda. In 1996 behaalde zij het atheneum diploma aan het Newmancollege in Breda. Datzelfde jaar begon zij met de studie Voeding en Gezondheid aan de toenmalige Landbouwuniversiteit Wageningen. Als onderdeel van de studie deed zij een afstudeervak voedingsleer bij de Vakgroep Humane Voeding en Epidemiologie WU/Afdeling Dietetiek, UMC Utrecht-Wilhelmina Kinderziekenhuis; een onderzoeksstage humane voeding bij de Dunn Human Nutrition Unit, Cambridge (UK); en een afstudeervak fysiologie bij Numico Research B.V., Wageningen/Nakgroep Fysiologie van Mens en Dier, WU. In maart 2001 studeerde zij af, waarna ze in mei 2001 begon als assistent in opleiding bij de Capaciteitsgroep Humane Biologie, Universiteit Maastricht. 